\title{
TYPES OF MARKET OFFERS ENABLED BY OPEN SOURCE HARDWARE
}

by

Edy Ferreira

A thesis submitted to the Faculty of Graduate Studies and Research in partial fulfillment of the requirements for the degree of

Master of Applied Science in Technology Innovation Management

Department of Systems and Computer Engineering

Carleton University

Ottawa, Canada, K1S 5B6

January 2010

CCopyright 2009 Edy Ferreira 


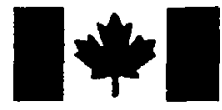

Library and Archives

Canada

Published Heritage Branch

395 Wellington Street Ottawa ON K1A ON4

Canada
Bibliothèque et

Archives Canada

Direction du

Patrimoine de l'édition

395, rue Wellington

Ottawa ON K1A ON4

Canada
Your file Votre reférence

ISBN: 978-0-494-63821-7

Ourfile Notre référence

ISBN: 978-0-494-63821-7
NOTICE:

The author has granted a nonexclusive license allowing Library and Archives Canada to reproduce, publish, archive, preserve, conserve, communicate to the public by telecommunication or on the Internet, loan, distribute and sell theses worldwide, for commercial or noncommercial purposes, in microform, paper, electronic and/or any other formats.

The author retains copyright ownership and moral rights in this thesis. Neither the thesis nor substantial extracts from it may be printed or otherwise reproduced without the author's permission.
AVIS:

L'auteur a accordé une licence non exclusive permettant à la Bibliothèque et Archives Canada de reproduire, publier, archiver, sauvegarder, conserver, transmettre au public par télécommunication ou par l'Internet, prêter, distribuer et vendre des thèses partout dans le monde, à des fins commerciales ou autres, sur support microforme, papier, électronique et/ou autres formats.

L'auteur conserve la propriété du droit d'auteur et des droits moraux qui protège cette thèse. $\mathrm{Ni}$ la thèse ni des extraits substantiels de celle-ci ne doivent être imprimés ou autrement reproduits sans son autorisation.
In compliance with the Canadian Privacy Act some supporting forms may have been removed from this thesis.

While these forms may be included in the document page count, their removal does not represent any loss of content from the thesis.
Conformément à la loi canadienne sur la protection de la vie privée, quelques formulaires secondaires ont été enlevés de cette thèse.

Bien que ces formulaires aient inclus dans la pagination, il n'y aura aucun contenu manquant. 


\begin{abstract}
Data from 65 market offers of 27 companies was used to: i) classify market offers enabled by open source hardware into nine types; ii) identify the customer value propositions, profit formula elements, key resources, and key processes for each type of market offer; iii) compare market offers enabled by open source software and hardware; iv) compare market offers enabled by open source intellectual property cores (IP Cores) and printed circuit boards (PCBs); and v) provide an open source model that can be applied to both open source hardware and software. The results of this research suggest that: i) open source hardware market offers rely on highly-restrictive licenses, and are enabled by only two types of assets - IP cores and PCBs; ii) two open source software market offer types were not found in the case of open source hardware - subscription services and testing; iii) the reason for the differences between open source hardware and open source software market offers is the tangible (physical) nature of hardware products; iv) the reasons for the differences between open source IP core market offers, and open source PCB market offers are related with differences in their manufacturing processes. This research contributes towards the development of a more general open source business framework that can be applied across different domains (e.g., software, hardware, content).
\end{abstract}




\section{ACKNOWLEDGMENTS}

I would like to thank my family for all the support that I received from them; to my wife, Antonieta, for her encouragement, love, and patience; to my son, Alejandro, because although he is only 6 year old, he was mature enough to understand why some times I could not spend more time with him; to my 1-year-old daughter, Elizabeth, because her smile always cheered me up; and to my parents, that although they are physically far away, I always feel that their hearths are beside mine.

This thesis was developed as part of the Competing in open environments research program led by Tony Bailetti, Carleton University, and Peter Carbone, Nortel. The support received from Nortel for this research and the M.A.Sc. in Technology Innovation Management program is gratefully acknowledged.

I am deeply grateful to Professor Stoyan Tanev, for his advice, and for all the months that I had the pleasure to work with him.

And last, but not least, I profusely thank Professor Tony Bailetti, for his tireless guidance, support, and encouragement. 


\section{TABLE OF CONTENTS}

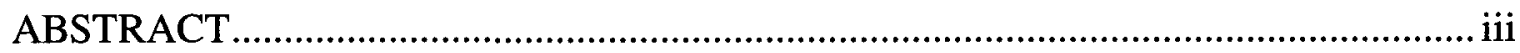

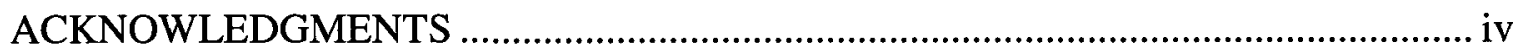

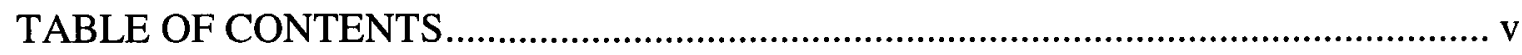

LIST OF TABLES ................................................................................................ vii

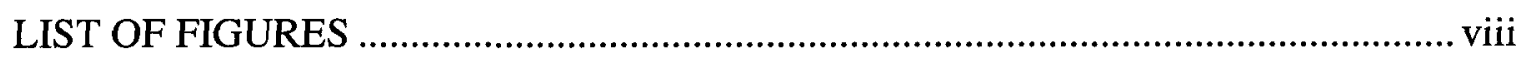

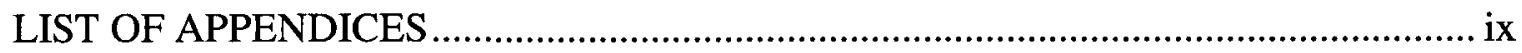

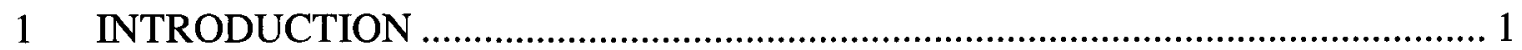

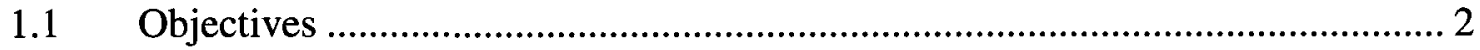

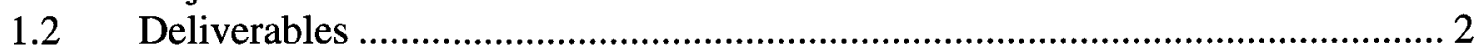

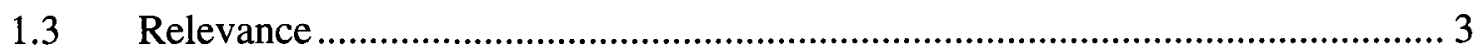

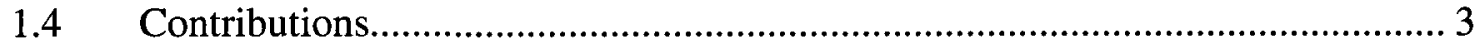

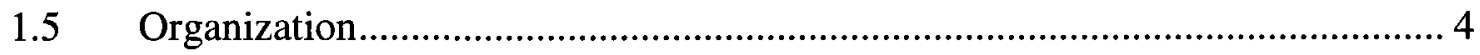

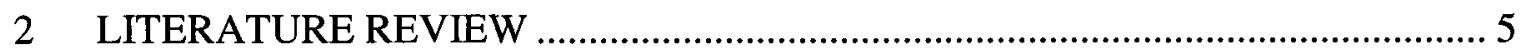

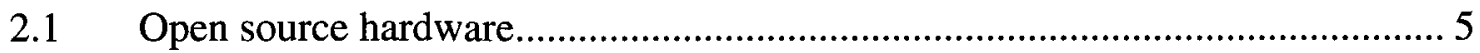

2.1.1 OSH definition and licensing ....................................................................... 5

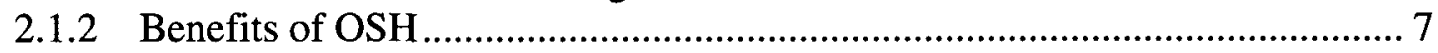

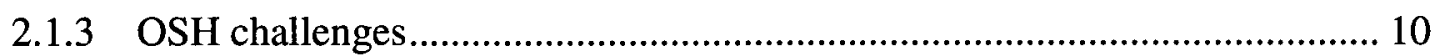

2.1.4 OSH business models ............................................................................... 15

$2.2 \quad$ Open Source Software ……………………….......................................... 16

$2.3 \quad$ Business models and market offers............................................................ 19

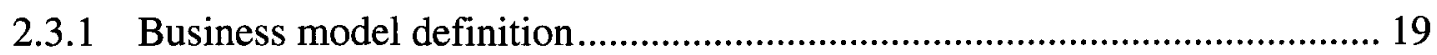

2.3.2 Business models characterization ............................................................ 20

2.3.3 OSS business models, strategies, and market offer classifications................ 23

2.3.4 The case of dual-licensing ............................................................................ 26

2.4 Lessons learned from the literature................................................................. 27

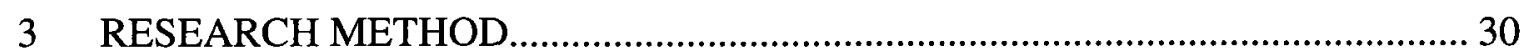

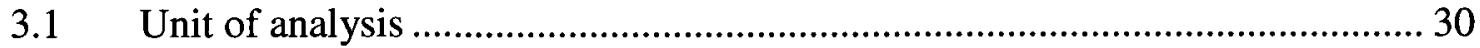

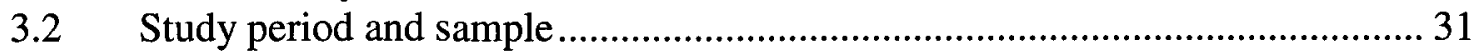

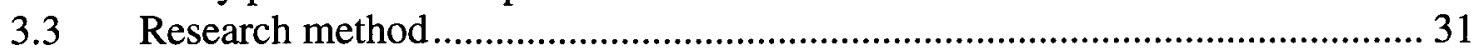

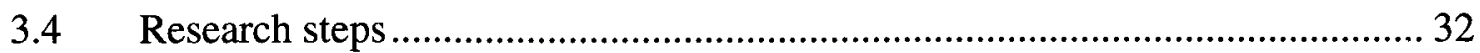

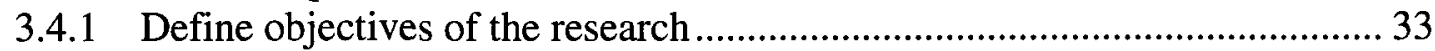

3.4.2 Identify OSH companies............................................................................. 33 
3.4.3 Build a database of OSH market offers ...................................................... 34

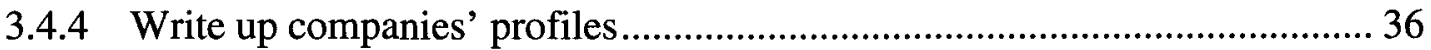

3.4.5 Classify the types of OSH market offers ....................................................... 36

3.4.6 Business models components for each market offer type.............................. 36

3.4.7 Compare results with existing OSS literature ................................................ 36

4 RESULTS .... -

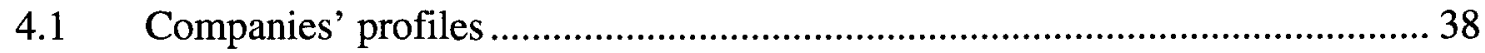

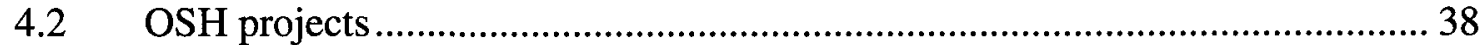

4.3 Classification of OSH market offers........................................................... 40

4.4 Business models components .................................................................. 42

4.4.1 Customer value propositions................................................................. 43

4.4.2 Profit formula......................................................................................... 45

4.4.3 Key resources and processes......................................................................... 46

4.5 A comparison between OSH market offers and OSS market offers.................. 48

5 DISCUSSION OF RESULTS ………………............................................... 50

5.1 A relatively small number of market offers but highly diverse types of offers 50

5.2 Only two types of assets associated with all the $\mathrm{OSH}$ market offer types........ 50

5.3 Only 3 OSH market offers target mass markets ............................................... 51

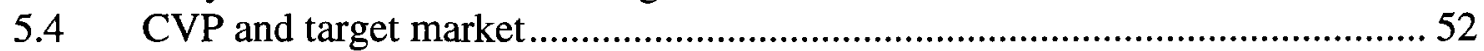

5.5 OSH strengthens the profit formula by reducing costs .....................................56

5.6 Four most frequent key resources and processes ............................................. 56

5.7 Most of the OSH companies use highly-restrictive licenses ............................ 61

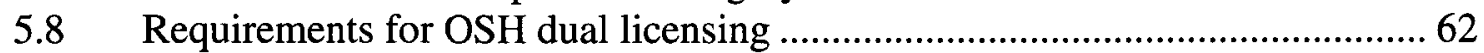

5.9 The use of OSS and OSH enables even more use of OSH ................................ 62

5.10 Comparison between OSH and OSS market offers .......................................... 63

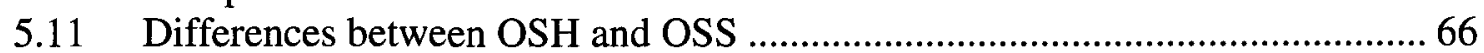

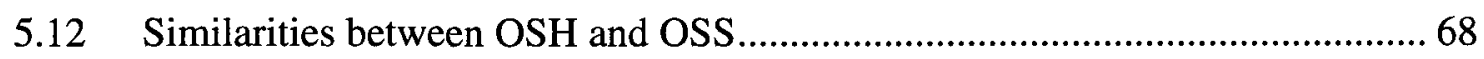

5.13 Differences between open source IP cores and open source PCB ..................... 69

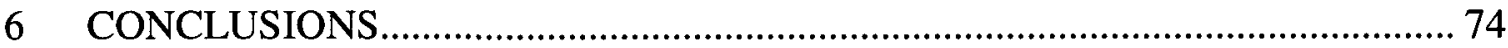

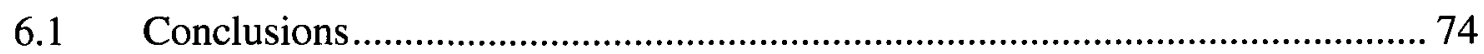

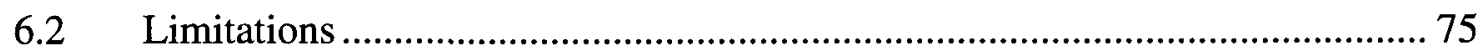

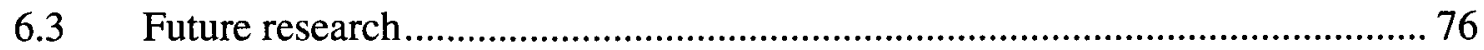

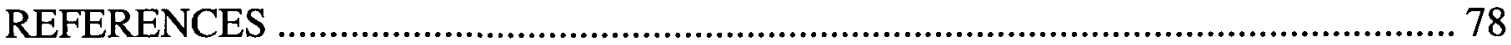

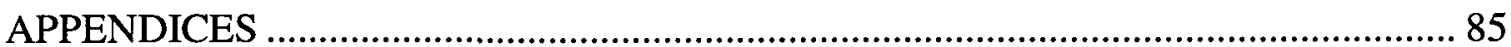




\section{LIST OF TABLES}

Table 1. Open source license classification (data found in Perens, 1999; Nissilä, 2004). 18

Table 2. OSS business models proposed by Raymond (2000b)....................................... 24

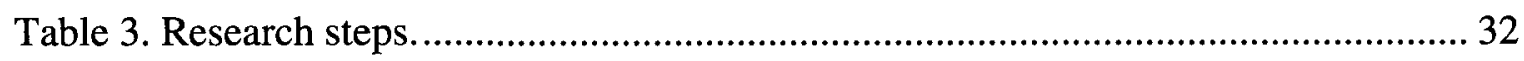

Table 4. Number of companies and market offers per type of market offer. .................... 40

Table 5. Number of companies, OSH projects, and market offers per type of license..... 42

Table 6. Number of companies and market offers per type of target market................... 52

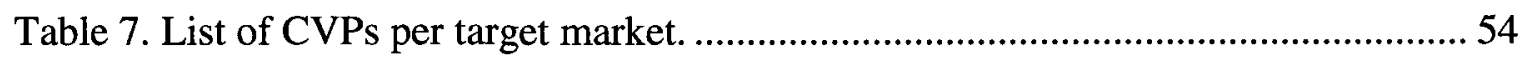

Table 8. Number of projects, offers, offer types, and companies per type of license. ..... 62

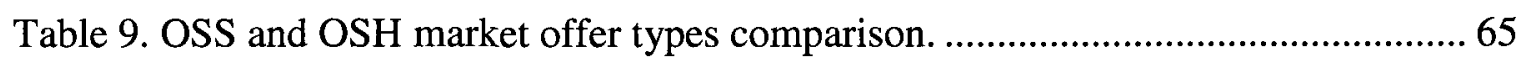

Table 10. Differences between OSS and OSH market offers.......................................... 66

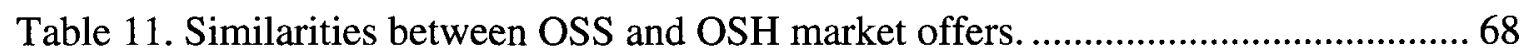

Table 12. Type of market offers per type of OSH asset. .................................................. 73

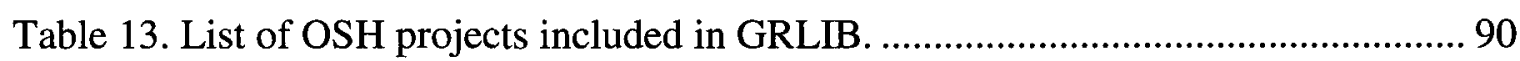




\section{LIST OF FIGURES}

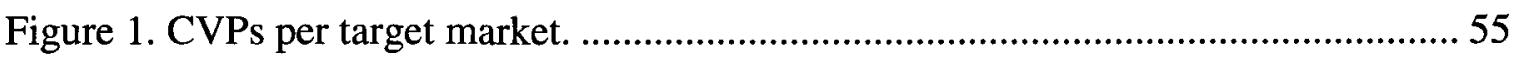

Figure 2. Most frequent combination of key resources and processes............................. 57

Figure 3. Second most frequent combination of key resources and processes................. 58

Figure 4. Third most frequent combination of key resources and processes.................... 60

Figure 5. Fourth most frequent combination of key resources and processes................. 61

Figure 6. Differences between open source IP cores and open source PCB . .................. 71

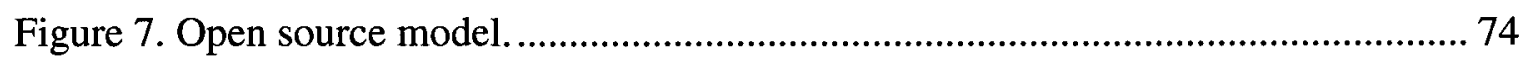




\section{LIST OF APPENDICES}

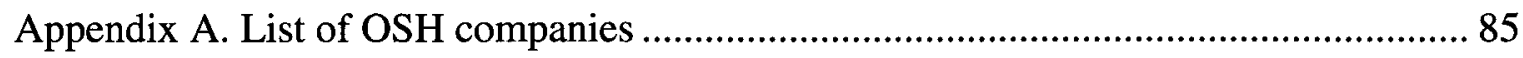

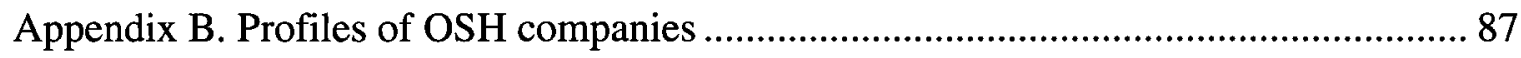

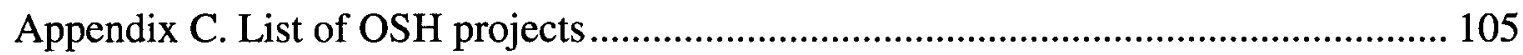

Appendix D. List of OSH market offers ................................................................... 121

Appendix E. Type of licenses and OSH assets per type market offer ............................ 129

Appendix F. CVP, profit formula elements and KRP per type market offer................... 130

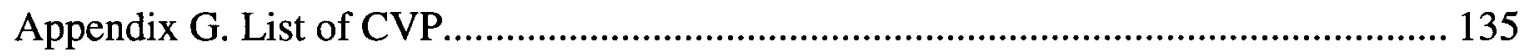

Appendix H. List of profit formula elements............................................................... 136

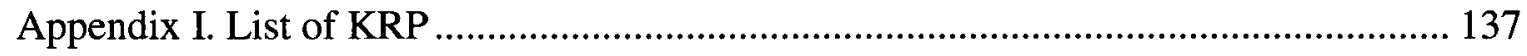

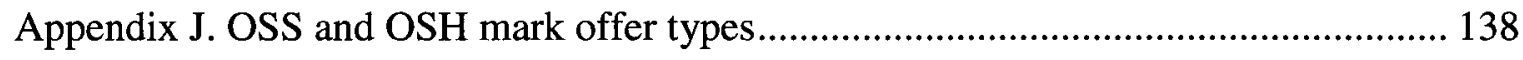

Appendix K. OSH market offers, OSS, and external OSH .......................................... 139

Appendix L. Combinations of KRP............................................................................. 142 


\section{INTRODUCTION}

There is an increasing interest in the ways of making money using open source assets other than open source software (OSS) (Salem \& Khatib, 2004; Pomerantz, 2000). Research on market offers and business models enabled by OSS (Nissilä, 2004; Hecker, 1999; Raymond, 2000b; Lerner \& Tirole, 2002a; Alam, 2006) have contributed to our understanding of how companies could generate revenue by leveraging open source assets. However, there is little known about the ways of making money from market offers that rely on open source hardware (OSH).

There is no general consensus on the definition of OSH (Rowe, 2007; Seaman, 2001; Khatib, 2000; Khatib \& Salem, 2004) and no publications based on empirical studies providing insights on the different types of offers enabled by OSH. Moreover, there is little research on the differences and similarities between the ways companies make money from market offers that rely on OSH and the ways companies make money from market offers that rely on OSS. For the purpose of this research, OSH is defined as any piece of hardware whose manufacturing information is distributed using a license that provides rights to users similar to the rights provided by OSS licenses.

The rest of this chapter is organized into five sections. Section 1.1 provides the objectives of the research. Section 1.2 lists the deliverables of the research. Section 1.3 discusses the relevance of the research. Section 1.4 summarizes the contributions of the research. Finally, section 1.5 describes how the thesis is organized. 


\subsection{Objectives}

This research examines companies with market offers enabled by OSH. There are two main objectives:

- Using publicly available data to identify market offer types and business models components used by companies with market offers enabled by OSH.

- Identifying the differences and similarities between market offers enabled by OSS and market offers enabled by OSH.

\subsection{Deliverables}

The deliverables of the research are:

- profiles of companies worldwide with market offers enabled by OSH (Appendix B);

- a data driven classification of market offers enabled by OSH (Section 4.3);

- a list of the business model components for each market offer type enabled by OSH (Appendix F);

- a list of differences and similarities between market offers enabled by OSS and market offers enabled by OSH (Section 5.10); and

- a model that captures the differences between market offers enabled by open source intellectual property (IP) cores, and market offers enabled by open source printed circuit boards (PCB) (Section 5.13). 


\subsection{Relevance}

The research is expected to be relevant to three groups of people. First, it should be relevant to top management teams of electronic circuit design companies, since the involvement in OSH projects and the development of OSH offers could enable new ways of making money.

Second, the research results will be relevant to academics, because of its contribution towards the development of a more general open source model that could be applied across different domains (software, hardware, content, or others).

Third, the research insights will be relevant to top management teams of companies that develop electronic design automation (EDA) tools, because OSH development will open new markets for the use of EDA tools.

\subsection{Contributions}

The research makes at least three contributions:

1. It moves the discussion of open source business practices out of the software domain, and provides a more general perspective of the key characteristics of open source market offers and business model components that could be applied to multiple domains. 
2. It provides a reusable process based on the recently developed business model framework by Christensen, Johnson, and Kagermann (2008) to examine market offers that rely on a particular asset.

3. It provides some practical examples and insights to companies willing to make money with market offers enabled by OSH projects.

\subsection{Organization}

This thesis is organized into six chapters. Chapter 1 includes the introduction and formulates the research objectives, deliverables, relevance and contributions. Chapter 2 contains the literature review and the lessons learned from it. Chapter 3 provides the research method and the research steps. Chapter 4 provides the results of this research, and chapter 5 discusses these results. Chapter 6 contains the conclusions, limitations, and suggestions for future research. 


\section{LITERATURE REVIEW}

The examination of the literature identified three main research streams that were found relevant to this research: (i) OSH; (ii) OSS; and (iii) business models and market offers.

Section 2.1 summarizes the insights from articles and press releases related to the definition, examples, characteristics, benefits and challenges of OSH. It also identifies possible ways to categorize OSH business models.

Section 2.2 includes the key findings from the literature on OSS. Section 2.3 includes a summary of academic research results on the classifications of business models, business strategies, and market offers.

Finally, Section 2.4 lists the lessons learned from the literature review.

\subsection{Open source hardware}

\subsubsection{OSH definition and licensing}

There is no widely accepted definition of OSH. Rowe (2007) describes OSH as "hardware for which all the design information is made available to the general public". However, Seaman (2001) argues that hardware cannot be considered as "open" if the information that is freely available is only about its design. Documentation about how to use the hardware must also be included, as well as free access to the tools required to modify the design. This definition is similar to the definition provided by Khatib (2000): 
"All design files should be available for free. This includes schematic, hardware description language (HDL) code, and layout files. Software and firmware interfaces such as drivers, compilers, instruction set, and registers interfaces should be available and open source. All information and documentation, like application notes and interfacing information, should be also openly available."

Sun Microsystems (2007) uses a development process perspective and defines OSH simply as "a collaborative process around developing new chips".

Pomerantz (2000) and Make Magazine (2007) define OSH from a license perspective by describing the characteristics that any license must have for being used for the distribution of OSH assets. OSH licenses must:

- grant permission to freely distribute the source code, and any hardware device based on it; and

- grant permission to create derivative works based on the source code, and distribute them under the same license.

The license characteristics are also discussed by Khatib and Salem (2004). They state that all OSH information should be disclosed following terms similar to those of the GPL-like licenses. 
Make Magazine (2007) divides up electronic hardware into six layers and explains that licensing concerns and shared source codes are different in each layer. The six layers are:

1. Hardware (mechanical) diagrams. This layer includes the physical dimensions for enclosures, mechanical subsystems, etc. Designs in this layer are normally described by vector graphic files.

2. Schematics and circuit diagrams. This layer includes symbolic diagrams of electronic circuit designs, as well as images (PDF, BMP, GIF, etc).

3. Parts list. This layer includes the lists of components that are needed for manufacturing the hardware.

4. Layout diagrams. This layer includes electronic circuit designs, PCB copper prints, and drill information distributed using Gerber RS274x and Excellon files.

5. Core / Firmware. This layer may refer to the source code that runs on an integrated circuit (IC). It may also refer to the design of the IC itself described in Hardware Description Language (HDL) files.

6. Software / API. This layer includes the source code of the software that is used to make the interface with the open source hardware.

\subsubsection{Benefits of OSH}

OSH for better hardware

It is argued that the OSH development process produces robust designs (Vallance, 2000) because of the participation of an extensive and multi-party community network (Khatib, 2000) that improves innovation and reduces debugging time (Vallance, 2000). Open 
source design processes also increase modularity, re-configurability and interchangeability, fostering the creation of standards (Vallance, 2000) and creating more versatile and universally accepted hardware designs (Khatib, 2000).

Proprietary hardware designs tend to be poorly documented because they are not intended for sharing. The open source development processes can improve the documentation of hardware designs (Khatib, 2000).

OSH for lowering hardware costs

Semiconductor companies are engaged in a costly and senseless war of designing everything in-house. The consequence is a great number of dispersed engineering teams "re-inventing the wheel" and spending resources. Engineering teams in different organizations do not collaborate to solve common issues (Pomerantz, 2000). OSH can increase collaboration across development organizations by enabling the sharing of development processes and the reuse of hardware designs (Vallance, 2000; Seaman, 2001).

OSH provides easy access to low cost IP for small and start-up companies (Seaman, 2001), by reducing support and ownership costs (Vallance, 2000). 
OSH for System on a Chip (SoC)

A System-on-a-chip (SoC) is an integrated circuit that contains, in a single chip, all the components needed to form a complete electronic system, such as a computer, cell phone or digital camera. With SoC, instead of designing circuit boards with various chips and components, a single chip is built integrating all the parts. The SoC technology promises to reduce designing costs by enabling the reuse of commodity IP core components as modular building blocks (Siliconfareast, 2006).

However, the benefits of SoC will not be enjoyed if there are not enough cheap commodity components (Pomerantz, 2000; Khatib, 2000). Additionally, a successful SoC revolution requires (Azhari, 2007):

- a new ecosystem to take advantage of new architectures;

- a modular and standard architecture;

- ability to innovate freely; and

- ability to cooperate freely as a community.

OSH can play an essential role in the SoC revolution by promoting high-quality standards, and creating low-cost SoC components without placing restrictions on intellectual property (Pomerantz, 2000; Kessner, 2000). 


\section{OSH for education}

OSH provides students of hardware designers an open environment where they can develop their skills (Khatib, 2000). An example of this benefit is Arduino, an open source development board. The intent of Arduino project is to make "things easy enough for students to get an understanding of how things work by trying them" instead of hiding complexity from users (Banzi et al., 2007).

\section{OSH for developing countries}

Khatib and Salem (2004) highlight the potential of OSH for reducing the technological, educational, and cultural gaps between developed and developing countries. OSH improves knowledge interchange, reduces costs, and brings more opportunities to start-up companies in developing countries.

\subsubsection{OSH challenges}

OSH does not mean free hardware

Stallman (1999) says that people using OSS tend to confuse the terms free and gratis because it often costs nothing to make a copy of a piece of software. However, in OSH the difference is clear. Hardware designs can be copied and distributed freely, but there are costs related to the manufacturing of the hardware itself.

In some cases, it is very expensive for individuals to manufacture the hardware that they are developing (Seaman, 2001). The collaboration process in OSH does not work in the 
same way as in OSS. Once the hardware manufacturing process has started, it is unlikely that developers can add new changes to the design (Brockmeier, 2007).

\section{Expensive tools}

The costs related to designing, verifying, and understanding hardware designs are high (Davidson, 2004). Carrying out these activities requires the use of expensive electronic design automation (EDA) tools (Seaman, 2001; Khatib, 2000; Davidson, 2004). In some cases, additional external hardware is needed, such as oscilloscopes, analyzers and wafer probes (Turley, 2002).

Communities that develop open source EDA tools exist. Although currently those open source tools do not meet the highest industry standards, they will eventually be competitive with commercial EDA tools (Seaman, 2001). An obstacle that open source EDA tools face is that the interfaces of some commercial Field-Programmable Gate Arrays (FPGA) are protected by commercial secrecy and copyrights. One of the suggested solutions to this obstacle is the creation of an open source FPGA, whose interface would be open enough to allow the use of any open source EDA tool (Seaman, 2001). 


\section{Manufacturing and integration costs}

In the case of software, most of the cost of the product is related to the cost of the IP, which includes the cost of the design. For some hardware, the cost of the IP is much lower than the cost associated with manufacturing (Khatib \& Salem, 2004) and integration (Spooner, 2001). Therefore, cost savings related to open-sourcing the IP tends to be lower in the case of OSH than in the case of OSS.

Davidson (2004) points out that, in the case of microprocessors, designs built only with OSH IP cores are unlikely to be commercially successful. Therefore, the cost of some proprietary IP cores must be added to the final cost of the product.

Bugs in hardware designs could unexpectedly increase manufacturing costs by causing physical damage to the chip and even to other parts of the system (Turley, 2002).

\section{Clean IP}

It is difficult for OSH developers to design products without infringing on existing patents (Asaravala, 2003). Established companies, such as IBM and Intel, argue that they are not directly challenged by the OSH movement because patents keep their products safe (Spooner, 2001). 


\section{Licensing}

Vilbrandt (2001) believes that the strength of the OSH movement has not increased because of the lack of an appropriate license for OSH designs. None of the existing licenses cover all the aspects of hardware designs (Seaman, 2001; Brockmeier, 2007).

Stallman (1999) affirms that although definitions of circuits, written in HDL, circuit drawings, or layouts can be copyleft; circuits themselves cannot be copyleft, because they cannot be copyright. A copyright can protect a design for being copied and modified, but it cannot regulate the manufacturing, distribution, and use of products based on the design. Patents are used in such cases, but they are expensive and not as flexible as copyrights. The consequence is that the benefits of copyleft in hardware are limited (i.e., benefits of using a GPL-like license are small).

Since 2007, the Tucson Amateur Packet Radio (TAPR) organization has been promoting the TAPR Open Hardware License (OHL) as a legal framework for OSH projects. The license is intended for any kind of physical tangible product. It is a share-alike license, meaning that any modified design can be redistributed only by using a license with the same rights that those granted by the license of the original design. The TAPR points out that "OHL is not primarily a copyright license", so it does not prohibit a company from enforcing its patent rights after patenting an invention related to the OSH design. However, the license states that parties who receive any benefits from an open hardware 
design "may not bring lawsuits claiming that design infringes their patents or other intellectual property" (Paul, 2007).

Jamey Hick, a Nokia researcher, proposed the Open Source Hardware License (OSHL) to the Open Source Initiative (OSI). This license is being used by the Armo project, which Nokia is carrying out jointly with the MIT (Brockmeier, 2007).

Licenses specifically created for OSH are not needed because existing OSS licenses can be used for OSH (Brockmeier, 2007). For the case of IP cores, the source code is Hardware Definition Languages (HDL) files, which are considered software by the Free Software Foundation (FSF). Therefore, IP core source code can be legally distributed using OSS licenses, such as GPL, or LGPL (Seaman, 2001).

\section{Modularity}

Modularity is a key factor for the success of open source development (Lerner \& Tirole, 2002a). Linus Torvalds stresses the importance that a modular architecture had for the success of Linux saying that "I couldn't do what I did with Linux for Windows, even if I had the source code. The architecture just wouldn't support it. Too much of the Windows source code consists of interdependent tightly coupled layers for a single developer to drop in a replacement module" (Raymond, 2000a). Netscape faced difficulties due to their non-modular architecture when they released the browser Mozilla as open source (Lerner \& Tirole, 2002a). 
Turley (2002) argues that one of the reasons why OSH will not succeed is because hardware cannot be as modular and compartmentalized as software.

\section{Credibility}

Lack of credibility with respect to proprietary hardware designs is another challenge for OSH. OSS faced a similar problem some years ago. However, Khatib and Salem (2004) argue that the OSH community will eventually convince users that high quality OSH designs can be produced.

\section{Less participation from the open source community}

The number of people that collaborate with the project decreases as you go down through the scripting, libraries, driver, kernel, firmware and hardware levels. Simon Phipps, from Sun Microsystems, states that the "the closer to hardware designs you get, the fewer contributors you will find" (Brockmeier, 2007). Extent of support for OSH projects is still vague.

\subsubsection{OSH business models}

A factor commonly associated with the success of open source projects is the existence of appropriate business models (Gallagher \& West, 2006). Khatib and Salem (2004) suggest that companies can make money from OSH projects in four ways: 
1. Design distribution: companies sell distributions containing a set of OSH designs.

2. Technical support: companies sell technical support related to OSH designs.

3. Design implementation: companies sell implementations of $\mathrm{OSH}$ designs, paying royalties to the original developers.

4. Releasing designs: Companies release some of their OSH designs under a GPLcompatible license, and receive royalties from other companies that sell the implementation.

Pomerantz (2000) identifies technical support as a major option for companies working with OSH, and suggests two additional ways companies can make money from OSH:

1. Collaboration: companies working under contract for a chip manufacturer can open source a design to enable the participation of other chip manufacturers and develop multi-purpose and customizable designs.

2. Open source IP: companies can open source IP that is not intended to be sold; the IP is then integrated into a product or service, thereby reducing development costs without risking revenues.

\subsection{Open Source Software}

OSS is defined as software whose source code is distributed under a license approved by the Open Source Initiative (Nissilä, 2004). The license must comply with these nine terms: 
1. The source code can be redistributed.

2. The source code must be available.

3. The source code can be modified and then redistributed using the same license.

4. The modifications to the source code can be redistributed as "patch files" along with the original source code.

5. There must be no restrictions in the license against any person.

6. There must be no restrictions in the license against any field or endeavor.

7. The rights granted by the license apply to any redistribution of the software.

8. The license must not be specific to a product.

9. The license must not place restriction in other software that is distributed along the licensed software.

\begin{abstract}
Although all the licenses used in OSS comply with the nine terms, there are differences between them. Perens (1999) classifies OSS licenses using four dimensions. Table 1 compares the most popular licenses using these four dimensions.
\end{abstract}




\begin{tabular}{|l|c|c|c|c|}
\hline License & $\begin{array}{l}\text { Can be mixed } \\
\text { With non-free } \\
\text { software? }\end{array}$ & $\begin{array}{l}\text { Modiffeations } \\
\text { can be taken } \\
\text { private and not } \\
\text { returned to } \\
\text { author? }\end{array}$ & $\begin{array}{l}\text { Can be re- } \\
\text { licensed by } \\
\text { anyone? }\end{array}$ & $\begin{array}{l}\text { Contains special } \\
\text { privileges for the } \\
\text { original copyright } \\
\text { holder over user's } \\
\text { modifications? }\end{array}$ \\
\hline GPL & No & No & No & No \\
\hline LPGL & Yes & No & No & No \\
\hline BSD & Yes & Yes & No & No \\
\hline $\begin{array}{l}\text { Netscape } \\
\begin{array}{l}\text { Public } \\
\text { license }\end{array}\end{array}$ & Yes & Yes & No & No \\
\hline $\begin{array}{l}\text { Mozilla } \\
\text { Public } \\
\text { License }\end{array}$ & Yes & Yes & Yes & \\
\hline
\end{tabular}

Table 1. Open source license classification (data found in Perens, 1999; Nissilä, 2004).

Lerner and Tirole (2002b) classified open source licenses using two dimensions: i) if the source code must or must not be available when modified versions of the program are distributed, and ii) if the source code can or cannot be combined with software that have a different license. The resulting classification describes three types of open source licenses:

- Unrestrictive licenses: modified versions of the program can be combined with software that have a different license and distributed without making the source code available. Some examples of this type of licenses are the BSD, and the MIT license.

- Restrictive licenses: modified versions of the program must be distributed along with the source code, but they can be combined with software that has a different license. One example of this type is the Lesser General Public License (LGPL). 
- Highly-restrictive licenses: modified versions of the program cannot be combined with software that has a different license and must be distributed along with the source code. One example of this type of license is the General Public License (GPL).

\subsection{Business models and market offers}

\subsubsection{Business model definition}

Business models are important to companies. However, research on business models is scant (Apel, D'Urso, Herman, \& Malone 2006). There is no general accepted definition of what a business model is (Nissilä, 2004; Allen et al., 2005), and sometimes the business model concept is used interchangeably with other concepts such as business strategy, revenue, or economic model (Magretta, 2002; Allen et al., 2005).

Most business model definitions found in the literature emphasize how a company makes money, with some definitions making emphasis also in how the customer value is created (Apel et al., 2006; Nissilä, 2004). Apel et al. (2006) define a business model in terms of the actions the business carries out, and how the business makes money doing those actions. Rajala, Rossi, Tuumaimen, and Korri (2001) explain that most of the business model definitions in the literature are related to the way of creating value for customers, and to how companies take business opportunities to generate profit through actors, activities and collaboration. 


\subsubsection{Business models characterization}

Christensen et al. (2008) state that a successful business model comprises four components:

1. Customer value proposition $(C V P)$ : What is the value that the company creates to customers?

2. Profit formula: What is the value that the company creates for itself? This includes the revenue model, cost structure, margin model, and resource velocity, which is the speed at which inventory and other assets are turned over.

3. Key resources: What are the important assets used to deliver the value to customers? This includes people, technology, equipment, and brands.

4. Key processes: How the value is delivered to customers? This includes training, development, manufacturing, sales, and services.

The term CVP is used in three different ways (Anderson, Narus, \& Rossum, 2006):

- All benefits: This includes all the benefits that the market offer provides to customers. It requires an understanding of the market offer.

- Favorable points of differences: This includes all the favorable or superior benefits that the market offer provides to customers in comparison with similar offers from competitors. It also requires an understanding of both the owned market offer, and the market offers from competitors.

- Resonating focus: This includes only the specific market offers benefits that are relevant to the customers, and their business needs. The benefits could include some 
favorable or superior characteristic, and some "points of parities" in comparison with market offers from competitors. It also requires an understanding of the owned market offer, the market offers from competitors, and the customer needs.

Allen et al. (2005) developed a framework for characterizing business models. The framework consists of three levels of decision-making:

- Foundation level: generic decisions about what the business is.

- Proprietary level: decisions about how to create value to obtain marketplace advantage.

- Rules level: guiding principles that rule the execution of the decisions taken in the other two levels.

In each of the three levels, a business model answers the following questions:

- How will the firm create value?

- For whom will the firm create value?

- What is the firm's internal source of advantage?

- How will the firm position itself in the marketplace?

- How will the firm make money?

- What are the entrepreneur's time, scope and size ambitions?

Nissilä, Rajala, and Westerlund (2006) make a distinction between business model and revenue model. The revenue model, which is an inseparable element of any business 
model, encloses sources of revenue, priced-quotation principles and cost structure. The other three elements that are included in a business model are:

- Offerings: the benefits for the buyers, and product features, such as styling, quality, brand name, licensing and packaging.

- Resources needed to develop and implement a business model: the tangible and intangible assets, such as physical and nonphysical resources; and capabilities, such as intangible knowledge resources.

- Relationship with actors: the value network.

Nissilä (2004) concludes that key elements of any software business model are:

- value creation and revenue logic;

- market offerings and positioning; and

- product development, implementation and servicing.

In addition, Nissilä (2004) also concludes that, for the case of business models for companies that rely on OSS, these following elements must also be considered:

- The extent of community development and review.

- The style of development method: cathedral or bazaar.

- The license type: more restrictive or more liberal.

- The importance of OSS in the end product: pure OSS (no proprietary components added), OSS driven (the core is open source with proprietary component added) or 
proprietary software driven (the core is proprietary with some open source components added).

\subsubsection{OSS business models, strategies, and market offer classifications}

Richard Stallman proposes that software should be treated as a service rather than intellectual property (Hecker, 1999). Table 2 is an adaptation of the OSS business models proposed by Raymond (2000b). In addition to those, Hecker (1999) includes "software franchising", as a combination of "brand licensing" and "support seller", to categorize companies that sell services to firms that develop custom software.

Koenig (2004) classifies open source business strategies into seven categories:

- Optimization: companies use OSS to commoditize a particular layer, moving profitability to adjacent interdependent layers of the software stack, where applications are optimized and have greater value.

- Dual Licensing: companies offer software with some limitations, and a license that allows its free use. Additionally, they offer similar software with a proprietary license that allows a fee commercial distribution, and a larger set of features.

- Consulting: companies offer consulting services, such as middleware integration.

- Subscriptions: companies offer support and services under a subscription.

- Patronage: companies sponsor OSS projects to create standards or eliminate competitors that are extracting values from a layer of the software stack.

- Hosting: Companies offer host services using OSS in their servers. 
- Embedded systems: Companies use OSS in embedded systems.

\begin{tabular}{|l|l|l|}
\hline \multicolumn{1}{|c|}{ Name } & \multicolumn{1}{|c|}{ Business model } & Example \\
\hline $\begin{array}{l}\text { Loss-leader / } \\
\text { Market positioner. }\end{array}$ & $\begin{array}{l}\text { Use OSS to maintain a market position for a related } \\
\text { proprietary software product. }\end{array}$ & $\begin{array}{l}\text { Netscape } \\
\text { Mozilla. }\end{array}$ \\
\hline Widget frosting. & Sell hardware with open source software. & $\begin{array}{l}\text { Apple's } \\
\text { MacOS X. }\end{array}$ \\
\hline $\begin{array}{l}\text { Give away the } \\
\text { recipe, open a } \\
\text { restaurant. }\end{array}$ & $\begin{array}{l}\text { Distribute OSS and sell service and support } \\
\text { contracts. }\end{array}$ & Red Hat. \\
\hline $\begin{array}{l}\text { Accessorizing. } \\
\text { Free the future, sell } \\
\text { the present. }\end{array}$ & $\begin{array}{l}\text { Sell close source software with a license that makes } \\
\text { it open source after a specific time period. }\end{array}$ & $\begin{array}{l}\text { Aladdin's } \\
\text { Ghostscript. }\end{array}$ \\
\hline $\begin{array}{l}\text { Free the software, } \\
\text { sell the brand. }\end{array}$ & $\begin{array}{l}\text { Sell to other developers a brand that certifies that } \\
\text { their implementation of your open source } \\
\text { technologies is compatible with all others who use } \\
\text { the brand. }\end{array}$ & $\begin{array}{l}\text { Sun's } \\
\text { StarOffice. }\end{array}$ \\
\hline $\begin{array}{l}\text { Free the software, } \\
\text { sell the content }\end{array}$ & $\begin{array}{l}\text { Develop an open source product that receives } \\
\text { proprietary content sold by the firm }\end{array}$ & N/A \\
\hline
\end{tabular}

Table 2. OSS business models proposed by Raymond (2000b). 
Krishnamurthy (2003) explains that the license affects the business strategy. He proposes four types of business models:

- Distributors: companies providing access to the source code and making money by selling services, upgrades, or CDs with the product.

- Software producers (Non-GPL): companies making money by incorporating the source code in an existing larger code base, or bundling it with existing products.

- Software producers (GPL): companies releasing a source code as open source to accelerate innovation.

- Third-party service providers: companies selling services for OSS developed by third parties.

Lerner and Tirole (2002a) list three ways of making money with OSS:

- Living symbiotically off an open source project: companies providing complementary services and products.

- Code release: companies participating more actively in the development of OSS by releasing existing proprietary source code and increasing profit in complementary segments.

- Intermediaries: companies offering consulting for companies that want to develop part of their software as open source. 
Alam (2006) classifies market offers enabled by OSS projects into 6 types:

- Hosting and content services: OSS is used in an infrastructure that delivers content. Companies receive income from content creators, from advertisement that is delivered together with the content, and from subscription to premium content.

- Training and testing services: companies providing training and professional certifications. This market offer type also includes testing and certification of software and hardware to guarantee their compatibility with the OSS asset.

- Support services: this category includes custom development and consulting.

- Subscription services: subscribed customers receive updates, upgrades, monitoring and management features for OSS products, and complementary assets.

- Commercial licenses: customers that do not want to stick to the open source license can obtain, under a commercial license, the same or an improved version of the OSS asset. This market offer type also includes the offering of trademarks, such as brands.

- Products / Applications: companies selling complementary products and applications. It also includes products and applications that integrate OSS with complementary assets to create a system.

\subsubsection{The case of dual-licensing}

Hecker (1999) calls dual-licensing a hybrid business model that uses both traditional licensing and an open source license for the same product. In addition to the revenues 
from selling the fee license, this model also provides complementary revuenues through technical support and services (Koeing, 2004).

Välimäki (2003) explains that dual-licensing has some differences with the pure free model. Firstly, the OSS community does not have the power to develop competing products because the control of the core is held by the original developer. Secondly, users have the possibility of buying a proprietary license. His research also found some fundamental legal requirements for a commercial successful dual-licensing model, such as the use of licenses with a strong copyleft clause, and "undisputed rights" that companies must have over the software. In addition, he lists three economic implications that must be considered before implementing a dual-licensing model:

1. There must be a sufficiently large user base for the product.

2. The effectiveness of the model depends on price discrimination.

3. There are no major requirements for enforcing the copyright.

\subsection{Lessons learned from the literature}

\section{Most of the existing literature is focused on OSS}

Most of the research on open source licensing, motivations for participating in open source projects, open development processes, and structure of open source communities, is centered on OSS. Similar research in other domains such as OSH or open content has not been carried out. 


\section{Lack of empirical research on OSH business models}

Articles that list possible business models for companies working with OSH do exist. However, none of those articles are based on empirical research. Additionally, most of the business models for OSH in the literature were taken directly from software companies, without considering the differences between software and hardware.

\section{Similarities between OSS and OSH}

The main two similarities between OSS and OSH include:

- Rights granted to users and developers: The licenses used in OSH are similar or the same as those used in OSS. They provide rights to users to have access, modify, and to re-distribute the source code without paying any royalties to the original developers.

- Open development process: OSH is developed using open development processes similar than those used in OSS. OSH receives all the benefits derived from open development processes, such as robustness in the design, increasing modularity, and better documentation. 


\section{Differences between OSS and OSH}

The differences between OSS and OSH include:

- The source code is different: The source code in OSS is software code. The source code in OSH is HDL code, diagrams or schematics.

- Tools for developing hardware are more expensive: Hardware designing requires Electronic Design Automation (EDA) tools that are expensive. Software development requires tools that are cheaper or open source.

- Hardware designs tend to be less modular: There are more inter-dependence of hardware modules than in the case of software modules.

- The distribution of the cost in hardware is different: In the case of software, most of the product cost is related to intellectual propriety. In the case of hardware, most of the product cost is related to testing and manufacturing.

- Hardware requires different distribution channels: As hardware is a physical product, and software is an intangible product, hardware distribution is more expensive than software distribution.

- Licenses do not cover all the aspects of hardware designs: Licenses cannot regulate the distribution and use of products based on hardware designs. Patents are used in such cases, but they are expensive and not as flexible as licenses. 


\section{RESEARCH METHOD}

This chapter is organized into four sections. Section 3.1 defines the unit of analysis. Section 3.2 defines the study period and sample. Section 3.3 describes the research method. Section 3.4 describes the research steps.

\subsection{Unit of analysis}

The unit of analysis is a market offer that is enabled by one or more OSH projects.

$\mathrm{OSH}$ is defined as any piece of hardware whose manufacturing information is distributed using a license that provides specific rights to users without the need to pay royalties to the original developers. These rights include:

- freedom to use the hardware for any purpose;

- freedom to study and modify the design; and

- freedom to redistribute copies of either the original or modified manufacturing information.

A market offer is defined as anything that is offered for attention, acquisition, use or consumption that might satisfy a want or need in the market (Kotler \& Turner, 1995; Alam, 2006). An OSH market offer is defined as any market offer that was enabled by one or more OSH projects. In the same way, an OSS market offer is defined as any market offer that was enabled by one or more OSS projects. 
In the cases where some of the companies offer different modules for a system that is being developed under the same OSH project, those modules are considered to be a single market offer when (1) inter-dependencies among interfaces exist, and (2) they were developed by the same company or group of people.

There are cases where the market offer depends more than one OSH project, e.g., the offering of custom designs based on more than one OSH project.

\subsection{Study period and sample}

The sample for the research is all OSH market offers worldwide available as of January 30, 2009.

\subsection{Research method}

This research is exploratory (Eisenhardt, 1989), and could be described as being a descriptive stage of the process of theory building (Christensen \& Carlile,2005).

The key research activities were developed around the identification and the classification of the OSH market offers. For each type of market offer, business models components were identified following Christensen et al. (2008). The different types of OSH market offers were then compared with existing OSS literature (Alam, 2006). The final results were then analyzed to generate insights about the similarities and differences between OSS, and OSH market offers. 


\subsection{Research steps}

Table 3 provides the activities carried out in this research and the rationale for each of them.

\begin{tabular}{|c|c|c|}
\hline No & Activity & Rationale \\
\hline 1 & Define research objectives & $\begin{array}{l}\text { - Establish the final goals for the } \\
\text { completion of the research } \\
\text { - Prioritize efforts }\end{array}$ \\
\hline 2 & $\begin{array}{l}\text { Identify market offers enabled by } \\
\text { OSH projects }\end{array}$ & - Identify the research sample \\
\hline 3 & $\begin{array}{l}\text { Build a database of market offers } \\
\text { enabled by OSH }\end{array}$ & $\begin{array}{l}\text { - Collect and organize information about } \\
\text { each OSH market offer } \\
\text { - Establish the criteria for classifying the } \\
\text { market offers }\end{array}$ \\
\hline 4 & Write up profiles of OSH companies & $\begin{array}{l}\text { - Provide empirical examples of } \\
\text { companies with market offers enabled } \\
\text { by OSH }\end{array}$ \\
\hline 5 & $\begin{array}{l}\text { Classify the types of OSH market } \\
\text { offers }\end{array}$ & $\begin{array}{l}\text { - Identify the different ways of how } \\
\text { companies make money with OSH }\end{array}$ \\
\hline 6 & $\begin{array}{l}\text { Identify business models components } \\
\text { for each type of OSH market offer }\end{array}$ & $\begin{array}{l}\text { - Describe the business models used by } \\
\text { OSH }\end{array}$ \\
\hline 7 & $\begin{array}{l}\text { Compare results with existing } \\
\text { literature about OSS market offers }\end{array}$ & $\begin{array}{l}\text { - Identify difference and similarities } \\
\text { between OSS market offers and OSH } \\
\text { market offers }\end{array}$ \\
\hline
\end{tabular}

Table 3. Research steps. 


\subsubsection{Define objectives of the research}

The research examines companies having market offers enabled by OSH. The objectives of this research are to:

- Use publicly available data to identify market offer types and business models components used by companies with market offers enabled by OSH.

- Identify differences and similarities between market offers enabled by OSS and market offers enabled by OSH.

\subsubsection{Identify OSH companies}

A search was conducted on Google with two different keywords: "Open Source Hardware" and "Open Hardware". The companies found were then investigated to identify companies involved in OSH and determine if they had market offers enabled by OSH projects. Additionally, OSH projects listed in both Opencores ${ }^{1}$ and Opencollector ${ }^{2}$ were investigated to determine if there were market offers related to them.

As a result, a database was created containing all the OSH market offers found as of January 30, 2009.

\footnotetext{
${ }^{1}$ http://www.opencores.com

${ }^{2}$ http://www.opencollector.org
} 


\subsubsection{Build a database of OSH market offers}

For each OSH market offer, the following information was collected from company web sites, OSH project web sites, and press releases:

- Name of the company

- Name of the market offer

- Description of the market offer

- Target market

- Business model components

- Description and names of the OSH projects that are related to the market offer

- Type of open source license for each OSH project

- Type of OSH assets

- Dependency on OSS projects or other OSH projects.

Open source licenses were grouped into three categories using the criteria suggested by Lerner and Tirole (2002b):

- Unrestrictive license: This type of license does not require redistributing the source code when redistributing a modified version of the asset, and the open source asset can be combined with assets that have different license types. Examples of this type of license are the BSD and MIT licenses.

- Restrictive license: This type of license requires the redistribution of the source code when redistributing a modified version of the asset; the open source asset can be 
combined with assets that have different license types. An example of this type of license is LGPL.

- Highly restrictive license: This type of license requires redistribution of the source code when redistributing a modified version of the asset; the open source asset cannot be combined with assets that have different license types. An example of this type of license is GPL.

The business models components of the market offers were identified following the business model framework described by Christensen et al. (2008). This framework identified the following components:

- Customer value proposition (CVP): CVP was defined as the favorable or superior benefits that the market offer provides to customers in comparison with similar offers from competitors. This CVP definition is what Anderson et al. (2006) categorized as "Favorable points of differences".

- Profit formula elements: The profit formula is the value that a company creates for itself. It includes the revenue model, the cost structure, the margin model, and the resource velocity, which is the speed at which inventory and other assets are turned over.

- Key resources and processes: These are the key assets used to deliver value to customers. It includes people, technology, equipment, and brand. It also includes processes, such as training, development, manufacturing, sales, and services. 


\subsubsection{Write up companies' profiles}

- For each company with one or more market offers that relied on OSH projects, a profile was produced. The profile included information about the market offer and the OSH projects of which the company was engaged.

\subsubsection{Classify the types of OSH market offers}

$\mathrm{OSH}$ market offers were classified based on the information found in companies' web pages and press releases. The classification was done on the basis of the following dimensions:

- description of the market offer; and

- description of the OSH assets that are related to the market offer.

Market offers having similar dimensions, were grouped together into the same OSH market offer type.

\subsubsection{Business models components for each market offer type}

Using the framework described by Christensen et al. (2008) (see section 3.4.3), all the business model components were identified and listed for each type of OSH market offer.

\subsubsection{Compare results with existing OSS literature}

The types of OSH market offers were compared with the OSS market offers results provided by Alam (2006). From this comparison, two lists were generated: (i) market 
offers that were found for OSS but not for OSH, and (ii) market offers that were found for OSH but not found in OSS. 


\section{RESULTS}

This chapter is organized into five sections. Section 4.1 provides the company profiles. Section 4.2 shows the data gathered. Section 4.3 classifies the OSH market offers. Section 4.4 identifies business model components for each market offer type. Section 4.5 compares the OSH market offers with existing OSS literature.

Appendix A provides a list of the 27 companies included in this study. Appendix $\mathrm{C}$ lists the 110 OSH projects that enable market offers. For those 110 projects, 10 are driven by companies or professional groups that do not have any OSH market offer. Appendix D lists the $65 \mathrm{OSH}$ market offers enabled by OSH projects.

\subsection{Companies' profiles}

Appendix B includes the profiles of the 27 companies with one or more market offers enabled by OSH.

\subsection{OSH projects}

Appendix $\mathrm{C}$ identifies the $\mathrm{OSH}$ projects that were found as a result of the web search.

The web search found that some of the OSH projects use licenses that were not identified by Lerner and Tirole (2002b) including: the Creative Commons Attribution Share-alike, the Creative Commons Attribution Non-commercial Share-alike, and the Creative 
Commons Attribution. Using the rationale in Lerner and Tirole (2002b), these licenses were classified as follows:

- The licenses "Creative Commons Attribution Share-alike", and "Creative Commons Attribution Non-commercial Share-alike" are classified as highly restrictive because (1) they require redistributing the source code when redistributing a modified version of the asset, and (2) the open source asset cannot be combine with assets that have different license types.

- The license "Creative Commons Attribution" was classified as unrestricted because (1) modified versions of the asset can be combined with assets that have different license types, and (2) the asset can be distributed without making the source code available.

The research found only two types of OSH assets associated with the market offers included in the research sample, IP Cores and PCBs. IP Cores are electronic designs that can be implemented or synthesized into integrated circuits. PCBs are electronic designs that are printed over circuit boards. Most of the OSH projects include either only PCB designs, or only IP core designs. However, there were two OSH projects found (the TS7300, and Model 353) that include both PCB designs and IP core designs. 


\subsection{Classification of OSH market offers}

Appendix D classifies the OSH market offers by market offer type. The data suggests that market offers enabled by OSH projects can be grouped into nine types. Table 4 shows the number of companies and market offers for each type of market offer.

\begin{tabular}{|c|c|c|c|}
\hline Type & Description & $\begin{array}{c}\text { Number } \\
\text { companies }\end{array}$ & $\begin{array}{c}\text { Number } \\
\text { offers }\end{array}$ \\
\hline A & Support services & 3 & 3 \\
\hline B & Training & 3 & 3 \\
\hline C & Hardware based on OSH designs & 15 & 17 \\
\hline D & Dual Licensing & 1 & 2 \\
\hline E & Hardware tools & 3 & 9 \\
\hline F & Parts and kits for building OSH & 6 & 25 \\
\hline G & Software tools & 1 & 3 \\
\hline H & Documentation & 2 & 2 \\
\hline I & Branding & 1 & 1 \\
\hline
\end{tabular}

Table 4. Number of companies and market offers per type of market offer.

The following provides a short description for each market offer type:

A) Support services: Companies provide consulting, and custom design services to customers willing to integrate the $\mathrm{OSH}$ asset with other assets, or modify the $\mathrm{OSH}$ asset to fulfill some specific needs. 
B) Training: Companies provide training services to users of a product that is based on OSH designs.

C) Hardware based on OSH designs: Companies manufacture and sell hardware that is based on OSH designs. The source code of the product is either open source, or a proprietary modified version of an OSH design.

D) Dual Licensing: Companies offer the source code of a hardware project under either an open source license, or a commercial license. Additionally, this type also includes the offering, under a commercial license, of a source code that is a modified version of an OSH design.

E) Hardware tools: Companies offer hardware tools for the development and testing of OSH designs.

F) Parts and kits for building OSH: Companies sell components, parts or ready-to-build kits for people who want to build hardware based on OSH designs.

G) Software tools: Companies offer software tools for the development and testing of OSH designs. 
H) Documentation: Companies sell books or magazines that include instructions about how to build, customize, or use hardware based on OSH designs.

I) Branding: Companies offer the trademark name of an OSH project to other companies that want to sell products related to the OSH project.

Appendix E lists the hardware types and licenses types used for each type of OSH market offer.

Table 5 shows the number of companies, OSH projects, and market offers per type of license

\begin{tabular}{|c|c|c|c|}
\hline Type of license & Companies & OSH projects & Market offers \\
\hline Highly-restrictive & 26 & 75 & 62 \\
\hline Restrictive & 1 & 2 & 1 \\
\hline Unrestrictive & 3 & 33 & 4 \\
\hline
\end{tabular}

Table 5. Number of companies, OSH projects, and market offers per type of license.

\subsection{Business models components}

For each type of OSH market offer, Appendix F shows the identified customer value propositions, profit formula elements, and key resources and processes. 


\subsubsection{Customer value propositions}

Using publicly available information on companies' websites, and following the framework proposed by Christensen et al. (2008), the research identified the following customer value propositions:

- Cross-platform product: The software for administrating and configuring the OSH runs on different operative systems, such as Windows, Linux, and MacOS.

- Easy and fast development and implementation: As the source code is open, developers can easily develop over the hardware to create new systems or implementations.

- Easy customization: As the source code is open, users can easily modify the hardware design to fulfill specific needs.

- Easy to build: The hardware is easy to build for any individual without any specialized knowledge.

- Easy to use: The product is easy to use and does not require any specialized knowledge.

- Expertise: The company provides the right expertise to offer technical or training services.

- High integration between software and hardware: As the source code of the hardware is open, software developers create optimized software that suits better the hardware and takes full advantage of the hardware design. Additionally, the hardware can be customized to make it more efficient for some software applications. 
- Large and growing number of applications and uses: The hardware can be used in a large and growing number of applications.

- Low cost: The product is cheaper than similar products from competitors.

- Meet standard quality: The product is certified as meeting the standard quality that is required by the people that control the OSH project.

- Modular product: The system is built modularly, where each module provides one or more functionalities. Users can buy and combine the modules that they need to enjoy specific functionalities.

- No subscription needed: The product displays free content downloaded from the Internet without requiring any subscription or fee from users.

- One-stop store: The company's online store provides all the components, kits, tools and instructions to build OSH projects.

- Online community: There is an online community where users can share opinions and experiences about the OSH product. The online community also provides a certain level of technical support.

- Small size: The product is small enough to make it portable, or to fit into systems of small size.

- Teach how to design and build hardware: The product is a kit easy to assemble, aimed at beginners that want to learn how to design and build hardware.

- Test the product first: As the source code is open, potential customers can test and evaluate the product before buying it. 
- The project will survive if the company dies: As the product is open source, and there is a community supporting it, the project will be kept alive even if the company disappears.

- Visual approach: The product is documentation that explains visually how to build OSH projects. It could be magazines and books with pictures, or instructional videos available in web sites.

For each CVP, Appendix G shows the number of offers and number of companies that refer to each value proposition on their website.

\subsubsection{Profit formula}

Using publicly available information from companies' websites, and following the framework proposed by Christensen et al. (2008), the research identified the following profit formulas:

- Deliver advertisement with free content: The product displays free content downloaded from the Internet, along with advertisement from the company and content partners.

- Lower cost of attracting new customers by using open source: There is an open community of users and developers around the OSH. Some of those users and developers become customers by buying related products or services. 
- Lower cost of product by using open source: Development, testing, and technical support costs are reduced because tasks associated with those cost are shared between the company, and the open source community.

- Open new markets by using open source: Users and developers can adapt and customize the hardware for its use in unexpected new markets.

- Speed the development and innovation process by using open source: Developers in the open source community accelerate the development and innovation process by fixing bugs, and increasing functionalities.

For each profit formula, Appendix $\mathrm{H}$ shows the number of market offers, companies, and market offer types identified.

\subsubsection{Key resources and processes}

Using publicly available information from companies' websites, and following the framework proposed by Christensen et al. (2008), the research identified the following key resources and processes:

- Brand: The company owns a recognized brand name that customers associate with high quality products.

- Content partners: The company has partnerships with other companies that provide content on the Internet.

- Customer support by chat: The company provides customer support through Internet chat applications. 
- Distributors: The company uses distributors to improve the communication with customers and deliver products and services.

- Expertise: The company has the right expertise to provide training and support services to customers.

- External OSH project(s): The company market offer is enabled by an OSH project that is based, or depends, on external OSH projects that are controlled by different groups of people.

- Infrastructure to deliver content: The company owns the infrastructure required to delivered the content to customers.

- Offices in different countries: The company has offices in different countries to improve the communication with customers and deliver products and services.

- OSH project(s) controlled by the company: The company controls the OSH projects that enable the OSH market offer.

- OSH project(s) not controlled by the company: The company does not control the OSH projects that enable the OSH market offers.

- OSS project(s): The company market offer is enabled by an OSH project that relies on the use OSS projects.

- Products are shipped to customers: The company products are directly shipped to customers.

- Products are sold by retailers: The company products are delivered by retail stores. 
- Selling through online store: The company products are sold through an online store in the company web site.

- Training delivered on site: The company provides training services on customer sites.

- Web-based training: The company provides online web-based training.

Appendix I shows the number of offers and the number of companies that refer to each key resource and process.

\subsection{A comparison between OSH market offers and OSS market offers}

Appendix $\mathbf{J}$ compares the OSH market offer types found in this research, with the OSS market offer types found by Alam (2006).

A comparative analysis provided the following insights on how OSS market offer types compare with the OSH market offer types:

- Hosted and content: There is no comparable OSH market offer type.

- Training and testing services: This type includes OSS companies that provide training services, equivalent to OSH market offer type B (Training). This type also includes OSS companies that provide testing services, which has no comparable OSH market offer type.

- Support services: It is comparable to OSH market offer type A (Support Services).

- Subscription services: There is no comparable OSH market offer type.

- Commercial licenses: It is comparable to OSH market offer type D (Dual licensing) 
- Applications / Products: There is no comparable OSH market offer type.

The following list contains the OSH market offer types that do not have comparable OSS market offer types:

- Hardware based on OSH designs

- Hardware tools

- Parts and kits for building OSH

- Software tools

- Documentation. 


\section{DISCUSSION OF RESULTS}

This chapter is organized into 13 sections. Sections 5.1, 5.2, and 5.3 discuss the characteristics of OSH market offers. Sections 5.4, 5.5, and 5.6 discuss the business model components. Sections 5.7 and 5.8 discuss the types of OSH licenses that companies use. Section 5.9 discusses OSS as an enabler for OSH. Sections 5.10, 5.11, and 5.12 discuss the similarities between OSS with OSH. Finally, section 5.13 discusses the differences between open source IP cores and open source PCB.

\subsection{A relatively small number of market offers but highly diverse types of offers}

Although this research found only 27 companies and $65 \mathrm{OSH}$ market offers, it identifies 9 different types of market offers. There is relatively small total number of companies and OSH market offers, but the market offers are quite diverse in types. One possible reason for such diversity could be that OSH companies were eager to adopt market offer types that had been previously known and introduced and tested by OSS companies.

\subsection{Only two types of assets associated with all the OSH market offer types}

Appendix E shows that there are only two types of assets that enable OSH market offers, IP Cores and PCB. There is no apparent reason for no having other types of OSH assets enabling market offers. For example, there were OSH projects related to mechanical parts 
for the automobile industry, such as the OScar project ${ }^{3}$, but there is no market offer related to those projects yet.

\subsection{Only 3 OSH market offers target mass markets}

The technology adoption life cycle (Rogers, 1983) describes the adoption of new innovations in time. The model splits the life cycle of an innovation into five stages, according with the characteristics of the adopters (Alam, 2006):

- Innovators: acquire the innovation because they are more risk-oriented, and eager to try new ideas.

- Early adopters: acquire the innovation because of a business opportunity.

- Early majority: acquire the innovation because early adopters demonstrated the benefits.

- Late majority: acquire the innovation after a vast majority demonstrated the benefits.

- Laggards: are the last ones to acquire the innovation because they are very conservatives.

Table 6 shows that there are only two vertical markets (hobbyists, and hardware developers), and one horizontal market (mass market) as the targets for the OSH market

\footnotetext{
${ }^{3}$ http://www.theoscarproject.org/
} 
offers. Out of the $65 \mathrm{OSH}$ market offers, 62 (95\%) target hardware developers, and hobbyists, while only 3 market offers (5\%) target mass markets. This suggests that OSH is still in the earliest stage of adoption in the technology adoption life cycle.

\begin{tabular}{|c|c|c|}
\hline Type target market & Companies & Offers \\
\hline Hardware developers & 18 & 35 \\
\hline Hobbyists & 7 & 27 \\
\hline Mass market & 3 & 3 \\
\hline
\end{tabular}

Table 6. Number of companies and market offers per type of target market.

\subsection{CVP and target market}

Table 7 shows that, although the research found 19 types of CVPs, only 3 of them are common to the three target markets - i) lower costs, ii) easy customization, and iii) easy to use. Appendix G shows that the same 3 CVPS are the most frequent ones among OSH companies:

- Low cost: 10 companies

- Easy customization: 8 companies

- Easy to use: 4 companies 


\begin{tabular}{|c|c|c|}
\hline Target market & CVP & Offers \\
\hline \multirow{13}{*}{$\begin{array}{l}\text { Hardware } \\
\text { developers }\end{array}$} & Cross-platform product & 1 \\
\hline & Easy and fast development and implementation & 4 \\
\hline & Easy customization & 4 \\
\hline & Easy to build & 1 \\
\hline & Easy to use & 2 \\
\hline & Expertise & 1 \\
\hline & High integration between software and hardware & 2 \\
\hline & Large and growing number of applications and uses & 3 \\
\hline & Low cost & 6 \\
\hline & Meet standard quality & 1 \\
\hline & Small size & 2 \\
\hline & Teach how to design and build hardware & 1 \\
\hline & Test the product first & 5 \\
\hline \multirow{10}{*}{ Hobbyists } & Easy and fast development and implementation & 2 \\
\hline & Easy customization & 5 \\
\hline & Easy to build & 14 \\
\hline & Easy to use & 1 \\
\hline & Expertise & 1 \\
\hline & Low cost & 5 \\
\hline & Modular product & 1 \\
\hline & One-stop store & 1 \\
\hline & Online community & 1 \\
\hline & Small size & 1 \\
\hline
\end{tabular}




\begin{tabular}{|c|c|c|}
\hline Target market & CVP & Offers \\
\hline \multirow{4}{*}{ Mass market } & Teach how to design and build hardware & 4 \\
\cline { 2 - 3 } & Visual approach & 1 \\
\cline { 2 - 3 } & Easy customization & 1 \\
\cline { 2 - 3 } & Earge and growing number of applications and uses & 1 \\
\cline { 2 - 3 } & Low cost & 1 \\
\cline { 2 - 3 } & No subscription needed & 1 \\
\cline { 2 - 3 } & The project will survive if the company dies & 1 \\
\cline { 2 - 3 } & Ty & 1 \\
\hline
\end{tabular}

Table 7. List of CVPs per target market.

Although the existing literature shows that an open development process is related to product modularity, only one company, Bug Labs, lists modularity as a CVP. This finding suggests that $\mathrm{OSH}$ is still in the earliest stage of adoption in the technology adoption life cycle, where products tend to be less modular than product in later stages.

Figure 1 shows the CVPs that are exclusive of each target market. It also shows the CVPs that are shared between two or three target markets. 
in

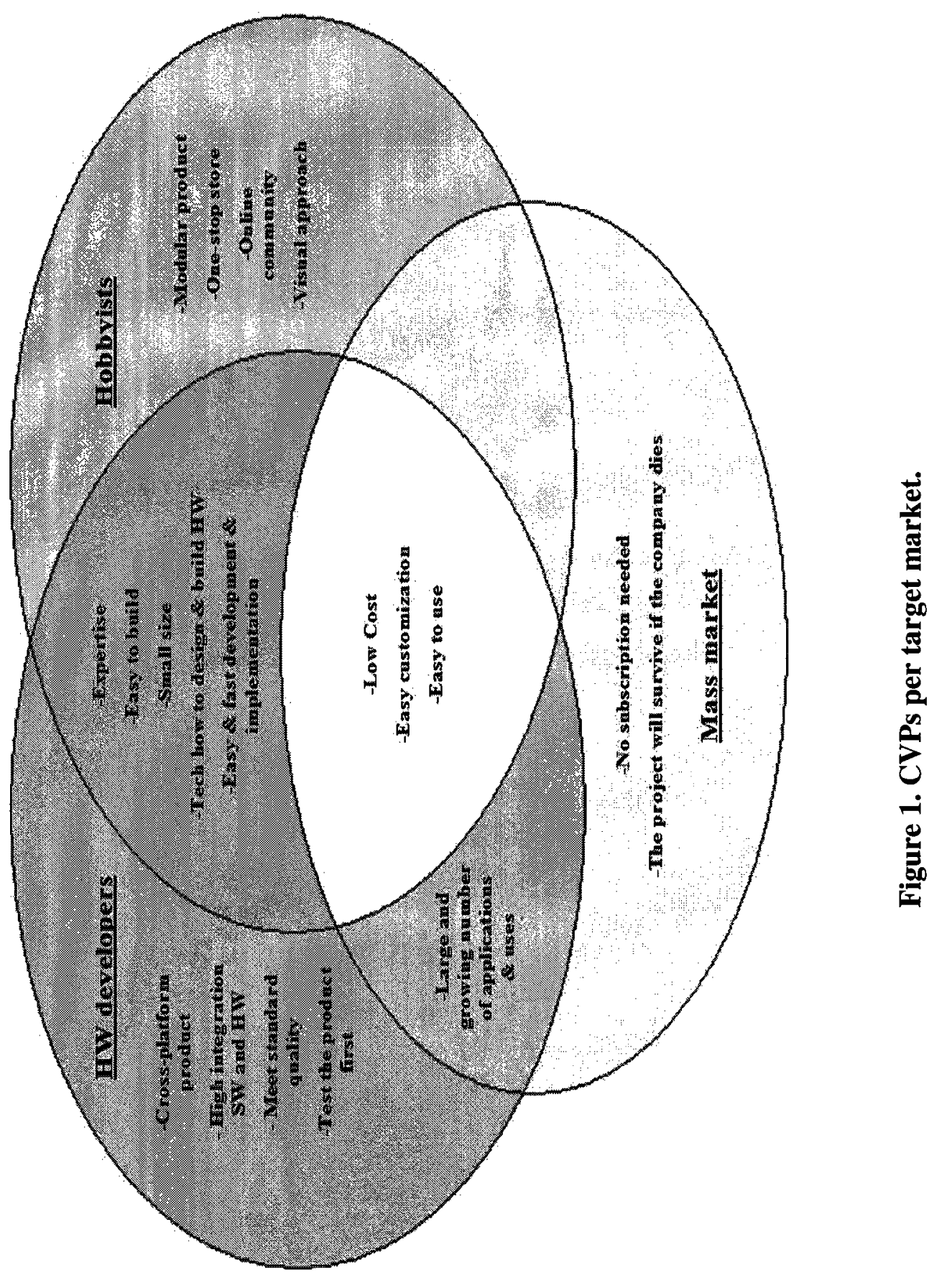




\subsection{OSH strengthens the profit formula by reducing costs}

Appendix $\mathrm{H}$ shows five profit formula elements listed by OSH companies. Four out of the five elements are enabled by the use of $\mathrm{OSH}$ and focus on cost reduction:

- Lower cost of system by using open source: The cost of the final product is lower.

- Lower cost of attracting new customers by using open source: Selling costs are lower.

- Open new markets by using open source: Selling and marketing costs are lower.

- Speed the development and innovation process by using open source: Development costs are lower.

The remaining profit formula element (delivering advertisement with free content) is not necessarily related to the use of OSH, and was found in only one company - Bug Labs. This profit formula element is exclusive to Bug Labs because the Bug Labs market offer is the only OSH market offer that displays content from the Internet.

\subsection{Four most frequent key resources and processes}

Appendix I shows that the four most used key resources and processes are:

- Selling through online store: 27 companies, 63 market offers.

- OSS project(s): 26 companies, 56 market offers.

- Products are shipped to customers: 24 companies, 51 market offers.

- OSH project(s) controlled by the company: 18 companies, 27 market offers. 
Appendix L shows that the most frequent combination of key resources and processes among the companies in the research sample ( 7 companies and 8 market offers) had these four elements:

- OSH project(s) controlled by the company

- OSS project(s)

- Products are shipped to customers

- Selling through online store.

Figure 2 shows a model that represents the most frequent combination of key resources and processes. The relation with the customer is enabled through an online store, and the product is shipped directly to customers. The product is enabled by OSH that is controlled by the company and includes OSS.

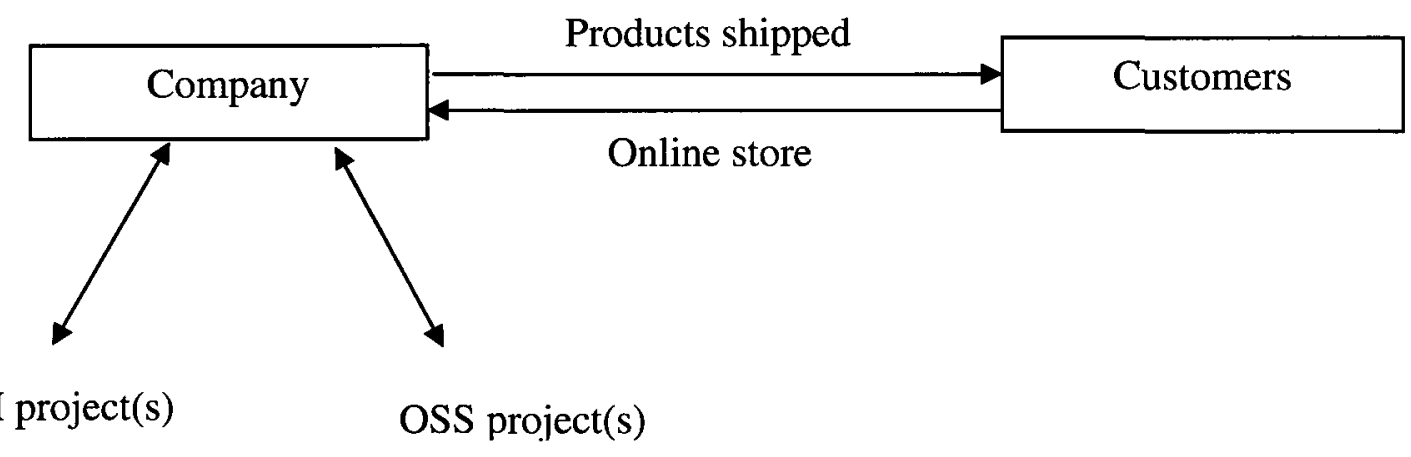

controlled by the

Figure 2. Most frequent combination of key resources and processes. 
The second most frequent combination of key resources and processes among companies (5 companies and 12 market offers) had these four elements:

- OSH project(s) not controlled by the company

- OSS project(s)

- Products are shipped to customers

- Selling through online store.

Figure 3 shows a model that represents the second most frequent combination of key resources and processes. The relation with the customer is enabled through an online store, and the product is shipped directly to customers. The product is enabled by $\mathrm{OSH}$ that is not controlled by the company and includes OSS.

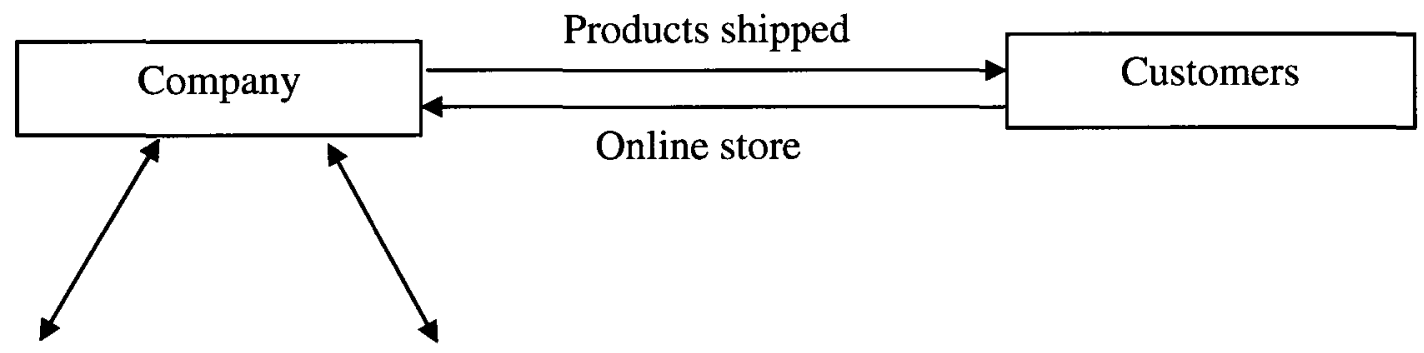

OSH project(s) not controlled by the OSS project(s) company

Figure 3. Second most frequent combination of key resources and processes. 
The third most frequent combinations of key resources and processes among companies (5 companies and 5 market offers) has these elements:

- OSH project(s) controlled by the company

- External OSH project(s)

- OSS project(s)

- Products are shipped to customers

- Selling through online store.

Figure 4 shows a model that represents the third most frequent combination of key resources and processes. The relation with the customer is enabled through an online store, and the product is shipped directly to customers. The product is enabled by OSH controlled by the company and include OSS. Additionally, the OSH project that enables the market offer depends on external OSH projects that are not controlled by the company. 
Products shipped
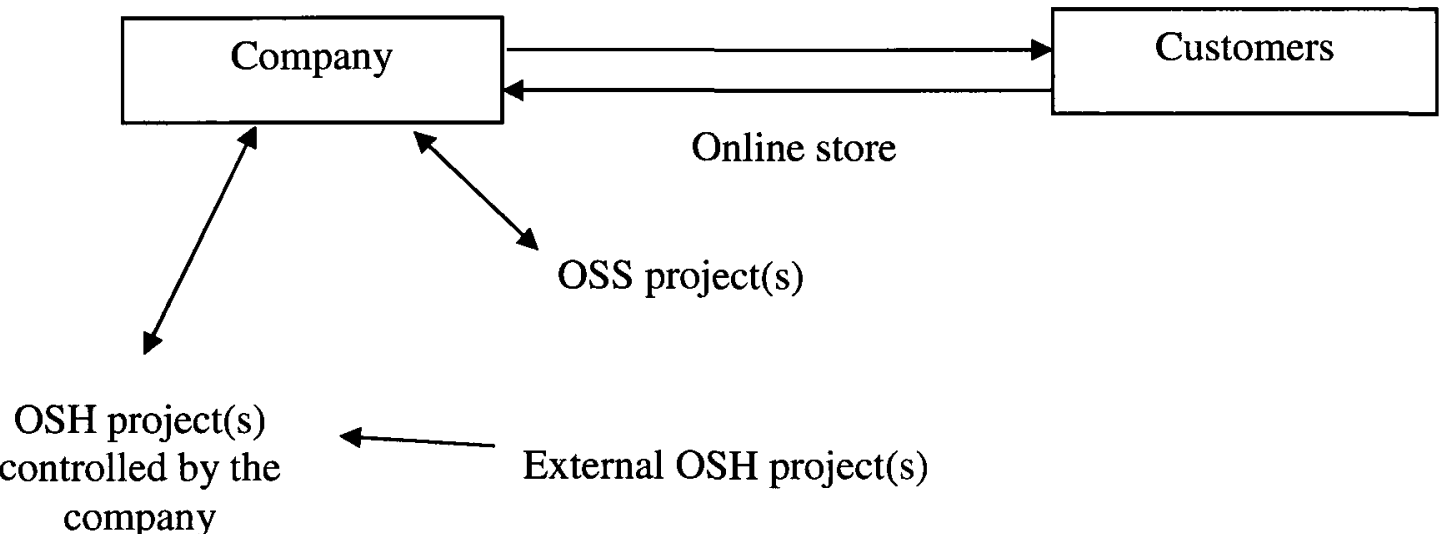

Figure 4. Third most frequent combination of key resources and processes.

The fourth most frequent combination of key resources and processes among companies

(4 companies and 6 market offers) has these elements:

- Distributors

- OSH project(s) not controlled by the company

- OSS project(s)

- Products are shipped to customers

- Selling through online store.

Figure 5 shows a model that represents the fourth most frequent combination of key resources and processes. The relation with the customer is either through an online store, or through distributors. The product is shipped directly to customers and is enabled by OSH not controlled by the company, and OSS. 


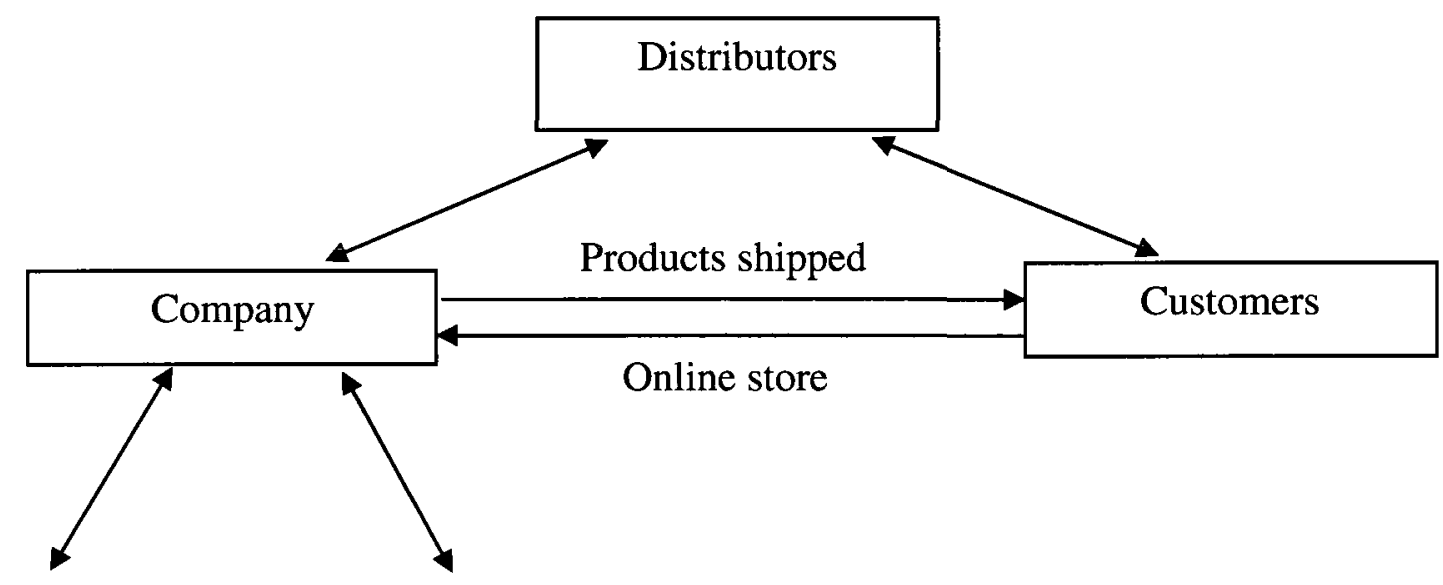

OSH project(s) not controlled by the OSS project(s) company

Figure 5. Fourth most frequent combination of key resources and processes.

\subsection{Most of the OSH companies use highly-restrictive licenses}

Most of the companies with OSS market offers choose highly-restrictive licenses for their OSS projects (Lerner \& Tirole, 2002b). Table 8 shows that this is also true for companies with OSH market offers. From the $27 \mathrm{OSH}$ companies, 26 of them (96\%) have at least one market offer enabled by OSH projects that uses a highly-restrictive license. Only four companies have market offers enabled by OSH projects that have restrictive, or unrestrictive licenses. 


\begin{tabular}{|c|c|c|c|c|}
\hline License type & Projects & Offers & Offer types Companies \\
\hline Highly-restrictive & 75 & 62 & 9 & 26 \\
\hline Restrictive & 2 & 1 & 1 & 1 \\
\hline Unrestrictive & 33 & 4 & 3 & 3 \\
\hline
\end{tabular}

Table 8. Number of projects, offers, offer types, and companies per type of license.

\subsection{Requirements for OSH dual licensing}

Making money with OSS using a dual-license model has two requirements (Välimäki 2003): (1) use of highly restrictive licenses, and (2) undisputed rights over the open source project. Appendix E shows that these two requirements are also present in all the OSH market offers using the dual-license model. Although only one OSH company (Aeroflex Gaisler) is following the dual-license model, they have undisputed rights over the $42 \mathrm{OSH}$ projects. Additionally, all those $42 \mathrm{OSH}$ projects have a highly restrictive license.

\subsection{The use of OSS and OSH enables even more use of OSH}

Appendix K shows that 56 out of the $65 \mathrm{OSH}$ market offers (86\%) are enabled by OSH projects that depend on the use of OSS. This information was taken from the list of key resources and processes for each market offer. Therefore, OSS has been a key enabler for the creation of OSH projects that enable market offers.

Appendix K also shows that 12 out of $65 \mathrm{OSH}$ market offers (18\%) are enabled by OSH projects that are based on external OSH projects controlled by a different group of 
people. Therefore, in some cases the creation of some OSH projects enables the creation of more OSH projects.

\subsection{Comparison between OSH and OSS market offers}

Appendix J shows a comparison of the OSH market offer types found by the research and the OSS market offers types found by Alam (2006).

The tangibility (i.e., the physical nature) of hardware products was found to be the key reason for the existence of three OSH market offer types that do not have comparable OSS market offer types. These three types are (1) hardware based on OSH designs, (2) hardware tools, and (3) parts and kits for building OSH.

By the time of his research, Alam didn't find any company that sold documentation for OSS developers. However, currently there are companies doing that, such as O'Reilly Media.

By the time of his research, Alam didn't find any company selling software tools for OSS developers. However, currently there are companies doing that, such as IBM and Sun Microsystems. Also, it is important to point out that all the OSH market offers that provide software and hardware tools are very specific and only useful for developing either the LEON 3, or the OpenSPARC families of processors. The tools cannot be used for the development of any other processor, or hardware. This is different from software, 
where tools tend to be generic and can be used not only for the development of a specific OSS project, but also for the development of any piece of software.

Four OSS market offer types found by Alam do not have comparable OSH market offer alternatives:

- Subscription services: There is no apparent reason for the no existence of a comparable OSH market offer type.

- Hosted and content: Tangibility of hardware is the reason for the lack of a comparable OSH market offer type.

- Products and Applications: This includes companies that offer proprietary software or hardware that is either based on OSS, or complementary to an OSS asset. Therefore, tangibility of hardware is the reason for the lack of a comparable OSH market offer type. However, we could draw an analogy between OSS and OSH, and include in this group companies such as EmQbit, and Aeroflex Gaisler, which offer proprietary hardware based on OSH designs.

- Testing: There is no apparent reason for the no existence of a comparable OSH market offer type.

Table 9 shows the market offers types that are common to OSS and OSH, the types that are exclusive of OSS due to intangibility, the types that are exclusive of OSH due to tangibility, and the types that are exclusive of OSS without any apparent reason. 


\begin{tabular}{|c|c|c|c|}
\hline & oss & OSH & \\
\hline \multirow{3}{*}{ Intangible } & Hosted and content & $\begin{array}{c}\text { Hardware base on OSH } \\
\text { designs }\end{array}$ & \multirow[b]{2}{*}{ Tangible } \\
\hline & \multirow[b]{2}{*}{ Applications / products } & Hardware tools & \\
\hline & & $\begin{array}{l}\text { Parts and kits for building } \\
\text { OSH }\end{array}$ & \\
\hline \multirow{2}{*}{$\begin{array}{l}\text { No reason } \\
\text { why only oss }\end{array}$} & Subscription services & & \\
\hline & Testing (certificate) & & \\
\hline \multicolumn{4}{|c|}{ Support services } \\
\hline \multicolumn{4}{|c|}{ Training } \\
\hline \multicolumn{4}{|c|}{ Commercial Licenses (Dual Licensing and Brand) } \\
\hline \multicolumn{4}{|c|}{ Software tools } \\
\hline \multicolumn{4}{|c|}{ Documentation } \\
\hline
\end{tabular}

Table 9. OSS and OSH market offer types comparison. 


\subsection{Differences between OSH and OSS}

Table 10 summarizes the differences between OSS and OSH market offers found in this research study.

\begin{tabular}{|c|c|c|}
\hline Asset & OSS & OSH \\
\hline Source code & Software code & $\begin{array}{l}\text { HDL code, schematics, } \\
\text { diagrams }\end{array}$ \\
\hline $\begin{array}{l}\text { Licenses used by } \\
\text { companies }\end{array}$ & $\begin{array}{c}\text { No Creative Common } \\
\text { licenses }\end{array}$ & $\begin{array}{l}\text { OSS licenses, and Creative } \\
\text { Common licenses }\end{array}$ \\
\hline Development tools & Tend to be cheap & Tend to be expensive \\
\hline $\begin{array}{l}\text { Proportion of IP } \\
\text { cost in relation with } \\
\text { product cost }\end{array}$ & High & Low \\
\hline Product tangibility & Intangible & $\begin{array}{c}\text { Tangible, which requires } \\
\text { manufacturing }\end{array}$ \\
\hline \multirow{4}{*}{$\begin{array}{l}\text { Unique market } \\
\text { offers types }\end{array}$} & Hosted and content & Hardware based on OSH \\
\hline & Applications / products & Hardware tools \\
\hline & Subscription services & Parts and kits for building \\
\hline & Testing & $\mathrm{OSH}$ \\
\hline $\begin{array}{c}\text { Product } \\
\text { distribution } \\
\text { chamnels }\end{array}$ & $\begin{array}{c}\text { Same channels than those } \\
\text { used for source code } \\
\text { distribution }\end{array}$ & $\begin{array}{c}\text { Different channels than those } \\
\text { used for source code } \\
\text { distribution }\end{array}$ \\
\hline
\end{tabular}

Table 10. Differences between OSS and OSH market offers. 
This differences include:

- Source code: The source code in OSS is software code. The source code is OSH is HDL code, schematics, or diagrams.

- License: Lerner and Tirole (2002b) did not found any OSS company using Creative Common licenses. This research found OSH companies using Creative Common licenses.

- Product tangibility: In OSS the product is intangible. In OSH the product is tangible.

- Market offer types: These market offer types were found only in OSS companies: hosted and content, application / products, subscription services, testing. These market offer types were found only in $\mathrm{OSH}$ : hardware based on $\mathrm{OSH}$, hardware tools, parts and kits for building OSH.

- Product distribution channels: OSS companies usually distribute the product using the same channels than those used for source code distribution. OSH companies distribute the product using different channels, such as distributors, retail stores, or curriers. 


\subsection{Similarities between OSH and OSS}

Table 11 summarizes the similarities between OSS and OSH market offers found in the research.

\begin{tabular}{|c|c|}
\hline \multirow{2}{*}{ Market offer types } & Support services \\
\cline { 2 - 2 } & Dual License \\
\cline { 2 - 2 } & Branding \\
\hline \multirow{2}{*}{ by opt common license type used } & Software tools \\
\hline Licenses used for Dual-license & Highly-restrictive \\
\hline
\end{tabular}

Table 11. Similarities between OSS and OSH market offers.

- Market offer types: The market offer types common to OSS and OSH companies are: support services, dual license, brand, software tools, and documentation.

- Licenses used by open source companies: Highly-restrictive licenses are the most common type of license used by both OSS companies, and OSH companies.

- Licenses used for dual-licensing model: Both OSS companies, and OSH companies use highly-restrictive licenses for dual-licensing market offers. 


\subsection{Differences between open source IP cores and open source PCB}

The research study found out that there were only two types of open source assets associated with the OSH market offers - IP cores and PCBs. Given the dominant presence of these two types of assets in the OSH market offers, an additional analysis was carried out to identify the key differences between them. Figure 6 shows two models that highlight the differences between open source IP core and PCB market offers.

Firstly, the information provided in appendix $\mathrm{C}$ shows that open source IP core projects use only OSS licenses, while open source PCB projects use either OSS licenses, or Creative Common licenses. The reason is that the source code for IP cores designs is HDL code, and most of the members of the open source community agree that OSS licenses can regulate the use of HDL code. In the case of open source PCBs the source code is in the form of diagrams and schematics and there is no consensus in the community about the type of license to be used.

Secondly, PCBs are manufactured by assembling parts, which are usually electronic components. IP cores are manufactured either by implementing the HDL code into a FPGA, or by synthesizing the HDL code into an ASIC. There is, therefore, a key difference in the particular nature of the two assets.

Thirdly, PCB designs usually require only generic tools for developing, testing, and manufacturing. IP cores require, in addition to generic tools, very specific specialized 
tools which are usually more expensive than those required for PCB development. There is, therefore, a key difference in the nature of the tools that are used to develop and test the two different assets, as well as, a difference in the ways they are being acquired and used.

Additionally, the research found that market offers enabled by open source IP cores target hardware developers and the mass market. Market offers enabled by open source PCBs, in addition to targeting the previous two markets, also target hobbyists. The most probable reason for this difference is the lower cost of the design tools and manufacturing in the case of open source PCBs, i.e. PCBs are more accessible to hobbyists as compared to IP cores. 
$\overline{1}$
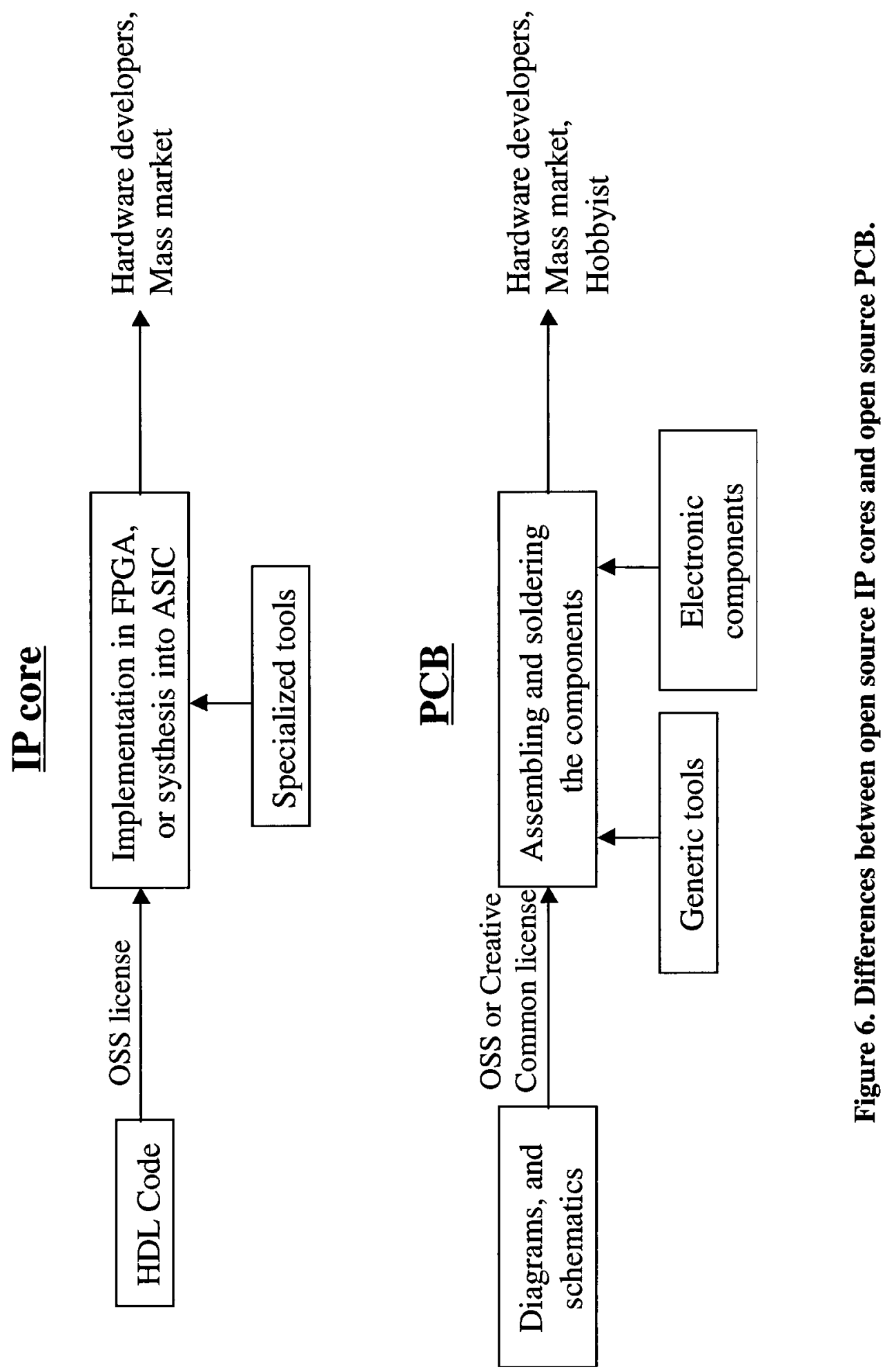
Appendix E includes a table that shows which market offer types are enabled by open source IP core projects, and which types are enabled by open source PCB projects.

The analysis of the data in the table provided in Appendix E suggests that:

- There is no apparent reason explaining the absence of market offers type D (Dual Licensing) in association with open source PCB projects.

- There is no apparent reason explaining the absence of market offers type B (Training) and type I (Branding) in association with open source IP core projects.

- The probable reason why market offer types $\mathrm{E}$ (Hardware tools), and G (software tools) are enabled only by open source IP core projects is because the development of IP cores tends to require tools that are exclusive for the development of specific IP cores. In the case of PCB development, tools tend to be generic and can be used for any type of PCB.

- The reason why there are only open source PCBs in market offer type F (Parts and Kits for Building $\mathrm{OSH}$ ) is due to the fact that $\mathrm{PCB}$ manufacturing requires physical electronic components that can be assembled manually.

Table 12 shows the market offer types that are common to IP cores and PCB market offers, the types that are exclusive of IP Cores, and the types that are exclusive to PCB. The table also shows the probable reason why some types of market offers are exclusive of one type of $\mathrm{OSH}$ asset. 


\begin{tabular}{|c|c|c|c|}
\hline \multicolumn{2}{|c|}{ Open source IP Cores } & \multicolumn{2}{|c|}{ Open source PCB } \\
\hline \multirow{2}{*}{$\begin{array}{l}\text { IP Cores } \\
\text { requires } \\
\text { specialized tools }\end{array}$} & Hardware tools & \multirow{2}{*}{$\begin{array}{l}\text { Parts and kits for building } \\
\text { OSH }\end{array}$} & \multirow{2}{*}{$\begin{array}{l}\text { PCB requires } \\
\text { physical } \\
\text { components }\end{array}$} \\
\hline & Software tools & & \\
\hline \multirow{2}{*}{$\begin{array}{l}\text { No reason why } \\
\text { only IP Cores }\end{array}$} & \multirow{2}{*}{ Dual Licensing } & Training & No reason why \\
\hline & & Branding & only PCB \\
\hline \multicolumn{4}{|c|}{ Support Services } \\
\hline \multicolumn{4}{|c|}{ Hardware based on OSH designs } \\
\hline \multicolumn{4}{|c|}{ Documentation } \\
\hline
\end{tabular}

Table 12. Type of market offers per type of OSH asset. 


\section{CONCLUSIONS}

This chapter is organized into three sections. Section 6.1 lists the conclusions of the research. Section 6.2 lists the limitations of the research. Section 6.3 lists some recommendations for future research.

\subsection{Conclusions}

The following conclusions can be drawn from the research:

- Research results suggest that the Christensen et al. (2008) framework can be used to identify key components of business models and generate insights relevant to both managers and academics.

- Figure 7 shows an open source model that applies to both OSS and OSH. The figure highlights the role that tools and parts play in the development and building of the final product. The importance of this role is usually much better visible in the case of OSH than in the case of OSS.

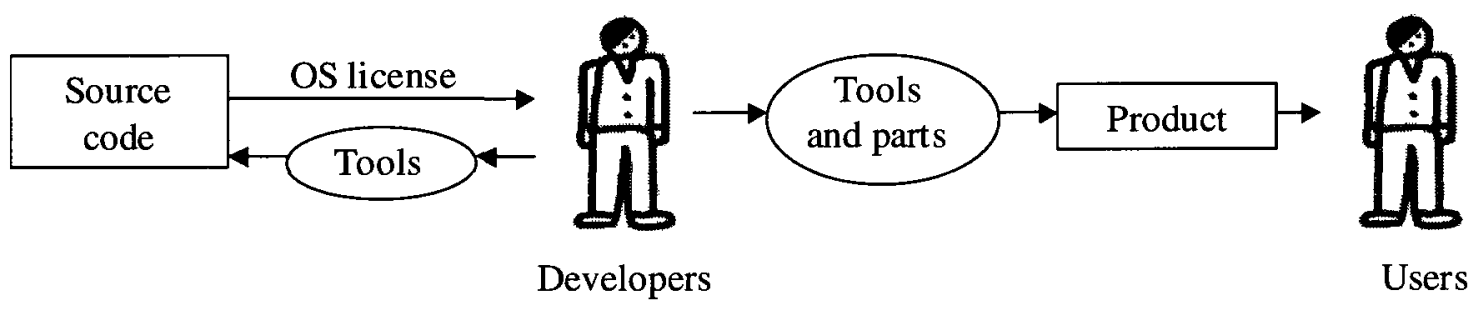

Figure 7. Open source model. 
The source code is distributed to developers using an open source license. Developers can modify the source code using development tools, and can build the final product. In the case of OSS the product is built by using tools that compile the source code. In the case of OSH the product is built by manufacturing the hardware using tools and parts. Finally, the product is distributed to users.

- The tangibility (physical nature) of hardware is the root of the differences between OSS and OSH market offers. Some OSS market offer types cannot exist in OSH. However, some companies have taken the differences between software and hardware as business opportunities, creating market offer types that are exclusive for OSH.

- There are potential OSH market offer types that have not been explored by OSH companies yet. This research found two of them - the selling of subscription services and the selling of testing services.

- Open source IP cores companies, and open source PCB companies have some key differences. These differences should be carefully taken into account in the generation of insights for both managers and academics.

\subsection{Limitations}

The research has at least these limitations:

- The research is based only on publicly available information. More accurate insights and conclusions could have been drawn if the research had included interviews with key players inside OSH companies. 
- There are two important repositories of OSH projects in the Internet (OpenCores, and OpenCollector), however none of them includes all existing OSH projects. Although the research followed multiple and complementary steps to find OSH projects not listed in those repositories, it is possible that some of the existing OSH projects could have been missed.

- The research is inductive and exploratory; it, therefore, required some degree of interpretation and the insights and conclusions might have been inevitably influenced by researcher's personal opinion.

\subsection{Future research}

The following suggestions are made for future research:

- The research sample included market offers enabled by OSH. However, it does not study how much revenue they generate, or how profitable they are. The first suggestion for future research is to identify which market offer types generate more profit to companies.

- The literature states that OSH projects receive less contribution from the open source community than OSS projects (Brockmeier, 2007; Turley, 2002). The second suggestion for future research is to provide empirical evidence to supports that difference between OSS and OSH. Additionally, future research could explore the motivations for contributing with $\mathrm{OSH}$ projects, and compare those with the motivations for contributing with OSS projects. 
- The research found few OSH market offers for the mass market. The third suggestion for future research is to identify the key success factors for OSH companies targeting in the mass market.

- The final suggestion for future research is to identify which OSH companies are startups and which one are incumbents, and explore how start-ups companies use OSH as a business strategies to compete against incumbents. 


\section{REFERENCES}

Alam, R. (2006), "Open Source Software projects, market offers, and competitive advantage" Unpublished Master thesis, Department of Systems and Computer Engineering, Carleton University, Canada.

Anderson, J., Narus, J., Rossum, W. V. 2006. Customer value proposition in business markets. Hardware Business Review. March.

Apel, T., D'Urso, V., Herman, G., Malone, T., Weill, P., Victoria, L., Woerner, S. 2006. Do some Business models perform better than others?. Working paper 4615-06. MIT

Asaravala, A. 2003. Open source takes on hardware biz. Wired news. Available at http://www.wired.com/techbiz/media/news/2003/12/61631 (retrieved June, 2007).

Azhari, F. 2007. Open source hardware - Myths becomes reality. Multi-core expo. March, $29^{\text {th }}$.

Brockmeier, J. 2007. Do we need an open hardware license?. Linux.com. July. Available at http://www.linux.com/feature/118198 (retrieved February, 2009)

Christensen, C., and Carlile, P. 2005. The cycles of theory building in management research. http://www.innosight.com . (retrieved June, 2007). 
Christensen, C., Johnson, M., Kagermann, H. 2008. Reinventing your business model. Hardware business review. December.

Davidson, S. 2004. Open-source hardware. IEEE design \& test of computers.

Eisenhardt, K. M. 1989. Building theories from case study research. Academy of management review. Vol 14, No.4, pp. 532-550.

Gallagher, S, West, J. 2006. Patterns of open innovation in open source software. In Chesbrough, H., Vanhaverbeke, W., West, J., Eds., Open Innovation: Researching a new paradigm. Oxford University Press. Oxford, 2006.

Hecker, F. 1999. Setting up shop: the business of open-source software. IEEE software. January/February.

Kessner, D. 2000. Open-source IP could ignite system-on-ship era. EETimes online. Available at http://www.eetimes.com/story/speakout/OEG20000131S0007. (retrieved June, 2007).

Khatib, J. 2000. Free chips for all. IBM developer works. Open source library, pp. 2, August. 
Khatib, J, Salem, M. 2004. An introduction to open-source hardware development. Available at http://www.eetimes.com/news/design/features/showArticle.jhtml?articleID=2210338 $\underline{3}$ (retrieved June, 2007).

Koenig, J. 2004. Seven open source business strategies for competitive advantage. IT manager's journal. Available at http://www.itmanagersjournal.com/feature/314. (retrieved June, 2007)

Kotler, P., Turner, R. 1995. Managing products, lines, brands, and packaging, marketing management - Analysis, planning, implementation, and control. Prentice Hall Canada. $420-449$.

Krishnamurthy, S. 2004. An Analysis of Open Source Business Models. Making sense of the bazaar: Perspectives on open source and free software, Joseph Feller, Brian Fitzgerald, Scott Hissam and Karim Lakhani, eds., MIT Press.

Lai, E. 2007. Open source... hardware? Someday, say ETech attendee. Available at http://www.computerworld.com/action/article.do?command=viewArticleBasic\&taxo nomyId=18\&articleId=9014440\&intsrc=hm_topic (retrieved June, 2007). 
Lambert, S. 2006. Do we need a "real" taxonomy of e-business models?. School of commerce research paper series: 06-6. Flinder University.

Lerner, J., Tirole, J. 2002a. Some simple economics of open source. The journal of industrial economics. June. Volumen L. No. 2.

Lerner, J., Tirole, J. 2002b. The Scope of Open Source Licensing. Available at http://www.people.hbs.edu/jlerner/OSLicense.pdf (retrieved April 30, 2008).

Make Magazine. 2007. Open source hardware, what is it? Here's a start... Make Magazine. Available at http://www.makezine.com/blog/archive/2007/04/open source hardware what.html (retrieved June, 2007).

Nissilä, Jussi. 2004. Towards better understanding of open source business models.

Paul, R. 2007. TAPR introduces open-source hardware license, OSI skeptical. ARS Technica. Available at http://arstechnica.com/news.ars/post/20070223-8911.html. (retrieved June, 2007).

Perens, B. 1999. The Open Source Definition. Open Source: Voices from the Open Source revolution. O’ Reilly \& Associates, Inc. 
Pomerantz, G. 2000. Business models for open source hardware design. Available at http://homepages.nyu.edu/ gmp216/papers/bmfosh-1.0.html (retrieved June, 2007).

Rajala, R., Rossi, M., Tuunaimen, V., Korri, S. 2001. Software Business Models. A framework for analyzing software industry. Technology Review 108/2001. Finnish National Technology Agency.

Raymond, E. S. 2000a. The cathedral and the bazaar. Available at http://www.catb.org/ esr/writings/cathedral-bazaar/ (retrieved February, 2009)

Raymond, E. S. 2000b. The magic cauldron. Available at http://www.catb.org/ esr/writings/cathedral-bazaar/magic-cauldron/ February, 2009)

Rogers. E. M. 1983. Diffusion of Innovation. Third edition. Free Press. New York

Rowe, J. 2007. Is open source hardware in our future. Cadalyst. Available at http://manufacturing.cadalyst.com/manufacturing/article/articleDetail.jsp?id=420352. (retrieved June, 2007).

Nissilä, J., Rajala, R., Westerlund, M. 2006. Determinants of OSS revenue model choices, Proceedings of ECIS. June. 
Schiff, A. 2002. The economics of open source software: A survey of the early literature. Review of network economics. March, Vol. 1, Issue 1.

Seaman, G. 2001. Free hardware Design - Past, Present, Future. Available at http://opencollector.org/Whyfree/freedesign.html. (retrieved June, 2007)

Siliconfareast. 2006. System on a chip (SoC). Available at http://www.siliconfareast.com/soc.htm (retrieved November 28, 2006).

Spooner, J. G. 2001. Open source moves into free hardware. ZDNET. Available at http://news.zdnet.co.uk/hardware/0,1000000091,2085331,00.htm (retrieved June, 2007).

Stallman, R. 1999. On “Free hardware”. Linux Today. Available at http://www.eetimes.com/news/design/features/showArticle.jhtml?articleID=2210338 3. (retrieved June, 2007).

Sun Microsystems. 2007. OpenSPARC. Available at http://www.opensparc.net. (retrieved June, 2007). 
Thompson, C. 2008. Build it. Profit. Can open source hardware work?. Wired Magazine. October. Available at http://www.wired.com/techbiz/startups/magazine/16-

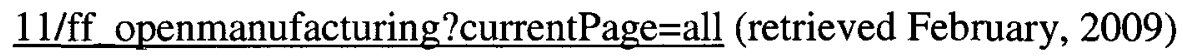

Turley, J. 2002. Open-source hardware. Embedded. Available at http://www.embedded.com/story/OEG20020524S0078. (retrieved June, 2007).

Välimäki, M. 2003. Dual Licensing in open source industry. Systemes dÍnformation et Management. Vol. 8, No. 1, pp. 63-75.

Vallance, R. 2000. Bazaar design of nano and micro manufacturing equipment. Nanotechnology workshop. University of Kentucky. July 14.

Vilbrandt, C. 2001. Introduction to extending the freedoms of free and open information. University of Aizu, Computer Arts Labs. 


\section{APPENDICES}

\section{Appendix A. List of OSH companies}

For each of the 27 companies identified, the table provides the number of the company's market offers that rely on $\mathrm{OSH}$, and the number of $\mathrm{OSH}$ projects that the company controls.

\begin{tabular}{|c|c|c|c|}
\hline Company name & Company's web site & $\begin{array}{c}\text { Market } \\
\text { offers }\end{array}$ & $\begin{array}{l}\text { OSH } \\
\text { projects }\end{array}$ \\
\hline 1. Adafruit Industries & http://www.adafruit.com/ & 11 & 8 \\
\hline 2. Aeroflex Gaisler & http://www.gaisler.com/ & 7 & 45 \\
\hline 3. Arduino Team & http://www.arduino.cc/ & 2 & 1 \\
\hline 4. ASICS.ws & http://www.asics.ws/ & 1 & 31 \\
\hline 5. Bits from Bytes & http://bitsfrombytes.com/ & 1 & 0 \\
\hline 6. Bug Labs & http://www.buglabs.net/ & 1 & 1 \\
\hline 7. Chumby Industries & http://www.chumby.com/ & 1 & 1 \\
\hline 8. Corgan Enterprises LLC & http://corganenterprises.com/ & 1 & 0 \\
\hline 9. Digi-Key & http://www.digikey.com/ & 2 & 0 \\
\hline 10. Digilent, Inc. & http://www.digilentinc.com/ & 1 & 0 \\
\hline 11. Elphel, Inc & http://www3.elphel.com/ & 1 & 1 \\
\hline 12. EmQbit & http://www.emqbit.com/ & 2 & 1 \\
\hline 13. Ettus Research LLC & http://www.ettus.com/ & 1 & 1 \\
\hline 14. Free Telephony Project & http://www.rowetel.com/ucasterisk & 1 & 1 \\
\hline
\end{tabular}




\begin{tabular}{|c|c|c|c|}
\hline Company name & Company's web site & $\begin{array}{l}\text { Market } \\
\text { offers }\end{array}$ & $\begin{array}{l}\text { OSH } \\
\text { projects }\end{array}$ \\
\hline 15. Fundamental Logic & http://www.fundamentallogic.com/ & 1 & 0 \\
\hline 16. Gleichmann Electronics & http://www.ger-fae.com/ & 3 & 0 \\
\hline 17. Gravitech & http://www.gravitech.us/ & 1 & 1 \\
\hline 18. Modern Device & http://www.moderndevice.com/ & 1 & 1 \\
\hline 19. NKC Electronics & http://www.nkcelectronics.com/ & 1 & 1 \\
\hline 20. O'Reilly Media & http://www.makezine.com/ & 11 & 1 \\
\hline $\begin{array}{l}\text { 21. Pender Electronic } \\
\text { Design }\end{array}$ & http://www.pender.ch/ & 5 & 0 \\
\hline 22. RobotFuzz & http://www.robotfuzz.com/ & 1 & 0 \\
\hline 23. SmartProject & http://www.smartpri.com/ & 1 & 0 \\
\hline 24. Sparkfun Electronics & http://www.sparkfun.com/ & 1 & 1 \\
\hline 25. Sun Microsystems & http://www.sun.com/ & 3 & 2 \\
\hline 26. Technology System & http://www.embeddedarm.com/ & 1 & 1 \\
\hline 27. Unimatic & http://www.unimatic.co.uk/ & 2 & 1 \\
\hline$+=$ & TOTAL & 65 & 100 \\
\hline
\end{tabular}




\section{Appendix B. Profiles of OSH companies}

\section{Adafruit Industries}

Web site: http://www.adafruit.com/

Adafruit Industries sells kits and parts for some of the OSH projects listed on Ladyada ${ }^{4}$ web site. Limor Fried is the founder of the company and owner of Ladyada. Adafruit Industries has redesigned some of the $\mathrm{OSH}$ projects to make them easier to solder and build. The target market is hobbyists and people with little experience in hardware building. The OSH markets offers from Adafruit Industries are:

- BoArduino: Easy-to-solder prototyping platform compatible with Arduino.

- DIGG it: A simple piece of hardware with one button and a three-digit display. The display shows a number that is incremented each time the button is pressed.

- Drawdio: Small synthesizer that creates sounds through the conductive properties of pencil graphite. Drawdio can be attached to a pencil.

- Fuzebox: 8-bit video game console. It is based on the Uzebox open source project.

- MIDIsense: Extensible sensor interface system that enables the integration of external sensors with MIDI software.

\footnotetext{
${ }^{4}$ https://www.ladyada.net/
} 
- MidiPOV v3: Persistence of vision toy that display text messages using a row of LEDs.

- Minty Boost: A battery-powered device that can re-charge USB devices, such as iPODs, mobile phones, and PDAs.

- SIM reader: Device that can read a write SIM cards using OSS.

- SpokePOV: Persistence of vision display that can be attached to bike wheels. It displays text messages using a row of LEDs.

- TV-B-Gone kit: Universal TV remote control with one button to turn on, or off, any of the most popular brands of TV sets.

- X0xb0x: MIDI controller compatible with TB-303.

\section{Aeroflex Gaisler}

Web site: http://www.gaisler.com/

Aeroflex Gaisler controls GRLIB, an open source library that includes 46 reusable open source IP cores for SoC development. GRLIB also contains the source code for Leon 3, an open source 32-bit synthesisable processor core based on the SPARC V8 architecture. The market offers related to GRLIB are:

- GRLIB: Some of the IP cores included in the GRLIB library are offered under either a GPL license, or a commercial license.

- Consulting and custom designs based on the IP cores included in the GRLIB. 
- GRMON: Debug monitor software for LEON 3 development.

- TSIM: Processor software simulator for LEON 3 development.

- GRSIM: Multiprocessor LEON 3 simulator framework for SoC development.

- LEON3FT: Source code for a fault-tolerant version of the LEON 3 processor.

- LEON3FT-RTAX: System-on-a-chip design based on the LEON3FT processor, and implemented on a FPGA.

Table 13 lists of all the OSH projects found in the GRLIB library. The second column shows the license that is used to distribute each OSH project, such as GPL, or LGPL. The cases where the design is available in either a GPL, or a commercial license, are listed as COM/GPL. 


\begin{tabular}{|l|c|}
\hline \multicolumn{1}{|c|}{ OSH Project name } & License \\
\hline AHBCTRL AMBA AHB bus controller with plug\&play & COM/GPL \\
\hline AHBJTAG JTAG/AHB debug interface & COM/GPL \\
\hline AHBMSTEM AHB master simulation model with scripting & COM/GPL \\
\hline AHBRAM Single-port RAM with AHB interface & COM/GPL \\
\hline AHBROM ROM generator with AHB interface & COM/GPL \\
\hline AHBSLVEM AHB slave simulation model with scripting & COM/GPL \\
\hline AHBSTAT AHB failing address register & COM/GPL \\
\hline AHBTRACE AMBA AHB Trace buffer & COM/GPL \\
\hline AHBUART Serial/AHB debug interface & COM/GPL \\
\hline APB2PW PacketWire Transmitter Interface & COM/GPL \\
\hline APBCTRL AMBA APB Bridge with plug\&play & COM/GPL \\
\hline APBPS2 PS2 Keyboard interface with APB interface & COM/GPL \\
\hline APBUART Programmable UART with APB interface & COM/GPL \\
\hline BIO1 Controller for HAPS I/O board BIO1 & COM/GPL \\
\hline CAN_OC Opencores CAN 2.0 MAC with AHB interface & COM/GPL \\
\hline DDR_1X1 64-bit DDR266 Controller for HAPS DDR_1x1 & COM/GPL \\
\hline DDRCTRL 8/16/32/64-bit DDR controller with two AHB ports & COM/GPL \\
\hline DDRSPA Single-port 16/32/64 bit DDR266 controller & COM/GPL \\
\hline DSU3 Multi-processor Debug support unit & COM/GPL \\
\hline GRCTM CCSDS Time manager & COM/GPL \\
\hline GRETH Gaisler Research 10/100 Mbit Ethernet MAC with AHB I/F & COM/GPL \\
\hline GRPW Packetwire receiver with AHB interface & COM/GPL \\
\hline HAPSTRAK HapsTrak controller for HAPS boards & GPL \\
\hline
\end{tabular}

Table 13. List of OSH projects included in GRLIB. 


\begin{tabular}{|l|c|}
\hline \multicolumn{1}{|c|}{ OSH Project name } & License \\
\hline I2CMST I2C Master with APB interface & COM/GPL \\
\hline I2CSLV I2C Slave with APB interface & COM/GPL \\
\hline IRQMP Multi-processor Interrupt controller & COM/GPL \\
\hline LEON3 SPARC V8 32-bit processor & COM/GPL \\
\hline MCTRL 8/16/32-bit PROM/SRAM/SDRAM controller & LGPL \\
\hline PCIARB PCI Bus arbiter & LGPL \\
\hline PCIDMA DMA controller for PCIMTF & COM/GPL \\
\hline PCIMTF/GRPCI 32-bit PCI master/target interface with FIFO & COM/GPL \\
\hline PCITARGET 32-bit target-only PCI interface & COM/GPL \\
\hline PCITRACE 32-bit PCI trace buffer & COM/GPL \\
\hline PW2APB PacketWire Receiver Interface & COM/GPL \\
\hline REGFILE_3P Parametrizable 3-port register file & COM/GPL \\
\hline SDCTRL PC133 SDRAM controller & COM/GPL \\
\hline SDRAM_1X1 32-bit SDRAM Controller for HAPS SDRAM_1x1 & COM/GPL \\
\hline SPICTRL SPI Controller with APB interface & COM/GPL \\
\hline SRAM SRAM simulation model with srecord pre-load & COM/GPL \\
\hline SRCTRL 8/32-bit PROM/SRAM controller & COM/GPL \\
\hline SYNCRAM Parametrizable 1-port RAM & COM/GPL \\
\hline SYNCRAM_2P Parametrizable 2-port RAM & COM/GPL \\
\hline SYNCRAM_DP Parametrizable dual-port RAM & COM/GPL \\
\hline TEST_1X2 Controller for HAPS test daughter board TEST_1x2 & COM/GPL \\
\hline WILD2AHB WildCard Debug Interface with DMA Master Interface & COM/GPL \\
\hline & \\
\hline
\end{tabular}

Table 13. List of OSH projects included in GRLIB (cont.) 


\section{Arduino Team}

Web site: http://www.arduino.cc/

The Arduino team is formed by the people who designed the first version of the Arduino prototyping platform. They offer consulting services for the integration of Arduino with other hardware projects. Additionally, they sell the Arduino brand name to any individual, or company, that wants to use such name for any Arduino-compatible product. The Arduino Team states that the trademark of the name is used to guarantee that low-quality products will not sully the brand name (Thompson, 2008).

\section{ASICS.ws}

Web site: $\underline{\text { http://www.asics.ws/ }}$

ASICS.ws specializes in ASIC and FPGA designs. Although ASICS.ws controls $31 \mathrm{OSH}$ projects listed in OpenCores, this company has only one OSH market offer. ASICS.ws offers custom designs adjusted to meet customer needs. The OSH projects that ASICS.ws controlled are networking IP cores, CPUs, DSPs, encryption and decryption IP cores, and other building blocks. All the open source IP core controlled by ASICS.ws are listed below:

- USB 1.1 Phy

- USB 1.1 Device

- USB 2.0 Device 
- Asynchronous Serial IO Controller

- Single Slot PCM Controller

- AC97 Controller

- I2C Master Controller

- ATA/ATAPI Host Controller

- Motorola DragonBall/68K to Wishbone Bridge

- Enhanced Motorola MC68HC11 SPI

- Mini-Risc CPU/Microcontroller (PIC Clone) IP Core

- Open 54x DSP clone

- DES

- Triple DES

- AES

- Single Precision FPU (IEEE-754 compliant)

- CORDIC Core

- Hardware Dividers

- Generic FIFOs

- DMA/Bridge IP Core

- WISHBONE Interconnect Matrix

- Simple General Purpose IO

- Simple Programmable Interrupt Controller

- Advanced Memory Controller 
- SSRAM Interface

- VGA/LCD Controller

- Video Compression System

- 8 x8 DCT, fully pipelined

- QNR, Quantization

- Huffman Encoder

- Huffman Decoder

\section{Bits from Bytes}

Web site: http://bitsfrombytes.com/

Bits from Bytes sells the parts for building RepRap, a 3D printer that uses filaments of either PolyEthene, or Poly Propylene, to produce solid objects from three-dimensional designs. RepRap is an open source project, started by Dr. Adrian Bowyer, whose objective is to build a machine that can replicate itself. While similar proprietary 3D printers cost 38,000 US\$, all the part for building RepRap are sold at 1,074 US\$. 


\section{Bug Labs}

Web site: http://www.buglabs.net/

Bug Labs sells a collection of easy-to-use electronic modules that snap together. Bug Labs describes its product as "a modular software and hardware platform that allows you to build your own custom gadgets". The hardware modules available are listed below:

- BUGbase: Base module that provides the interface to other modules.

- BUGsound: Speaker, microphone, and hardware stereo codecs.

- BUGview: LCD screen with touch-sensitive interface.

- BUGmotion: Motion detector and accelerometer.

- BUGcam2MP: Digital camera.

- BUGlocate: GPS receiver.

- BUGvonHippel: USB port and a female breakout board.

As all those modules are controlled by the same company, and related to the same $\mathrm{OSH}$ project, for the purpose of the research, they are considered a single market offer.

\section{Chumby Industries}

Web site: http://www.chumby.com/

Chumby Industries sells Chumby, a small screen with Wi-Fi capabilities that displays free content from the Internet. Chumby uses "widgets", which are software modules, to 
download data from the Internet and present it to the user. The data can be text, pictures, video, or audio. Some of the "widgets" have been created by the open source community and are distributed using the "free Chumby network". The screen also displays advertisement from Chumby Industries and its content partners.

\section{Corgan Enterprises LLC}

Web site: http://corganenterprises.com/

Corgan Enterprises provides training for the GNU Radio, and the Universal Software Radio Peripheral (USRP). The GNU Radio project is an OSS development toolkit that supplies the blocks for building software RF radios using external hardware. The USRP is an OSH project that provides PCB designs for low-cost hardware that can be used, together with the GNU radio project, to create software RF radios.

\section{Digi-Key}

Web site: http://www.digikey.com/

Digi-key sells kits and part for building electronics projects. Additionally, Digi-Key sells electronics boards. One of those boards is BeagleBoard, a low-cost fan-less computer that is embedded in a single board. Digi-Key also offers training for BeagleBoard users. 


\section{Digilent}

Web site: http://www.digilentinc.com

Digilent sells Virtex 5, which is a programmable evaluation platform for the OpenSPARC family of processors. Virtex 5 was designed by Sun Microsystems and Xilinx, and allows OpenSPARC developers to implement a reference design of any OpenSPARC processor into a FPGA, for later testing and evaluation.

\section{Elphel, Inc.}

Web site: http://www.elphel.com/

Andrey Filippov started Elphel in 2001 as a one-man company to sell video cameras based on OSS and OSH designs. The latest version of his video cameras is model 353.

\section{EmQbit}

Web site: http://www.emqbit.com/

EmQbit is a company with expertise on embedded devices. EmQbit controls and sells the ECB_AT91 V1, a single board computer based on OSS and OSH designs. Additionally, EmQbit sells the ECB_AT91 V2, a single board computer whose proprietary design is based on the ECB_AT91 V1 design with extended features. 


\section{Ettus Research LLC}

Web site: http://www.ettus.com/

Ettus Research LLC sells the motherboard and daughter boards for the Universal Software Radio Peripheral (USRP). The USRP is a device that is used to create a software radio using software from the open source GNU radio project. The list of USRP daughter boards includes transceivers, receivers, and transmitters for different radio frequencies.

As all boards are controlled by the same company, and related to the same OSH project, for the purpose of the research, they are considered to be a single market offer

\section{Free Telephony Project}

Web site: http://www.rowetel.com/ucasterisk/

David Rowe started the Free Telephony Project to enable the creation of low-cost telephone systems by using OSS and OSH. He and other developers designed the IP04, a VoIP embedded telephone system that includes 4 voice ports. IP04 uses the Blackfin processor; uClinux, a Linux distribution for the Blackfin processor; and Astfin, an Asterisk distribution for the same processor. The Free Telephony Project sells the motherboard and two daughter boards for the IP04 system. 


\section{Fundamental Logic}

Web site: http://www.fundamentallogic.com/

Fundamental Logic is a company that sells electronic components and kits for hobbyists and hardware developers. One of the products is a kit for building iDuino, and open source prototyping board. iDuino is an Arduino clone that includes an onboard USB interface.

\section{Gleichmann Electronics}

Web site: http://www.ger-fae.com/

Gleichmann Electronics is an Austrian company created in 2004. It develops FGPA and ASIC design tools, as well as SoC solutions. Gleichmann Electronics designed and sells 3 different models of development boards for the LEON 3 processor. The models are listed below:

- HPE-Mini-AC2.

- HPE-Mini-LEC.

- HPE-Compact. 


\section{Gravitech}

Web Site: http://www.gravitech.us/

Gravitech offers electronic components, kits, boards and tools for hobbyist and hardware developers. Gravitech sells Arduino Nano, a mount breadboard embedded version of Arduino with integrated USB interface.

\section{Modern Device}

Web Site: http://www.moderndevice.com/

Modern Device developed and sells the kit for building the Bare Bones Board, a prototyping board compatible and smaller than Arduino.

\section{NKC Electronics}

Web Site: http://www.nkcelectronics.com/

NKC Electronics offers electronic components, kits and boards for hobbyists and hardware developers. NKC Electronics sells Seeeduino, a prototyping board compatible with Arduino. 


\section{O'Reilly Media}

Web Site: http://www.makezine.com/

O’Reilly Media publishes a quarterly magazine named "Make Magazine" for hobbyists and amateur hardware developers that want to build do-it-yourself projects. Some of the projects that have been published by the magazine are OSH projects.

\section{Pender Electronic Design}

Web site: http://www.pender.ch/

Pender Electronic Design is a company that cooperates with Aeroflex Gaisler to promote and support LEON 3 development. Pender Electronics Design sells development boards for LEON 3 processors. Currently, there are 5 different models of LEON 3 development boards available:

- GR-PCI-XC5V,

- GR-XC3S-1500,

- GR-CPCI-AT697,

- GR-CPCCI-AX2000,

- and GR-CPCI-XC4V. 


\section{RobotFuzz}

Web Site: http://www.robotfuzz.com/

RobotFuzz provides OSS and OSH products for hobbyist and hardware developers in the areas of electronics and robotics. RobotFuzz sells OpenServo, a digital servo for robotics projects.

\section{SmartProjects}

Web site: http://www.smartpri.com/

SmartProject manufactures Arduino, an open source electronics prototyping platform. Arduino can receive input from multiple sensors, produce output using lights, and control motors.

\section{Sparkfun Electronics}

Web Site: http://www.sparkfun.com/

Sparkfun Electronics offers components, kits, and tools for hobbyists and hardware developers in the area of microcontrollers. The company sells Arduino Pro, a prototyping platform compatible with Arduino. 


\section{Sun Microsystems}

Web site: http://www.sun.com/

In March 2006, Sun Microsystems made available the source code of the OpenSPARC T1 processor under a GPL license. OpenSPARC T1 is a 64-bit multithreaded microprocessor based on the UltraSPARC $\mathrm{T} 1$ processor. The company also opened some software development tools, such as simulators, design verification suites, and hypervisor source code. In 2007, Sun Microsystems released the processor UltraSPARC T2 and, simultaneously, made available the source code of the OpenSPARC T2 processor, which is base on the UltraSPARC T2 processor. Sun Microsystems also sells a book, called "OpenSPARC internals", as an introductory documentation for users and developers of the OpenSPARC family of processors.

\section{Technology Systems}

Web site: http://www.embeddedarm.com/

Technology Systems develops products and custom designs for embedded computing solutions. Technology Systems sells the TS-7300, an open source single board computer. TS-7300 is aimed to hardware developers that need security, flexibility and reliability for critical applications. 


\section{Unimatic}

Web Site: http://www.unimatic.co.uk/

Unimatic offers expertise, training and products for hardware prototyping and short-run production. Unimatic sells CAD software for 3D design, 3D printers for rapid prototyping, 3D scanners, and laser engraving and cutting systems. Unimatic offers a kit to build RapMan, a 3D printer based on the open source RepRap project. It also offers training for RapMan users. 


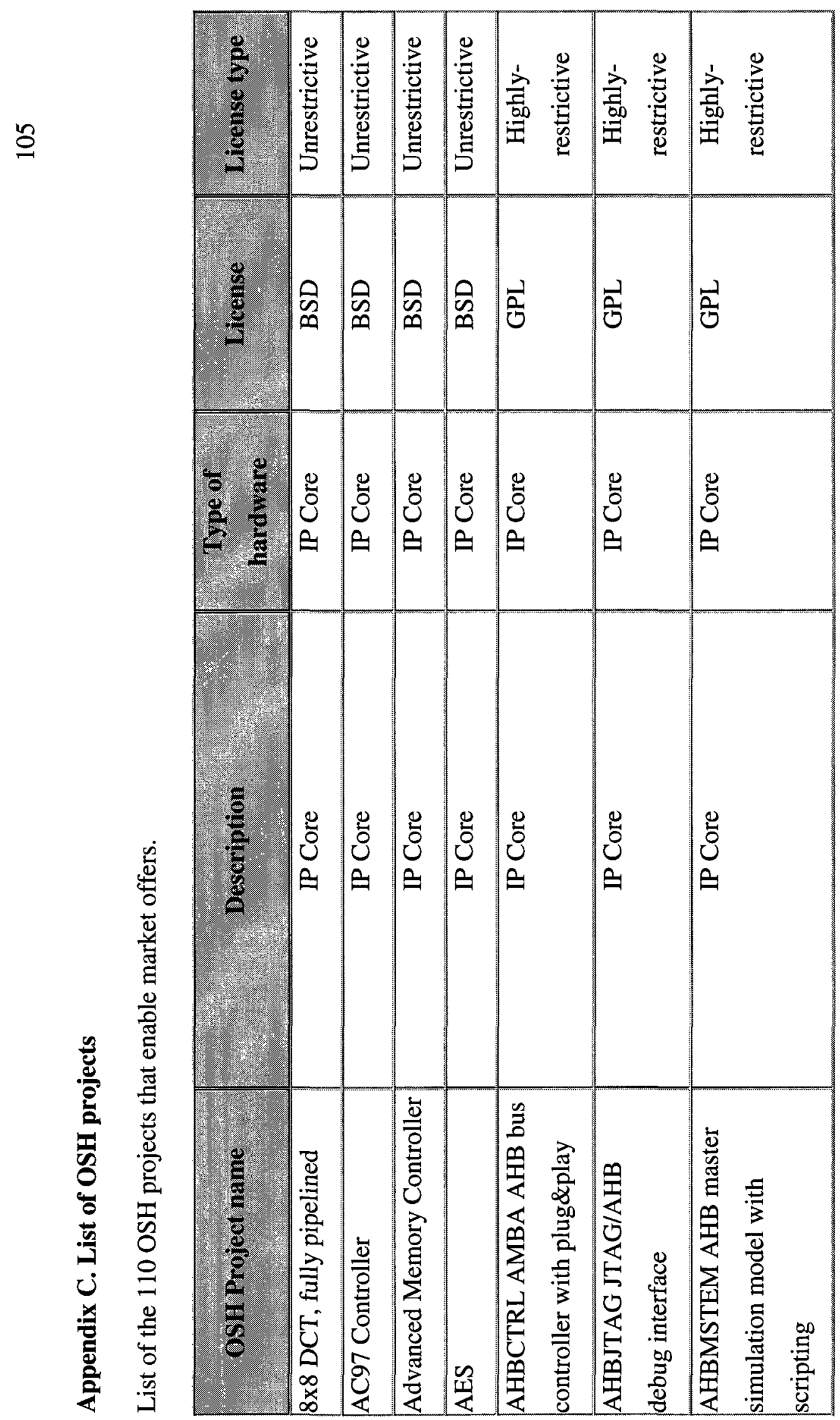




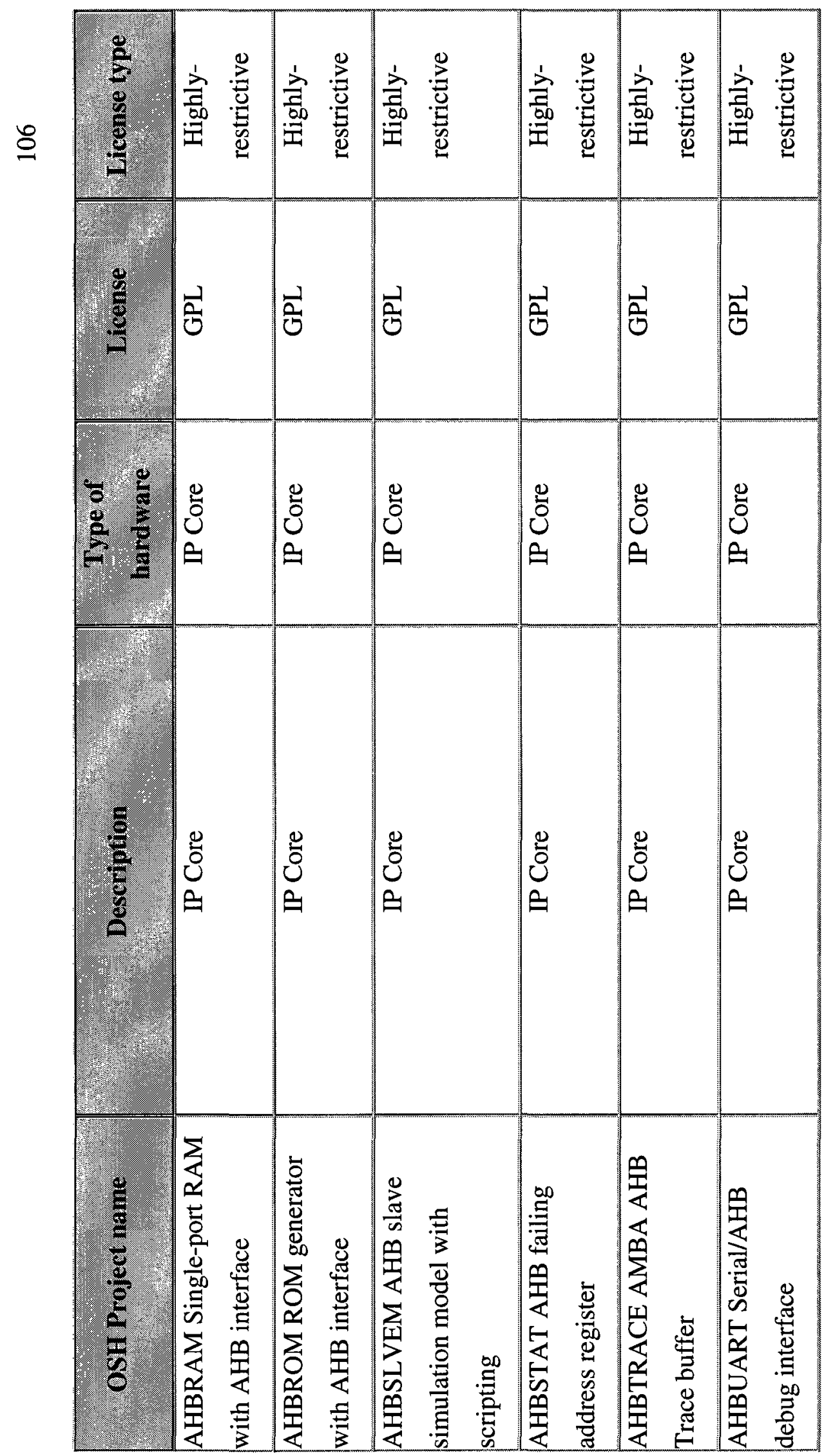




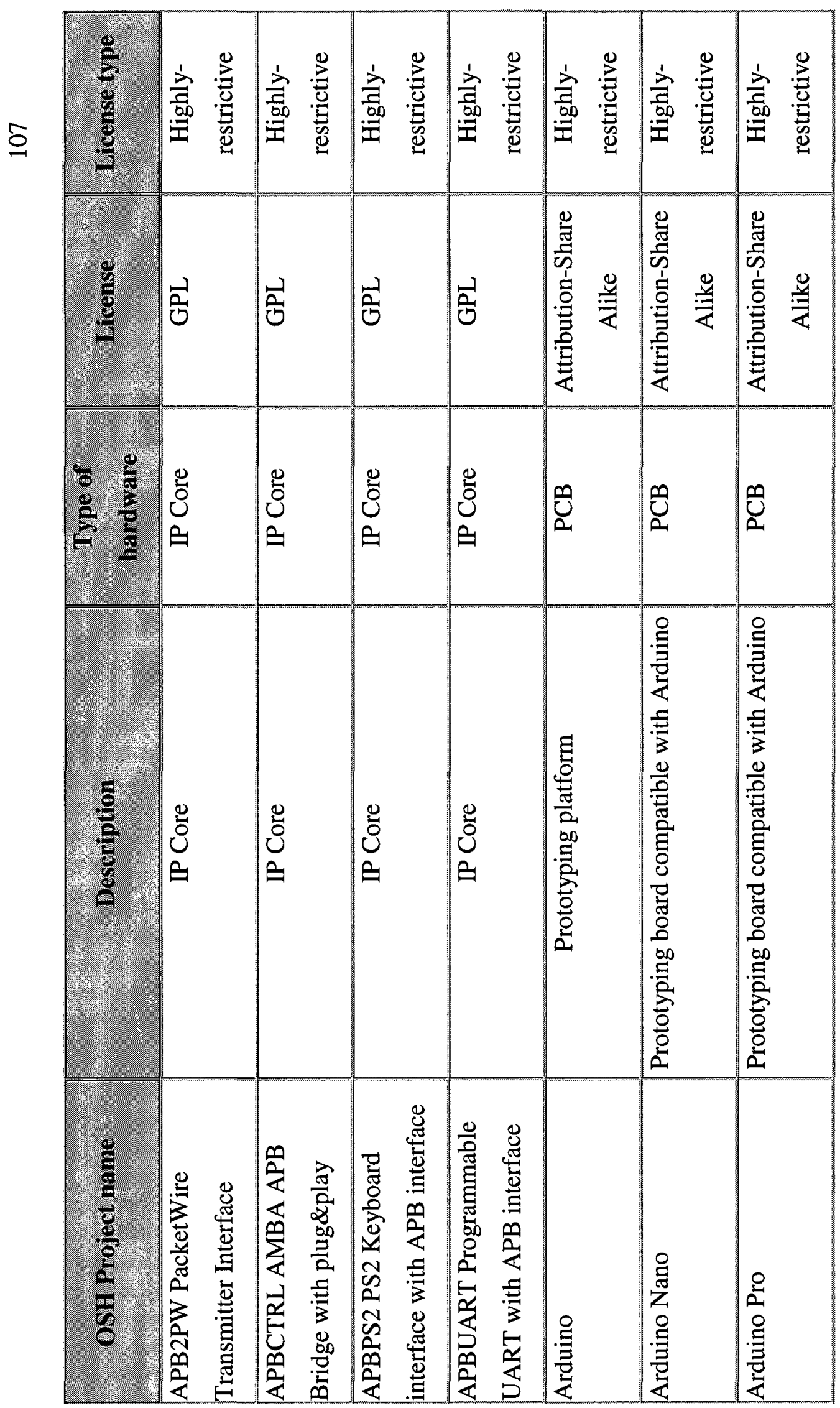




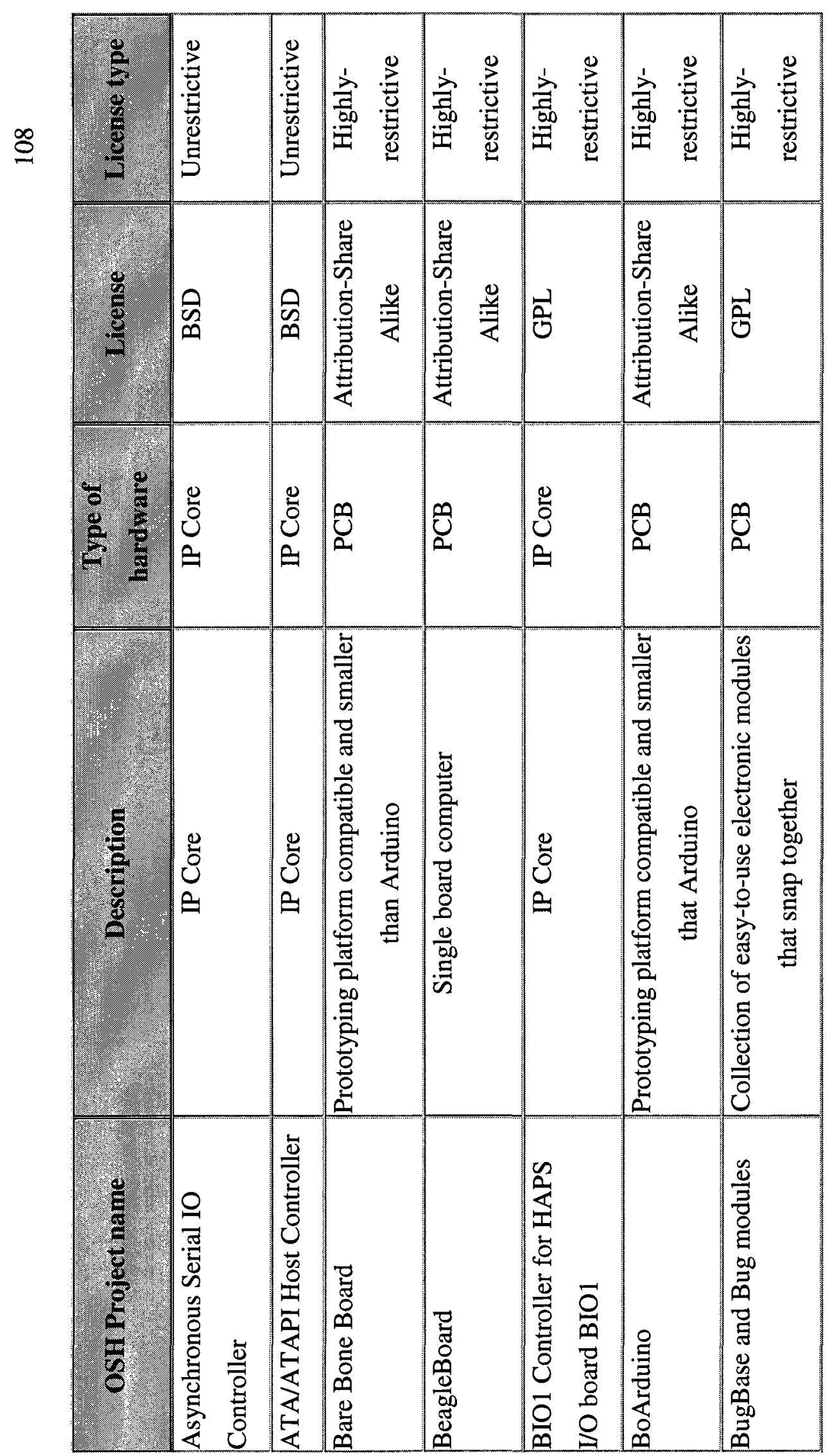




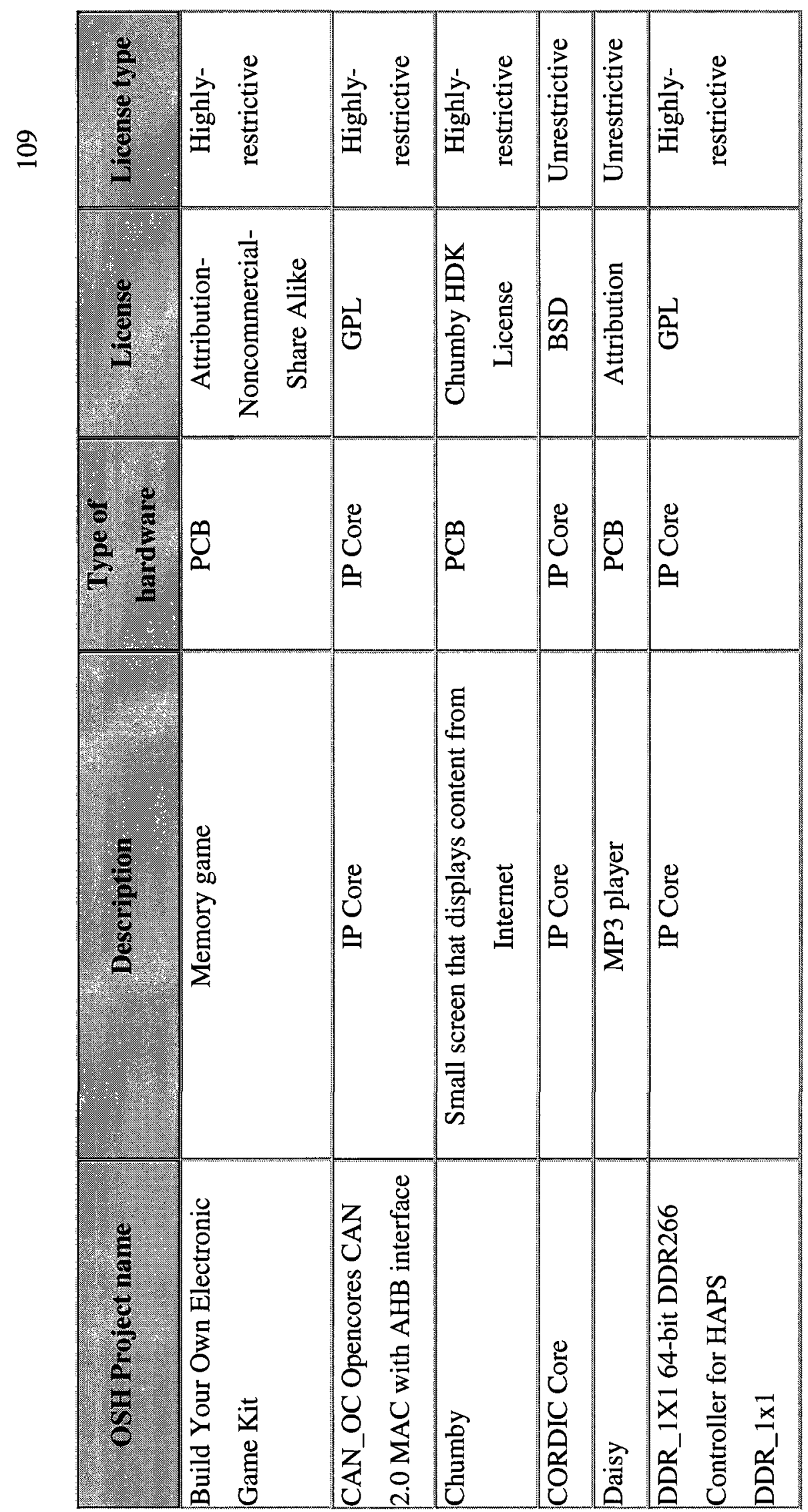




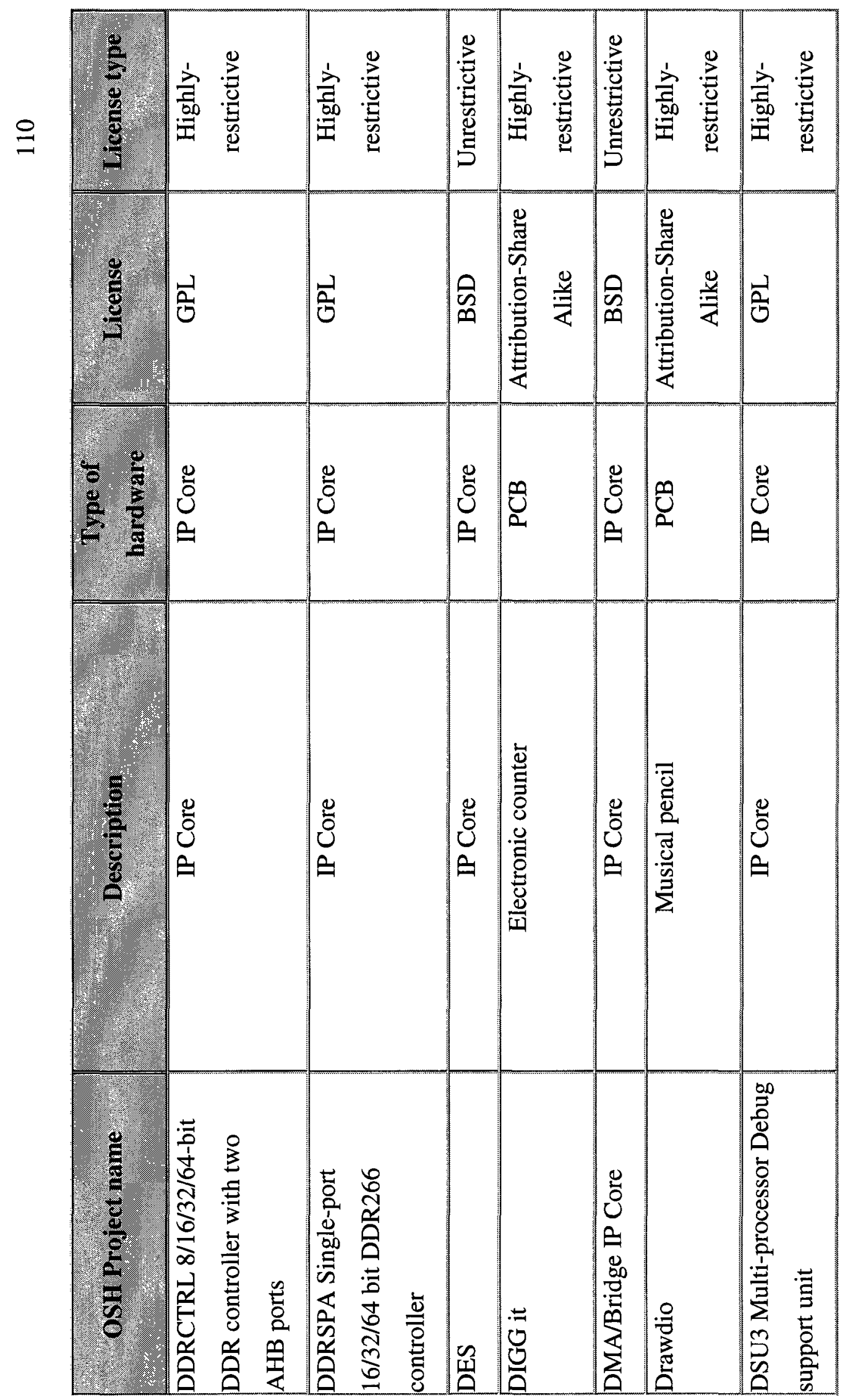




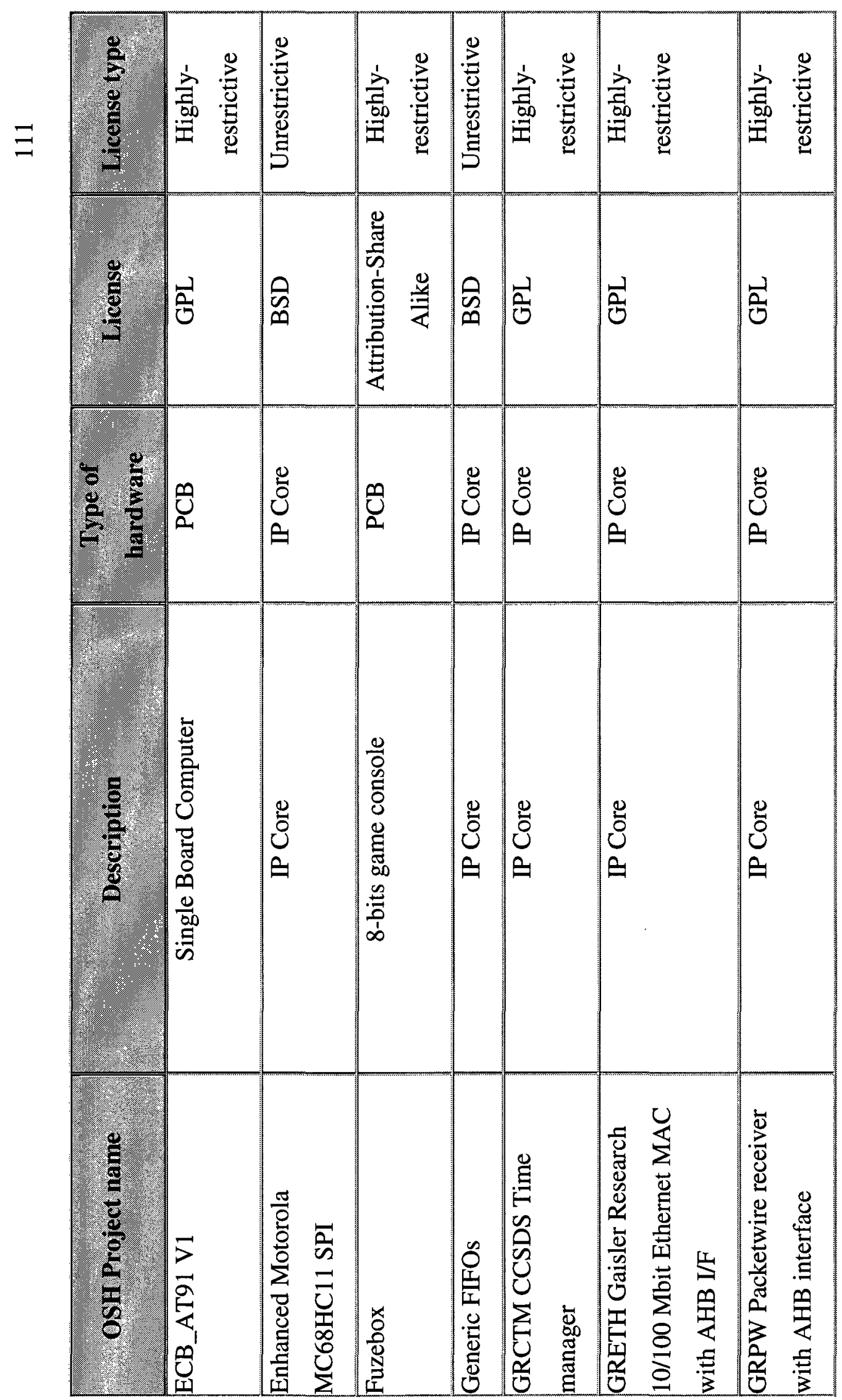




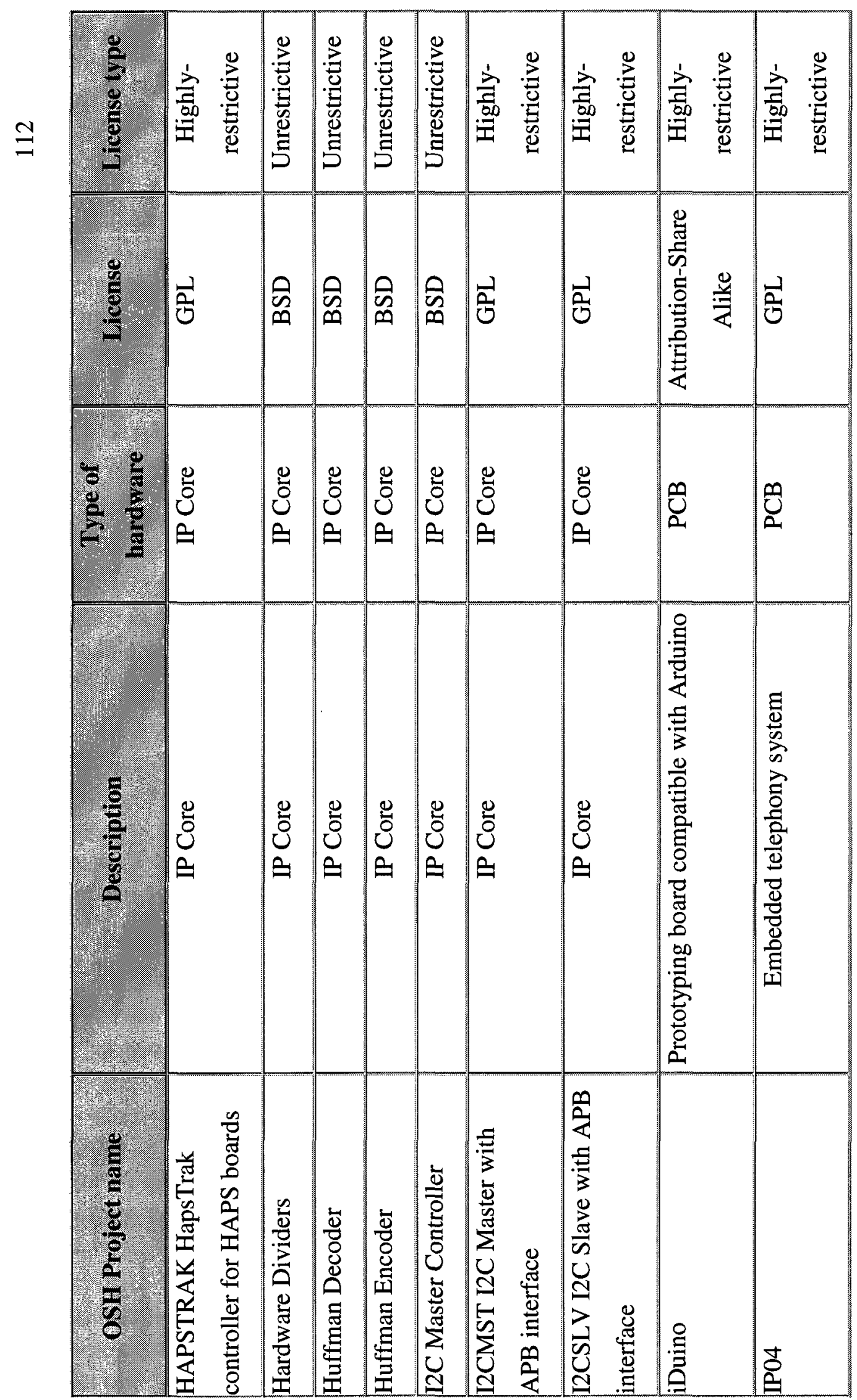




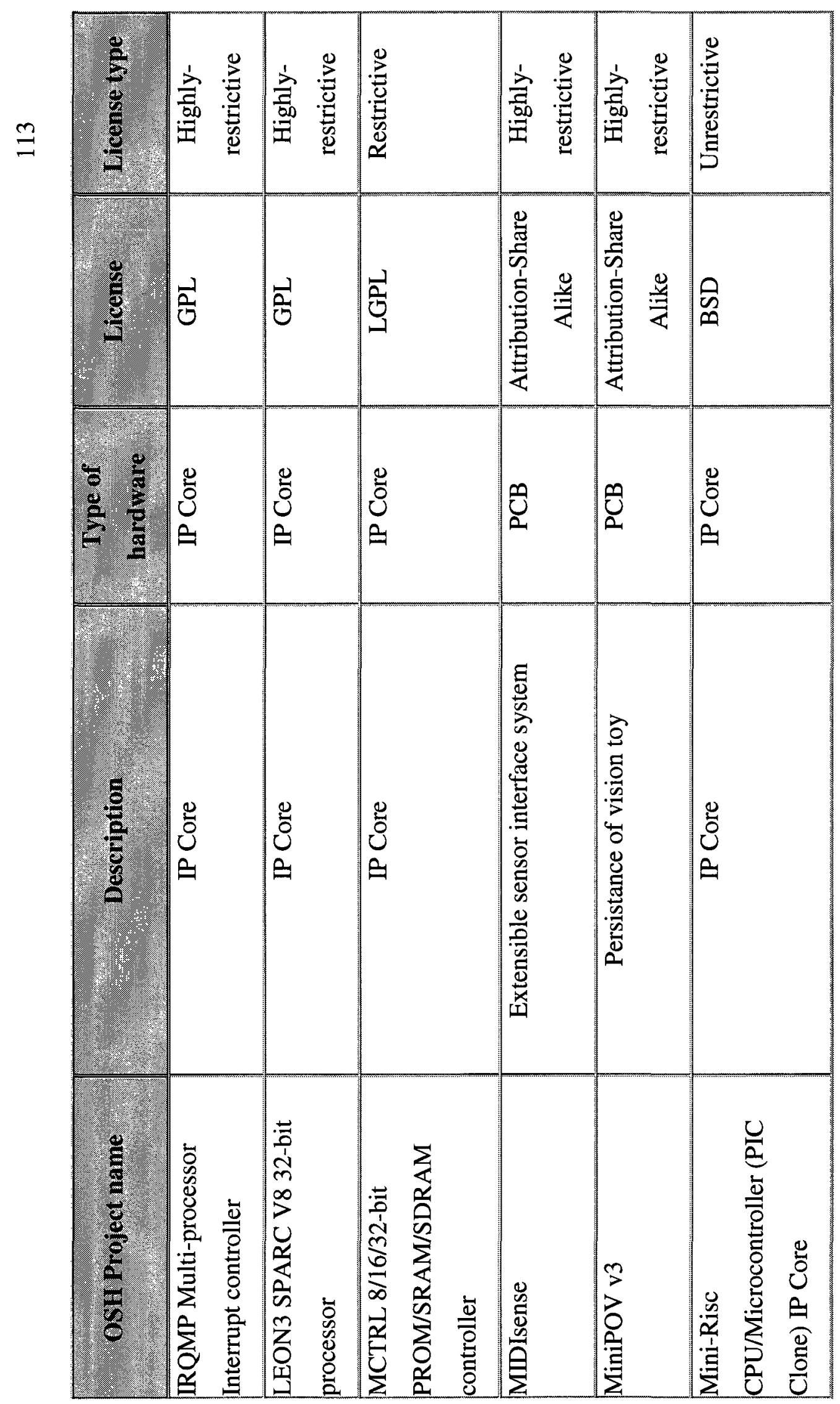




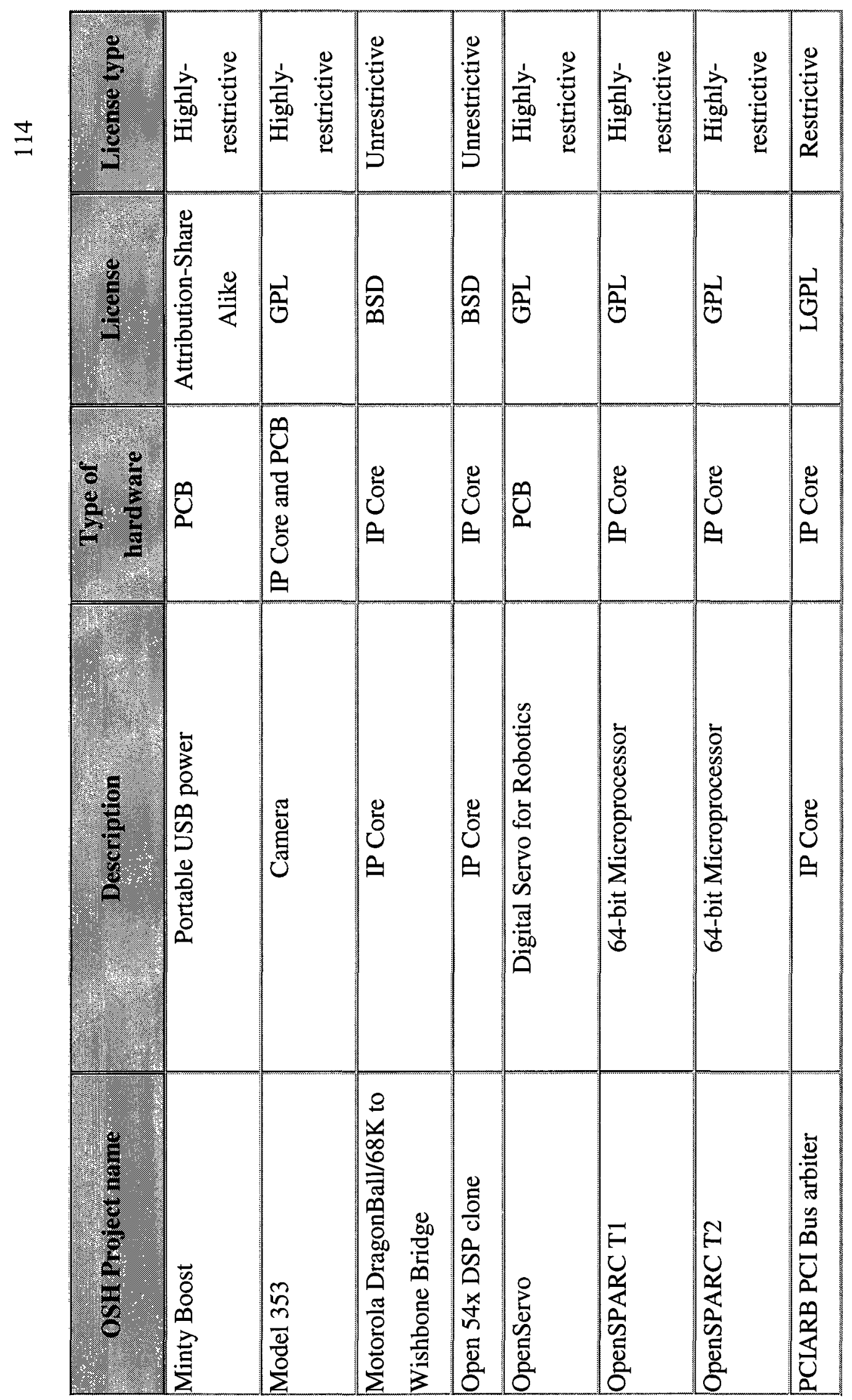




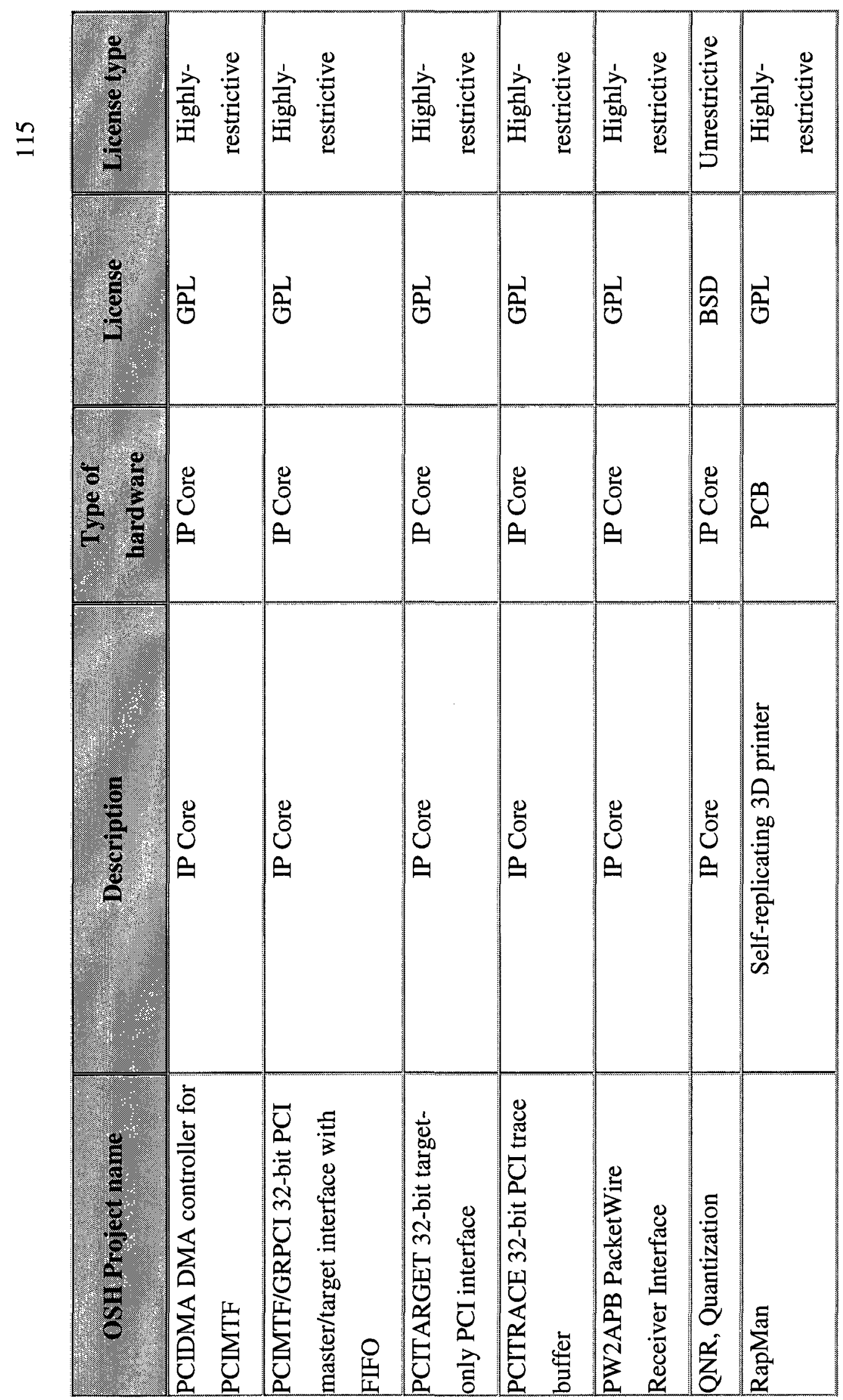




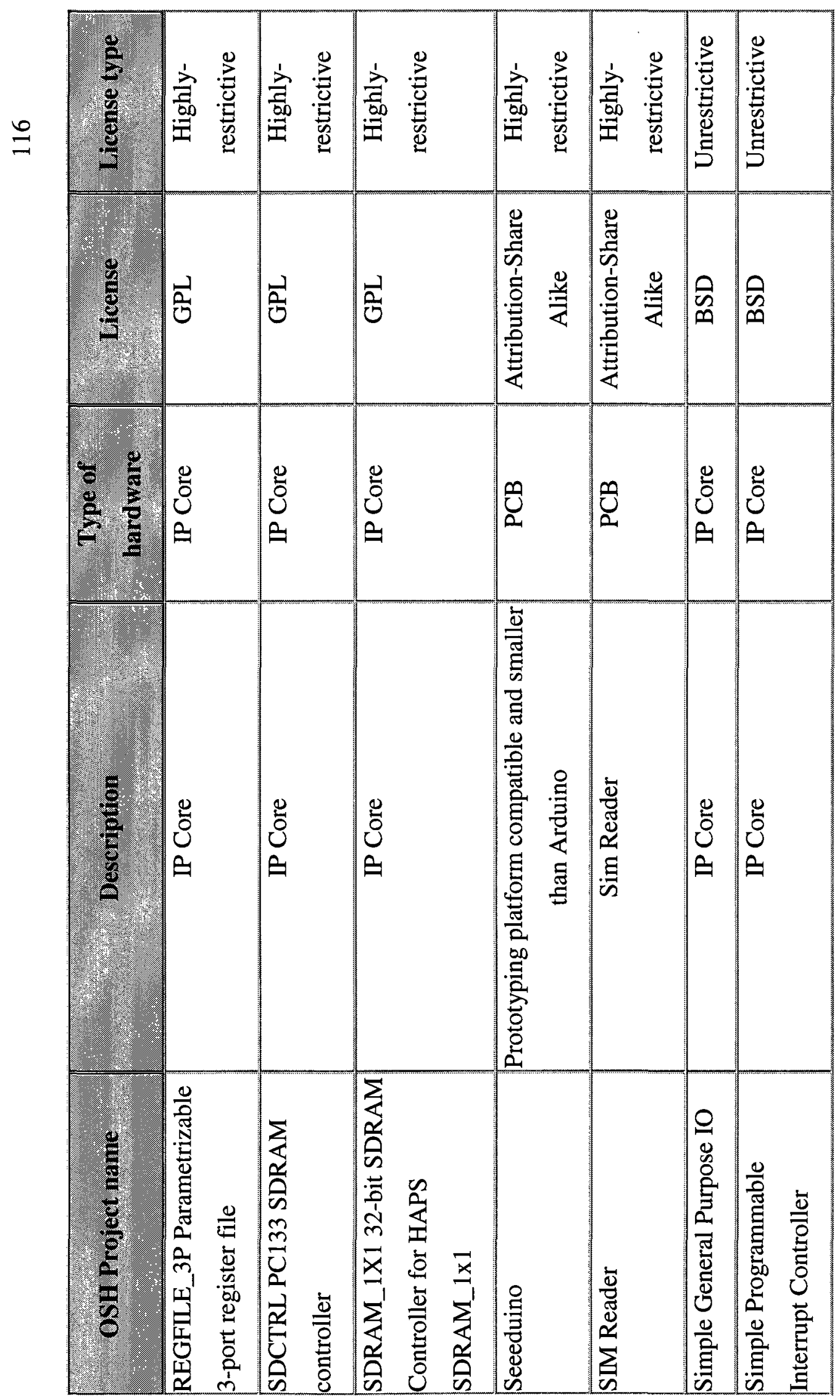




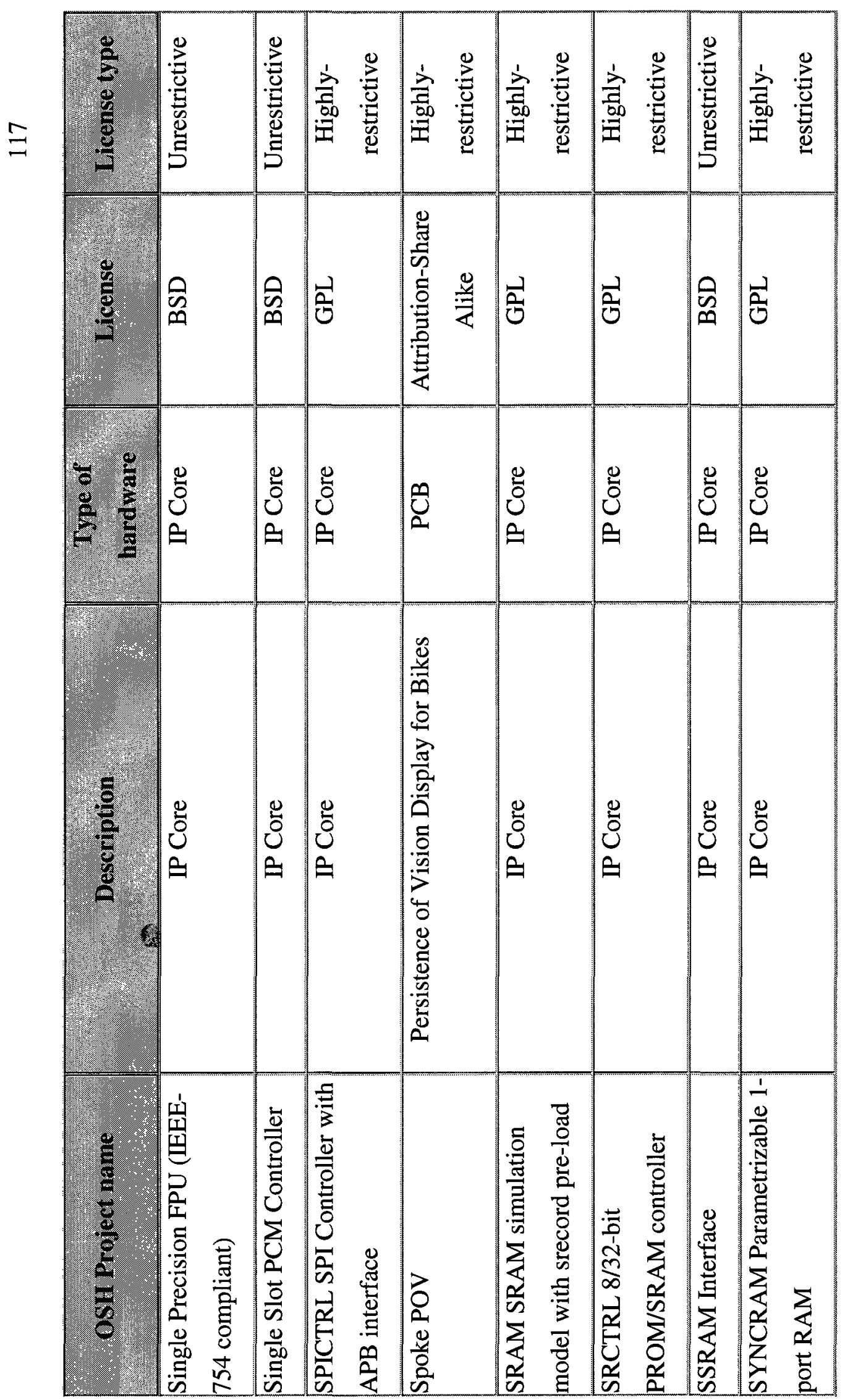




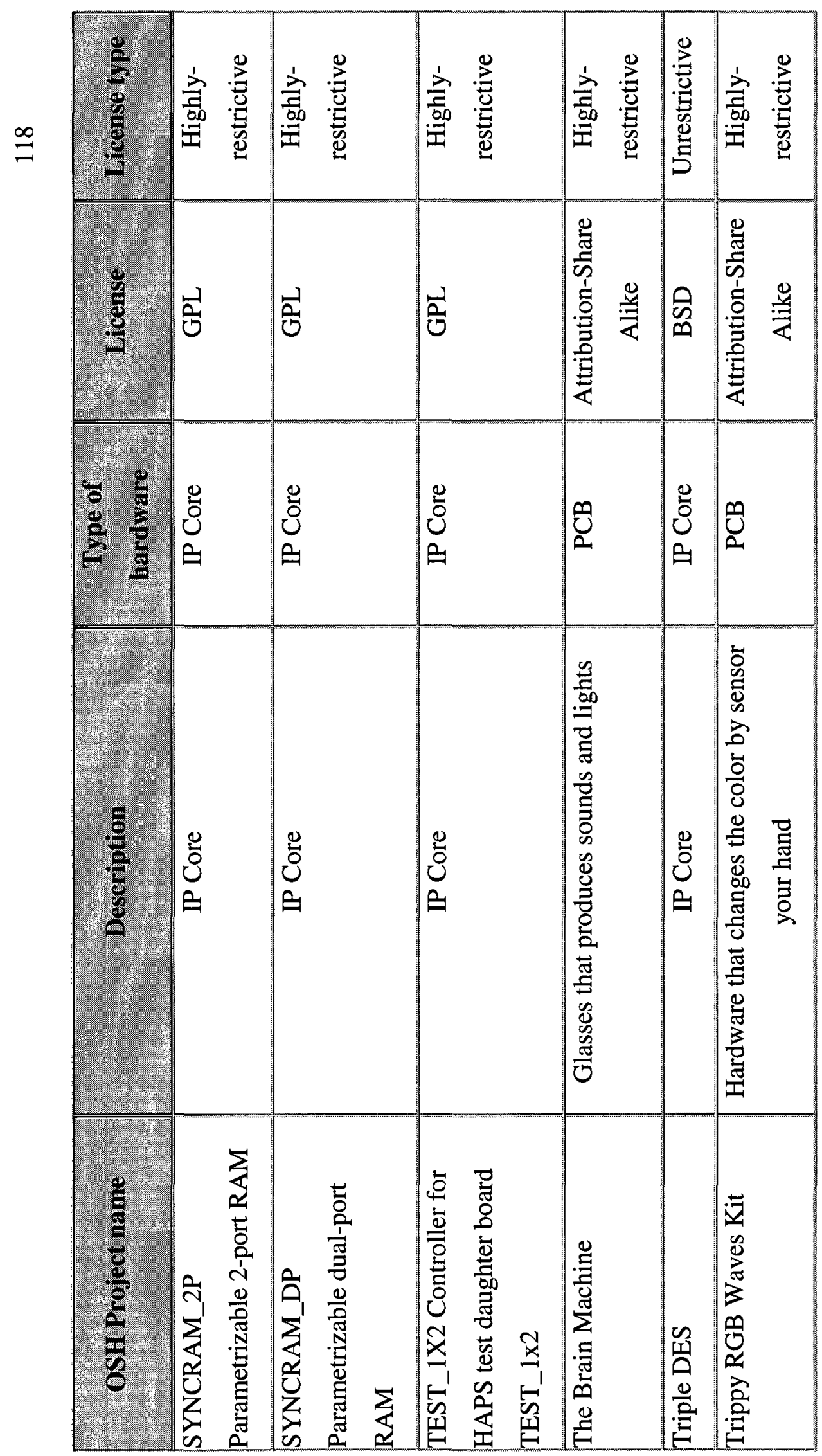




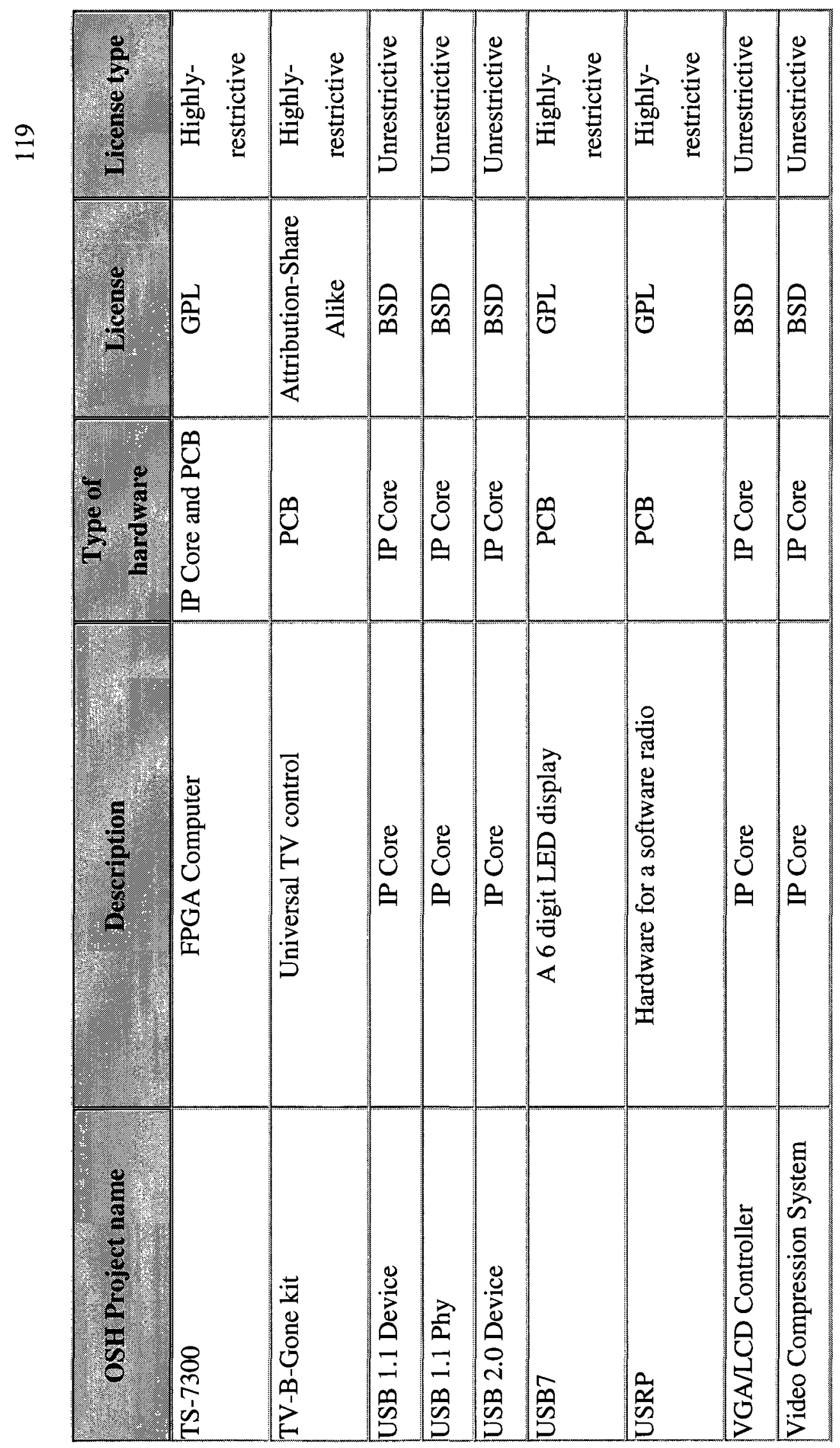




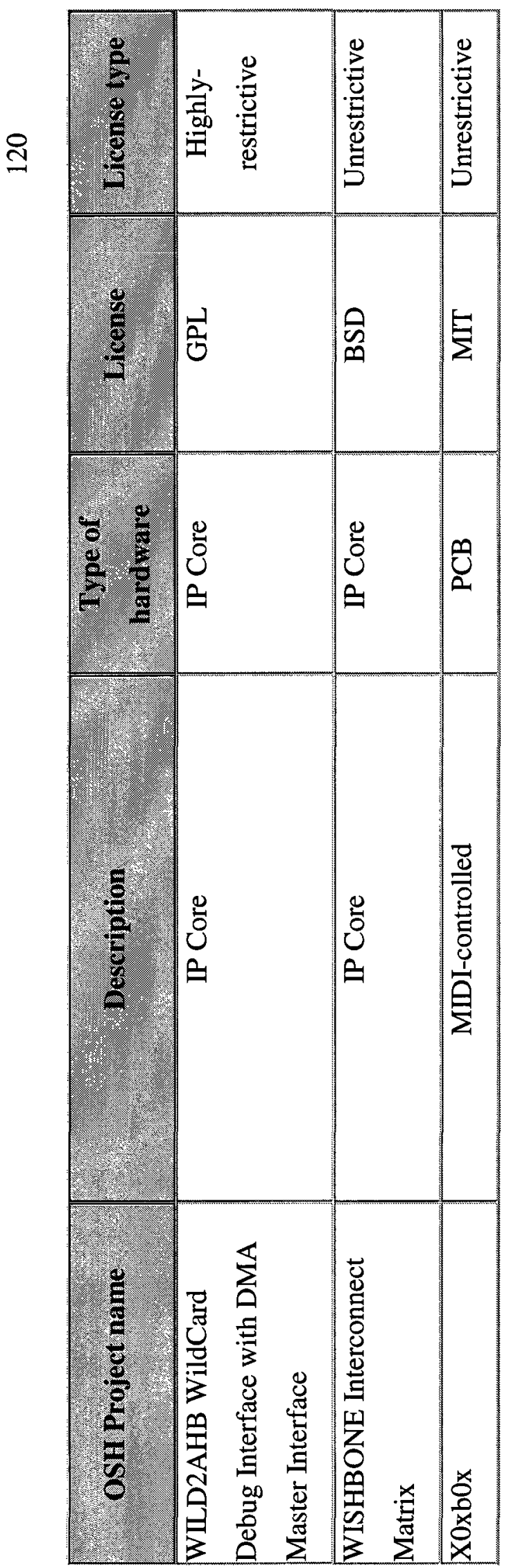




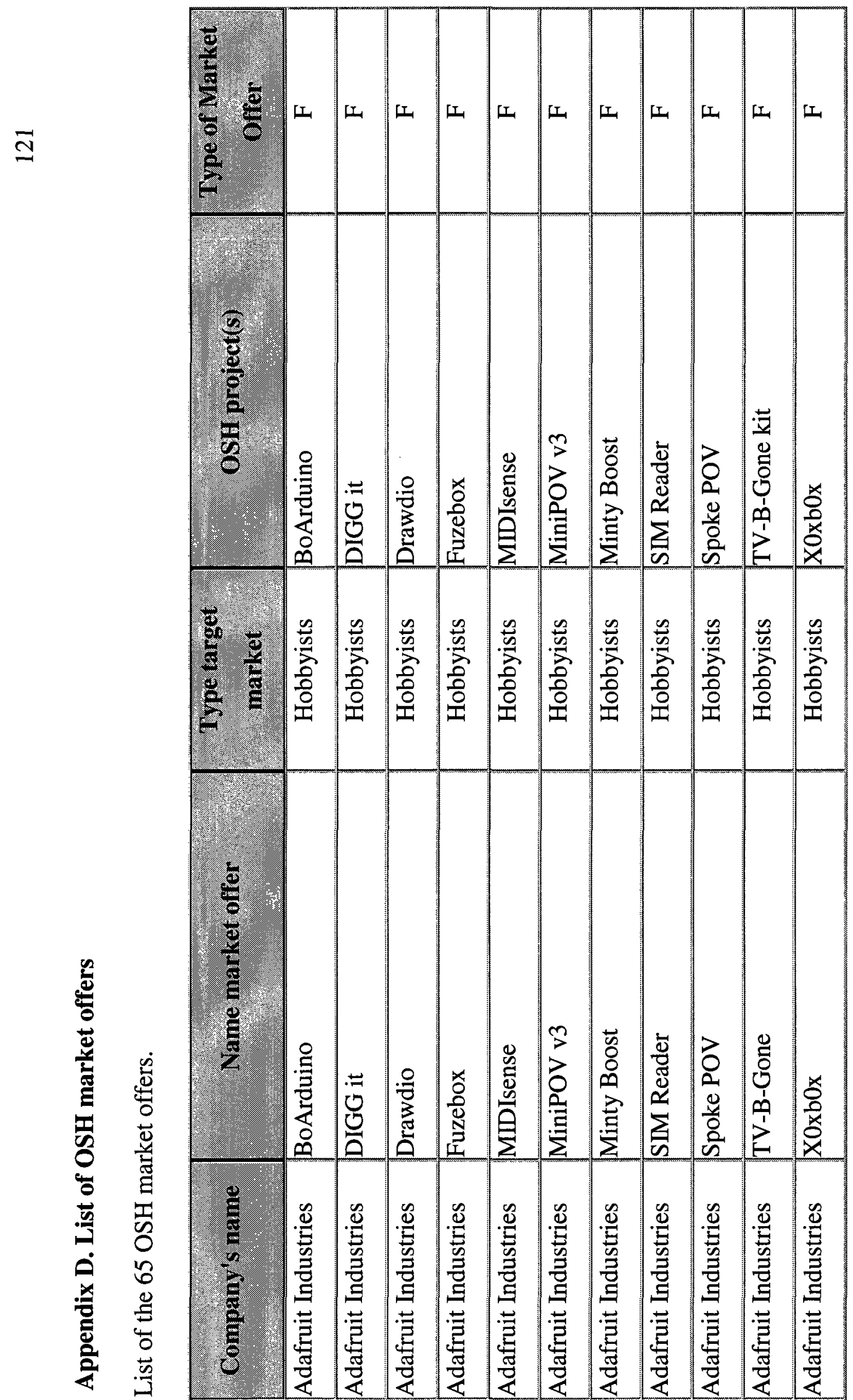




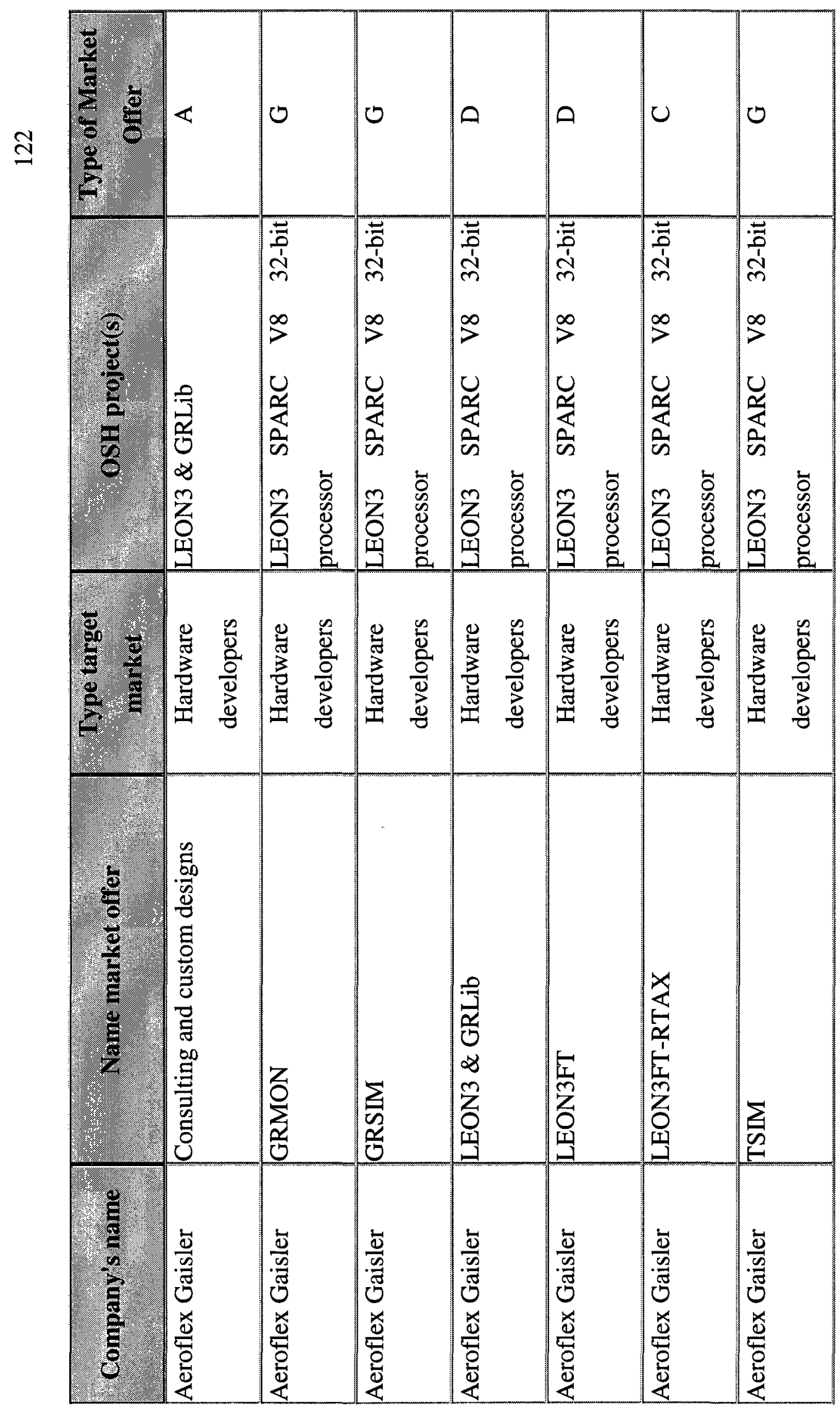




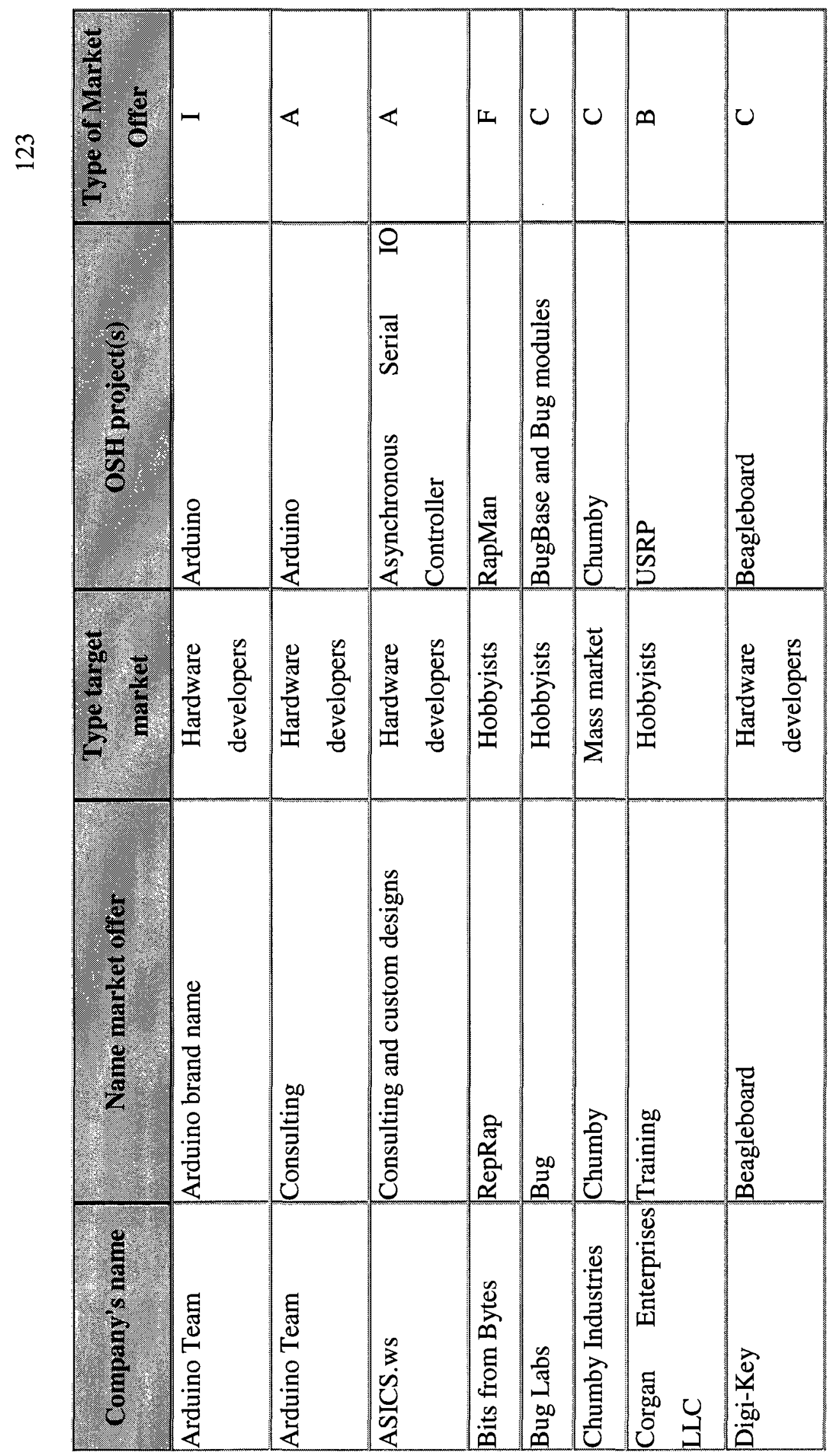




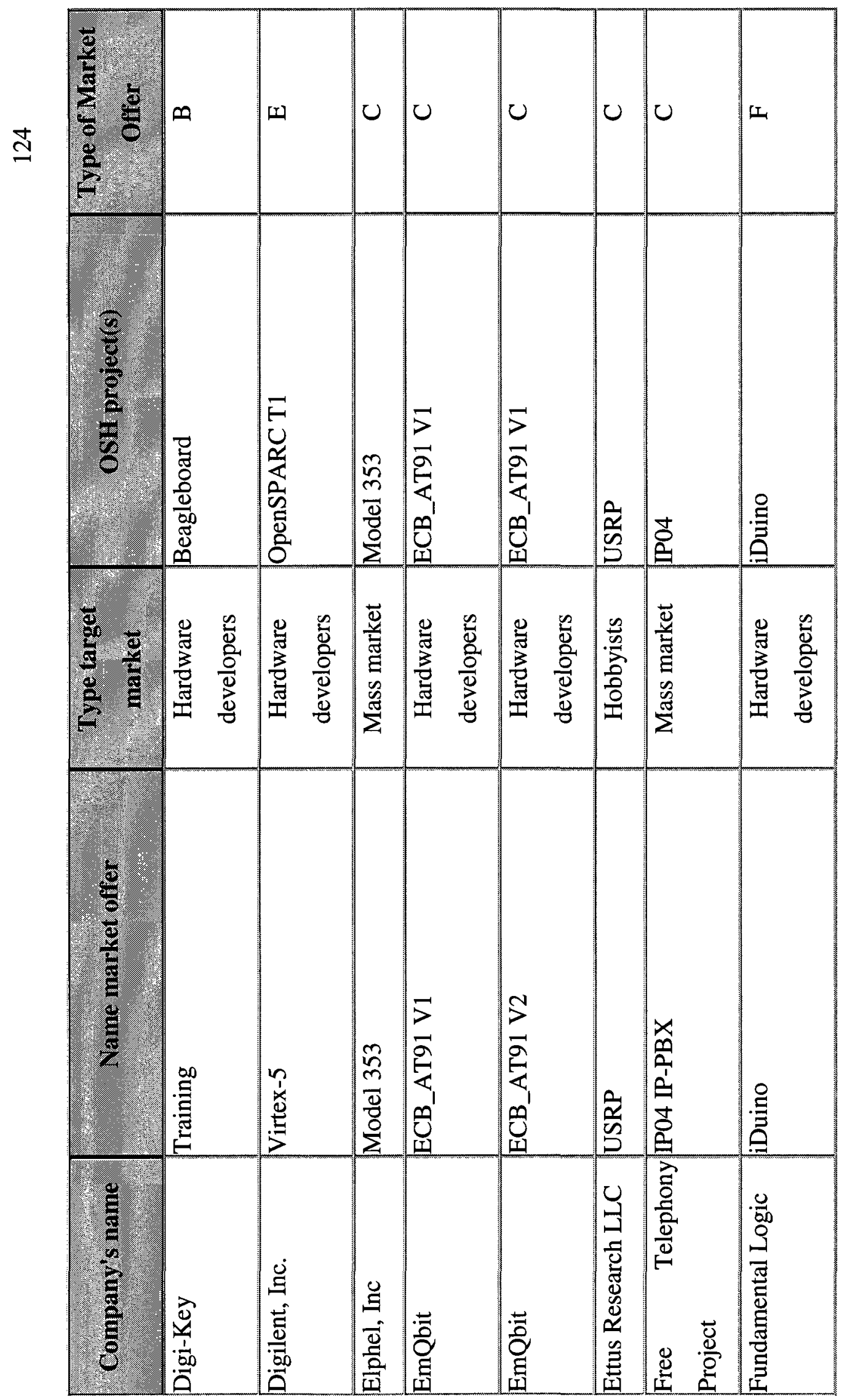




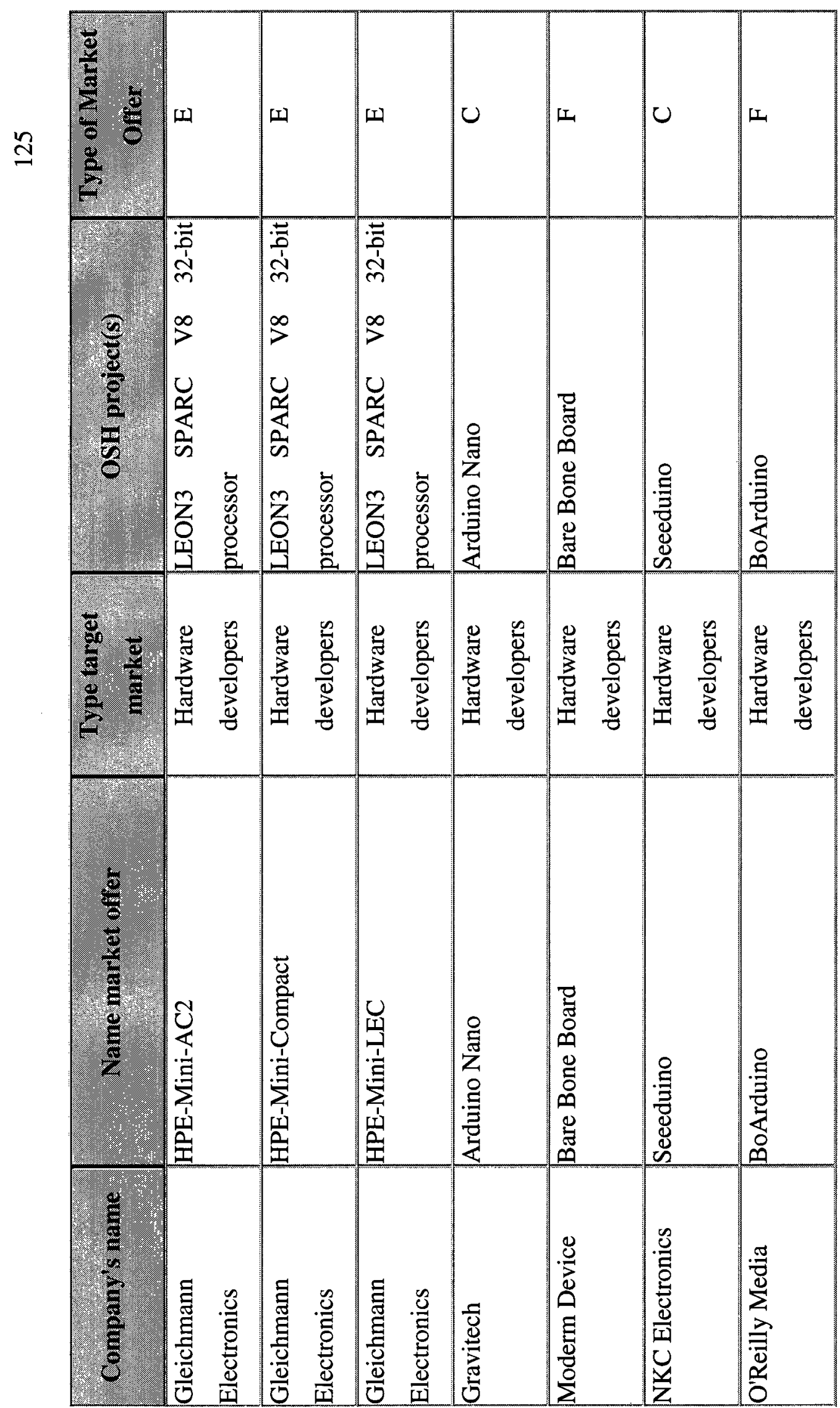




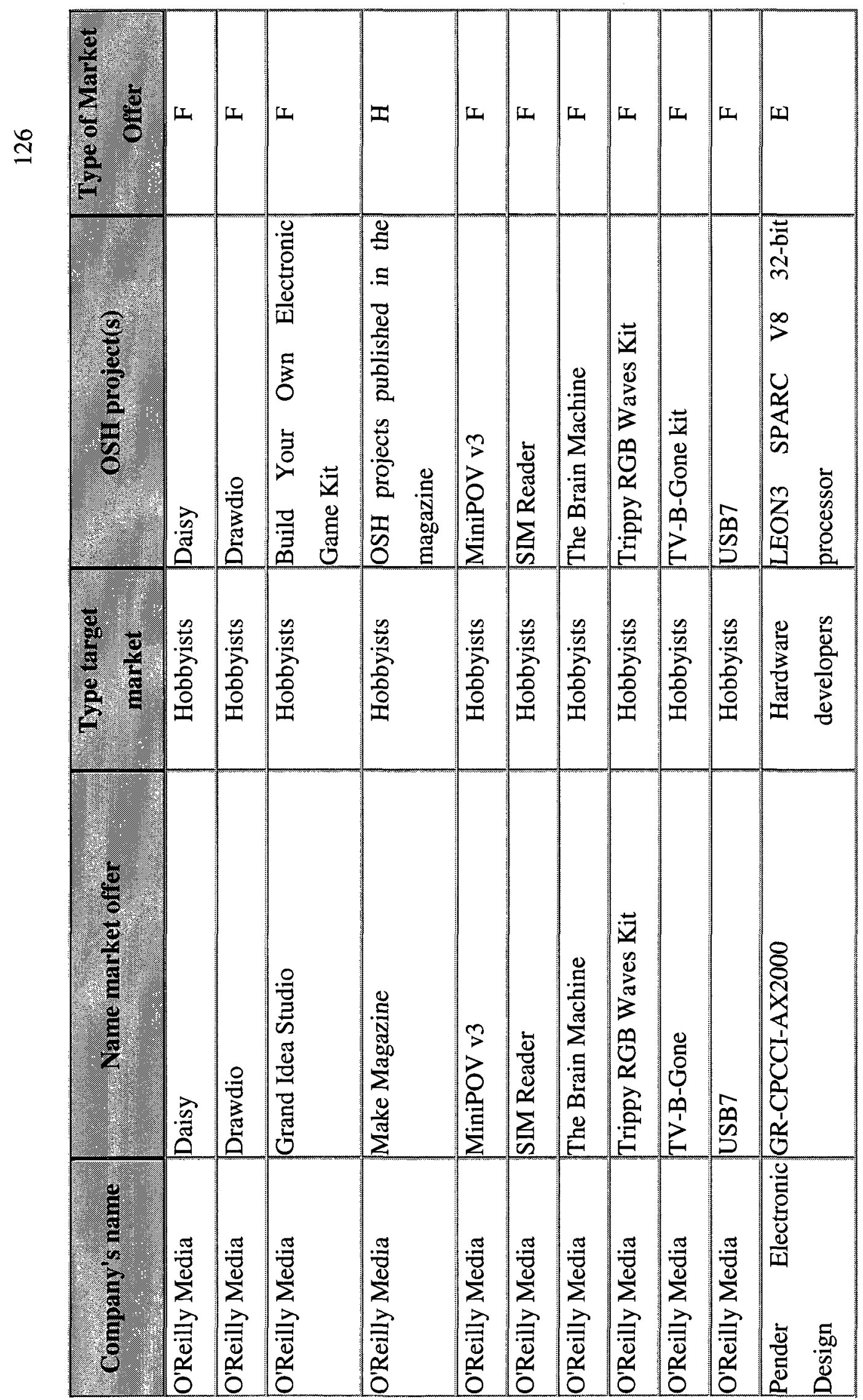




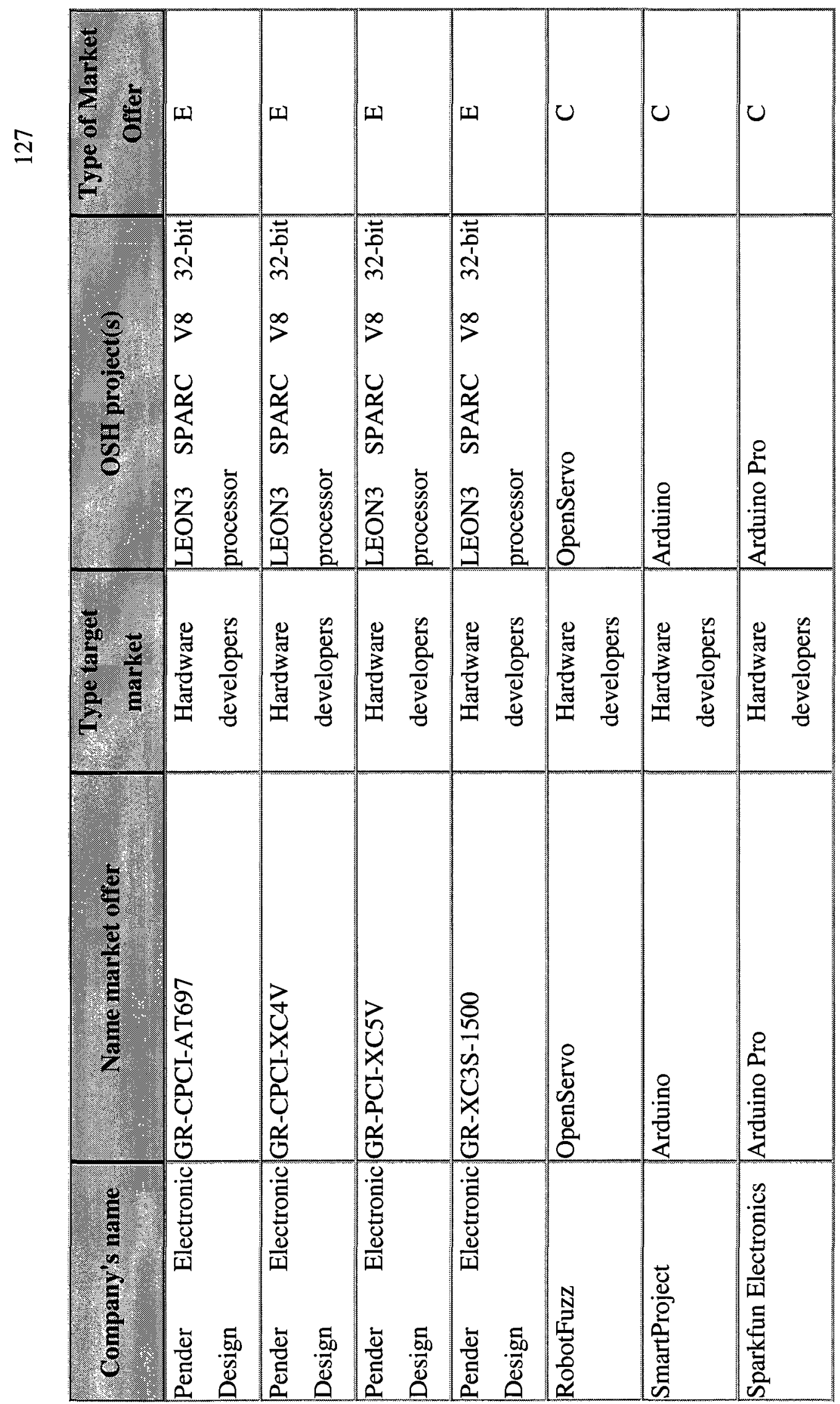




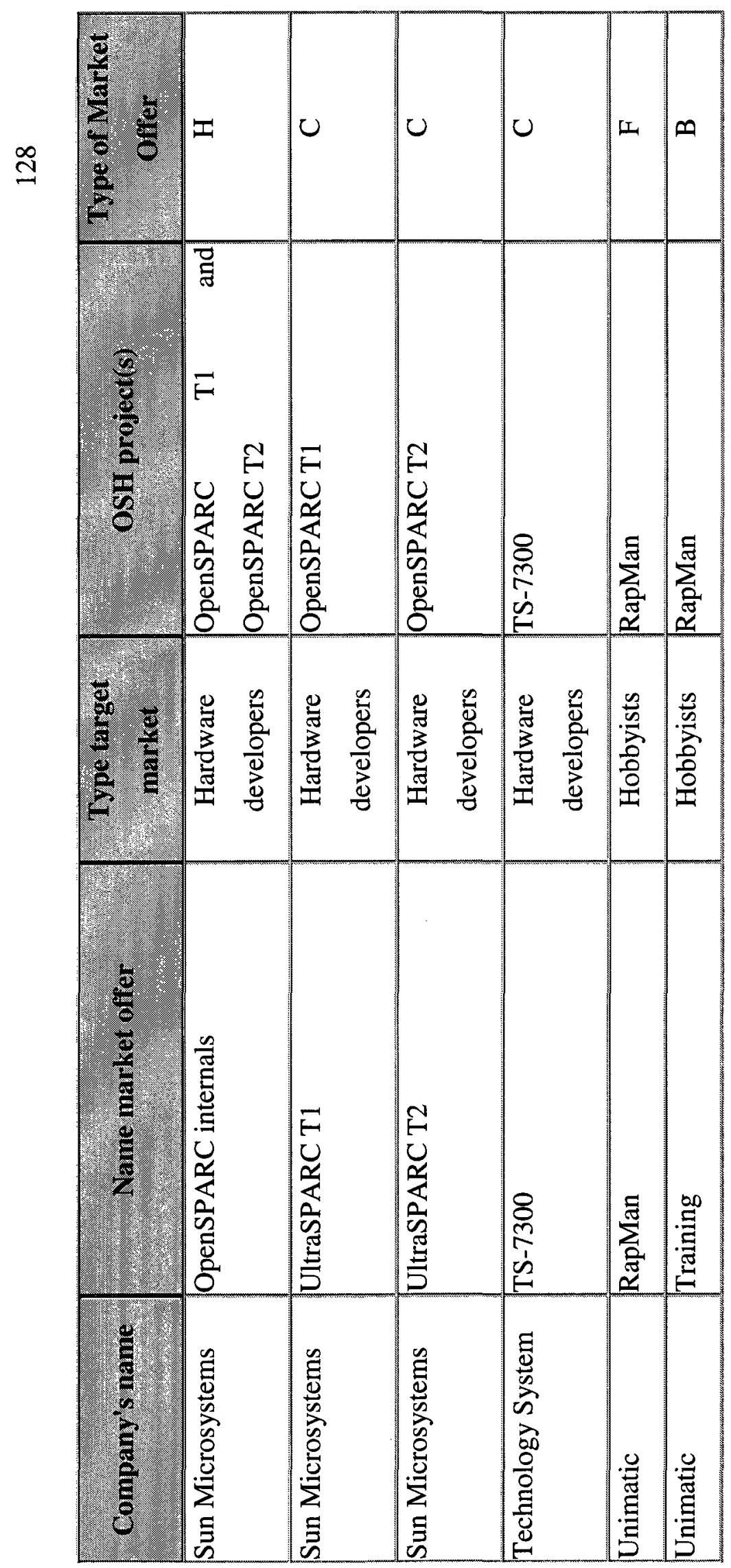




\section{Appendix E. Type of licenses and OSH assets per type market offer}

List of license types and OSH asset types per type of OSH market offer.

\begin{tabular}{|c|c|c|c|}
\hline Type & Description & License type & Type OSH asset \\
\hline \multirow{3}{*}{ A } & \multirow{3}{*}{ Support Services } & Highly-restrictive & \multirow{3}{*}{ IP core \& PCB } \\
\hline & & Restrictive & \\
\hline & & Unrestrictive & \\
\hline B & Training & Highly-restrictive & PCB \\
\hline $\mathrm{C}$ & $\begin{array}{c}\text { Hardware based on OSH } \\
\text { designs }\end{array}$ & Highly-restrictive & IP core \& PCB \\
\hline $\mathrm{D}$ & Dual Licensing & Highly-restrictive & IP core \\
\hline$E$ & Hardware tools & Highly-restrictive & IP core \\
\hline \multirow{2}{*}{$\mathrm{F}$} & \multirow{2}{*}{$\begin{array}{c}\text { Parts and kits for building } \\
\text { OSH }\end{array}$} & Highly-restrictive & \multirow{2}{*}{ PCB } \\
\hline & & Unrestrictive & \\
\hline $\bar{G}$ & Software tools & Highly-restrictive & IP core \\
\hline \multirow{2}{*}{$\mathrm{H}$} & \multirow{2}{*}{ Documentation } & Highly-restrictive & \multirow{2}{*}{ IP core \& PCB } \\
\hline & & Unrestrictive & \\
\hline I & Branding & Highly-restrictive & PCB \\
\hline
\end{tabular}




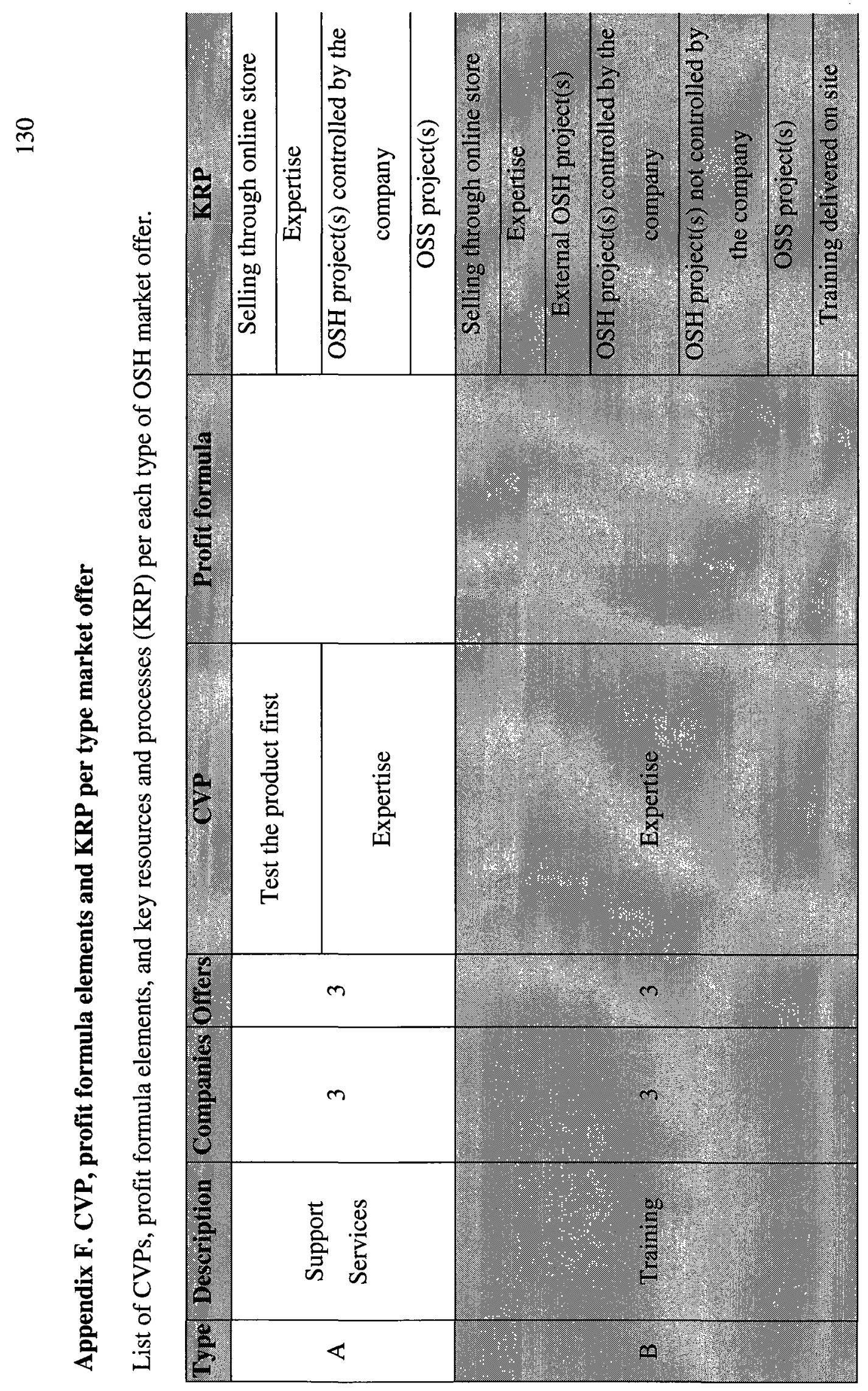




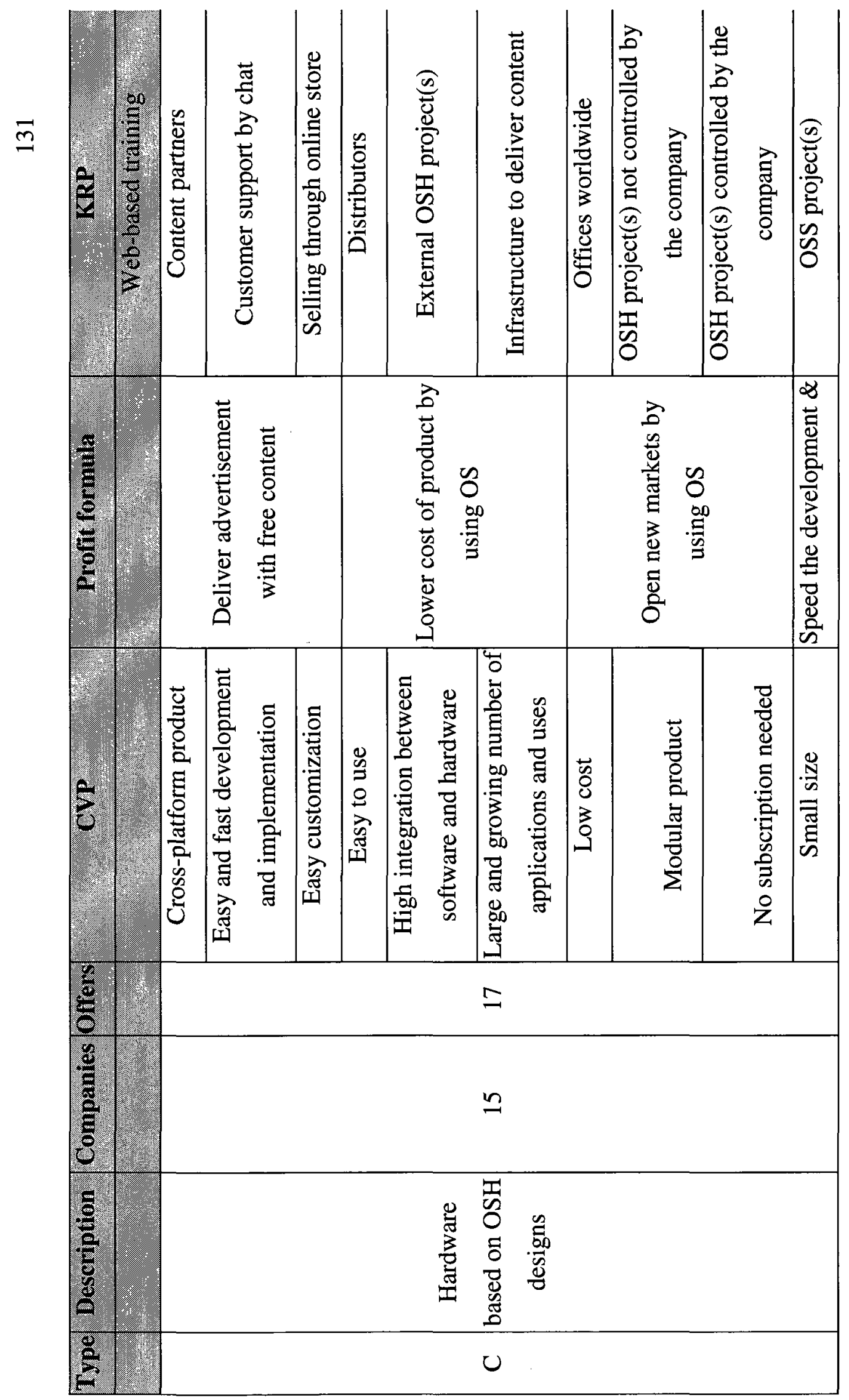




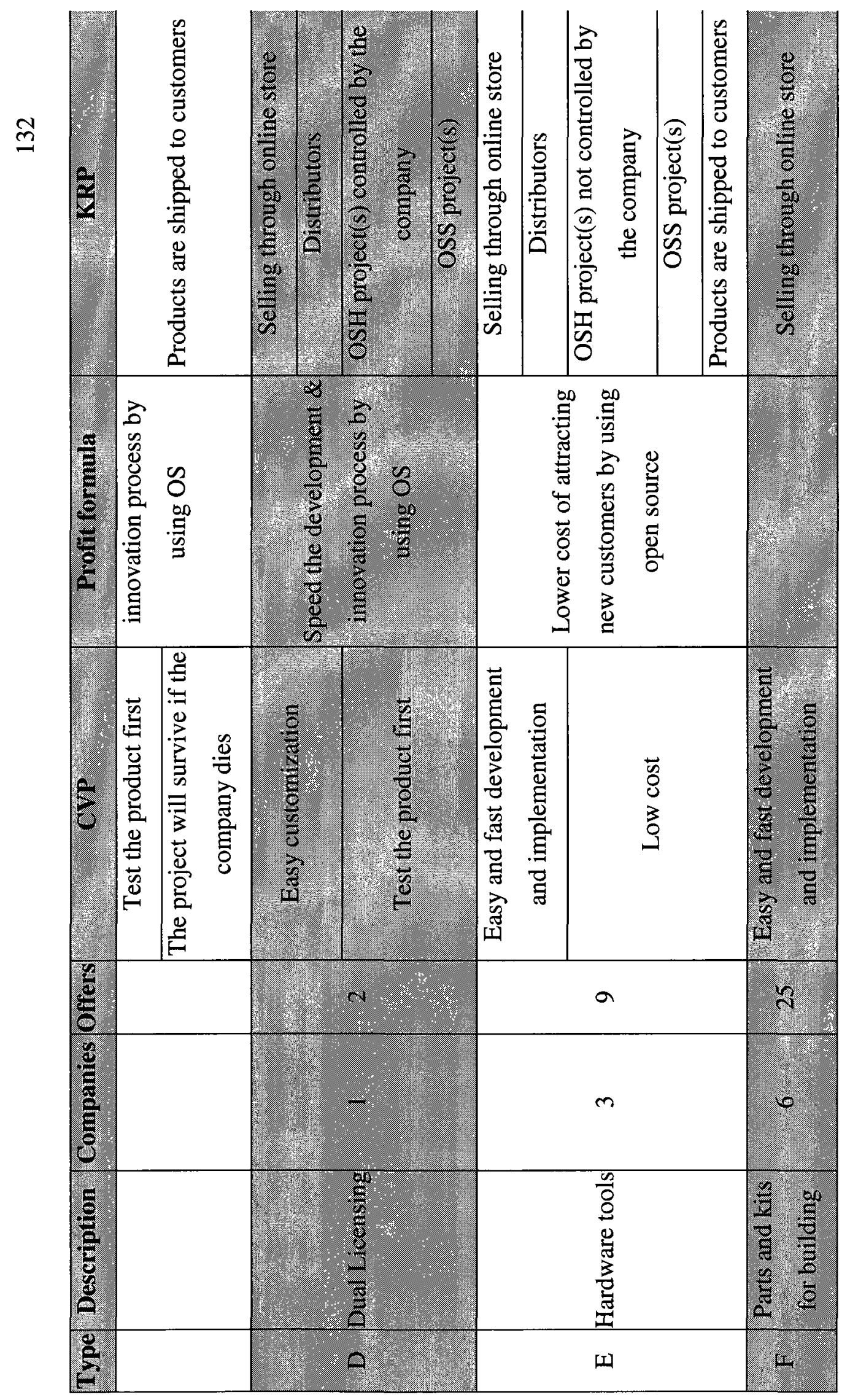




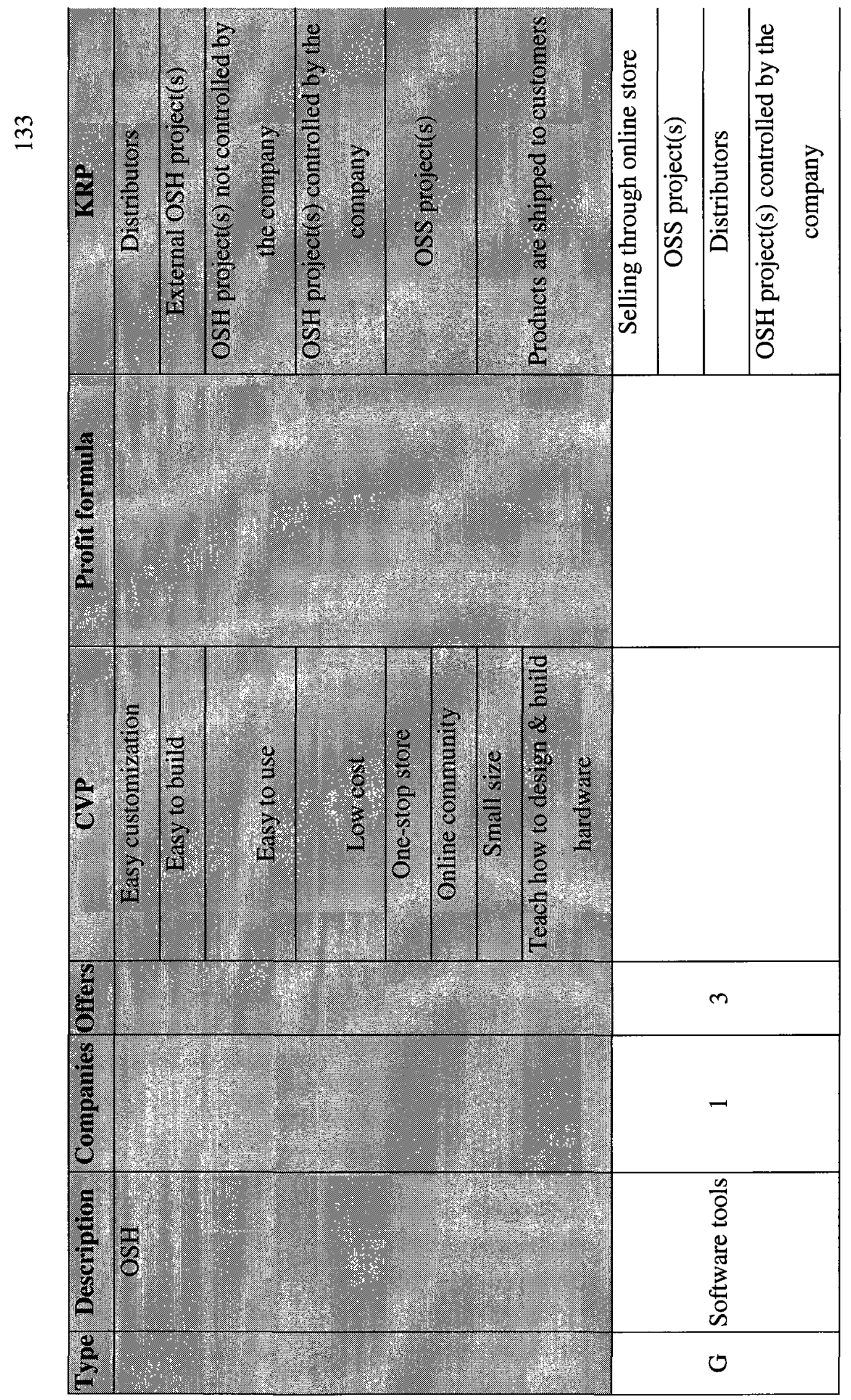




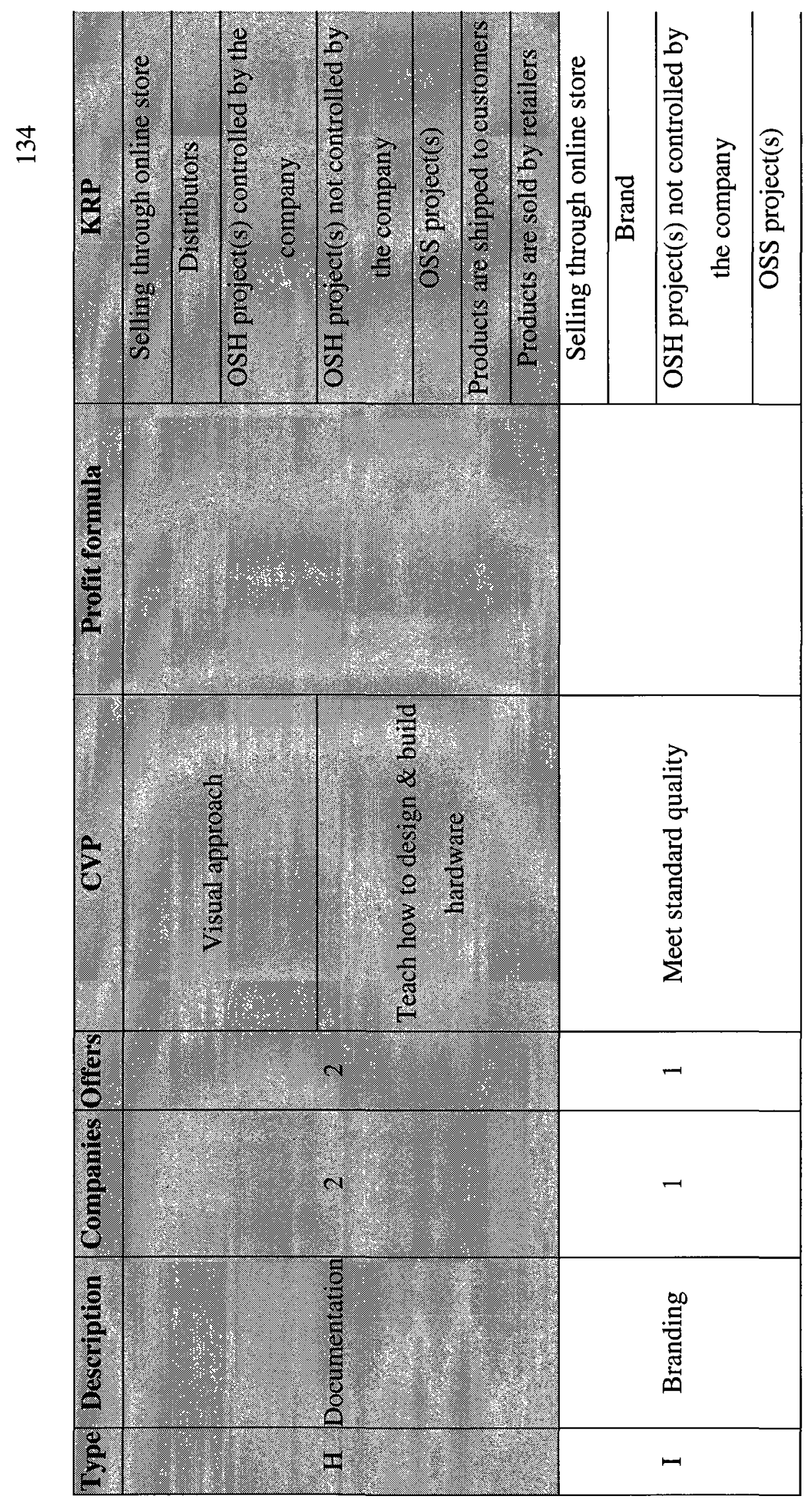




\section{Appendix G. List of CVP}

Number of offers, companies and offer types per CVP.

\begin{tabular}{|c|c|c|c|}
\hline CVP & Offers & Companies & Offer types \\
\hline Cross-platform product & 1 & 1 & 1 \\
\hline Easy and fast development and implementation & 6 & 3 & 3 \\
\hline Easy customization & 10 & 8 & 3 \\
\hline Easy to build & 15 & 2 & 1 \\
\hline Easy to use & 4 & 4 & 2 \\
\hline Expertise & 2 & 2 & 2 \\
\hline High integration between software and hardware & 2 & 1 & 1 \\
\hline Large and growing number of applications and uses & 4 & 3 & 1 \\
\hline Low cost & 12 & 10 & 3 \\
\hline Meet standard quality & 1 & 1 & 1 \\
\hline Modular product & 1 & 1 & 1 \\
\hline No subscription needed & 1 & 1 & 1 \\
\hline One-stop store & 1 & 1 & 1 \\
\hline Online community & 1 & 1 & 1 \\
\hline Small size & 3 & 3 & 2 \\
\hline Test the product first & 5 & 3 & 2 \\
\hline Teach how to design \& build hardware & 1 & 1 & 1 \\
\hline Visual approach & 1 & 1 & 1 \\
\hline
\end{tabular}




\section{Appendix H. List of profit formula elements}

Number of offers, companies and offer types per profit formula element.

\begin{tabular}{|c|c|c|c|}
\hline Profit formula element & Offers & Companies & Offer types \\
\hline Deliver advertisement with free content & 1 & 1 & 1 \\
\hline Lower cost of product by using open source & 2 & 2 & 1 \\
\hline $\begin{array}{c}\text { Lower cost of attracting new customers by using open } \\
\text { source }\end{array}$ & 1 & 1 & 1 \\
\hline Open new markets by using open source & 2 & 1 & 1 \\
\hline $\begin{array}{c}\text { Speed the development \& innovation process by using } \\
\text { open source }\end{array}$ & 4 & 3 & 2 \\
\hline
\end{tabular}




\section{Appendix I. List of KRP}

Number of offers, companies and offer types per key resource and process.

\begin{tabular}{|c|c|c|c|}
\hline Key resource and process & Offers & Companies & Offer types \\
\hline Brand & 1 & 1 & 1 \\
\hline Content partners & 1 & 1 & 1 \\
\hline Customer support by chat & 1 & 1 & 1 \\
\hline Distributors & 24 & 7 & 6 \\
\hline Expertise & 6 & 6 & 2 \\
\hline External OSH project(s) & 12 & 8 & 3 \\
\hline Infrastructure to deliver content & 1 & 1 & 1 \\
\hline Offices in different countries & 2 & 1 & 1 \\
\hline OSH project(s) controlled by the company & 37 & 18 & 8 \\
\hline OSH project(s) not controlled by the & & & \\
\hline company & 29 & 11 & 5 \\
\hline OSS project(s) & 56 & 26 & 9 \\
\hline Products are shipped to customers & 51 & 24 & 4 \\
\hline Products are sold by retailers & 1 & 1 & 1 \\
\hline Selling through online store & 63 & 27 & 9 \\
\hline Training delivered on site & 2 & 2 & 1 \\
\hline Web-based training & 1 & 1 & 1 \\
\hline
\end{tabular}




\section{Appendix J. OSS and OSH mark offer types}

OSS market offers vs. OSH market offers. The OSS and OSH market offer types that are equivalent are listed in the same row.

\begin{tabular}{|c|c|c|}
\hline Type & OSH market offer types & OSS market offer types (Alam, \\
\hline A & Support services & Support services \\
\hline B & Training & Training \\
\hline C & Hardware based on OSH designs & \\
\hline D & Dual Licensing & Commercial licenses \\
\hline E & Hardware tools & \\
\hline F & Parts and kits for building OSH & \\
\hline G & Software tools & \\
\hline H & Documentation & \\
\hline I & Branding & Commercial licenses \\
\hline & & Subscription services \\
\cline { 2 - 3 } & & Hosted and content \\
\cline { 2 - 3 } & & Applications / Products \\
\cline { 3 - 3 } & & Testing (certificate) \\
\hline
\end{tabular}




\section{Appendix K. OSH market offers, OSS, and external OSH}

List of OSH market offers, indicating which of those are enabled by OSH projects that rely on the use of OSS; and which of those depends, or are based on external OSH projects that are controlled by a different group of people.

\begin{tabular}{|c|c|c|}
\hline Name market offer & OSS & External OSH \\
project(s)
\end{tabular}




\begin{tabular}{|c|c|c|}
\hline Name market offer & $\begin{array}{l}\text { OSS } \\
\text { Project(s) }\end{array}$ & $\begin{array}{l}\text { External OSH } \\
\text { project(s) }\end{array}$ \\
\hline \multicolumn{3}{|l|}{ Grand Idea Studio } \\
\hline GR-CPCCI-AX2000 & $\bar{X}$ & \\
\hline GR-CPCI-AT697 & $\mathrm{X}$ & \\
\hline GR-CPCI-XC4V & $\mathrm{X}$ & \\
\hline GRMON & $\mathrm{X}$ & \\
\hline GR-PCI-XC5V & $\mathrm{X}$ & \\
\hline GRSIM & $\mathrm{X}$ & \\
\hline GR-XC3S-1500 & $\bar{X}$ & \\
\hline HPE-Mini-AC2 & $\mathrm{X}$ & \\
\hline HPE-Mini-Compact & $\mathrm{X}$ & \\
\hline HPE-Mini-LEC & $\mathrm{X}$ & \\
\hline iDuino & $\mathrm{X}$ & $\mathrm{X}$ \\
\hline IP04 IP-PBX & $\mathrm{X}$ & \\
\hline LEON3 \& GRLib & $\mathrm{X}$ & \\
\hline LEON3FT & $\mathrm{X}$ & \\
\hline LEON3FT-RTAX & $\mathrm{X}$ & \\
\hline Make & $\bar{X}$ & \\
\hline MIDIsense & $\mathrm{X}$ & \\
\hline MiniPOV v3 by Adafruit & $\mathrm{X}$ & \\
\hline MiniPOV v3 by Make Magazine & $\mathrm{X}$ & \\
\hline \multicolumn{3}{|l|}{ Minty Boost } \\
\hline Model 353 & $\mathrm{X}$ & \\
\hline OpenServo & $\mathrm{X}$ & \\
\hline OpenSPARC internals & $\mathrm{X}$ & \\
\hline RapMan & $\mathrm{X}$ & $\mathrm{X}$ \\
\hline
\end{tabular}




\begin{tabular}{|c|c|c|}
\hline Name market offer & $\begin{array}{c}\text { OsS } \\
\text { Project(s) }\end{array}$ & $\begin{array}{l}\text { External OSH } \\
\text { project(s) }\end{array}$ \\
\hline RepRap & $\mathrm{X}$ & \\
\hline Seeeduino & $\mathrm{X}$ & $\mathrm{X}$ \\
\hline SIM Reader by Adafruit & $\mathrm{X}$ & \\
\hline SIM Reader by Make Magazine & $\mathrm{X}$ & \\
\hline Spoke POV & $\mathrm{X}$ & \\
\hline The Brain Machine & $\mathrm{X}$ & $\mathrm{X}$ \\
\hline Training Corgan Enterprise & $\mathrm{X}$ & \\
\hline Training Digi-Key & $\mathrm{X}$ & \\
\hline Training Unimatic & $\mathrm{X}$ & $\mathrm{X}$ \\
\hline Trippy RGB Waves Kit & & $\mathrm{X}$ \\
\hline TS-7300 & $\mathrm{X}$ & $\mathrm{X}$ \\
\hline TSIM & $\bar{X}$ & \\
\hline \multicolumn{3}{|l|}{ TV-B-Gone by Adafruit } \\
\hline \multicolumn{3}{|l|}{ TV-B-Gone by Make Magazine } \\
\hline UltraSPARC T1 & $\mathrm{X}$ & \\
\hline UltraSPARC T2 & $\bar{X}$ & \\
\hline USB7 & $\bar{X}$ & \\
\hline USRP & $\mathrm{X}$ & \\
\hline Virtex-5 & $\mathrm{X}$ & \\
\hline $\mathrm{X0xb0x}$ & $\mathrm{X}$ & \\
\hline
\end{tabular}




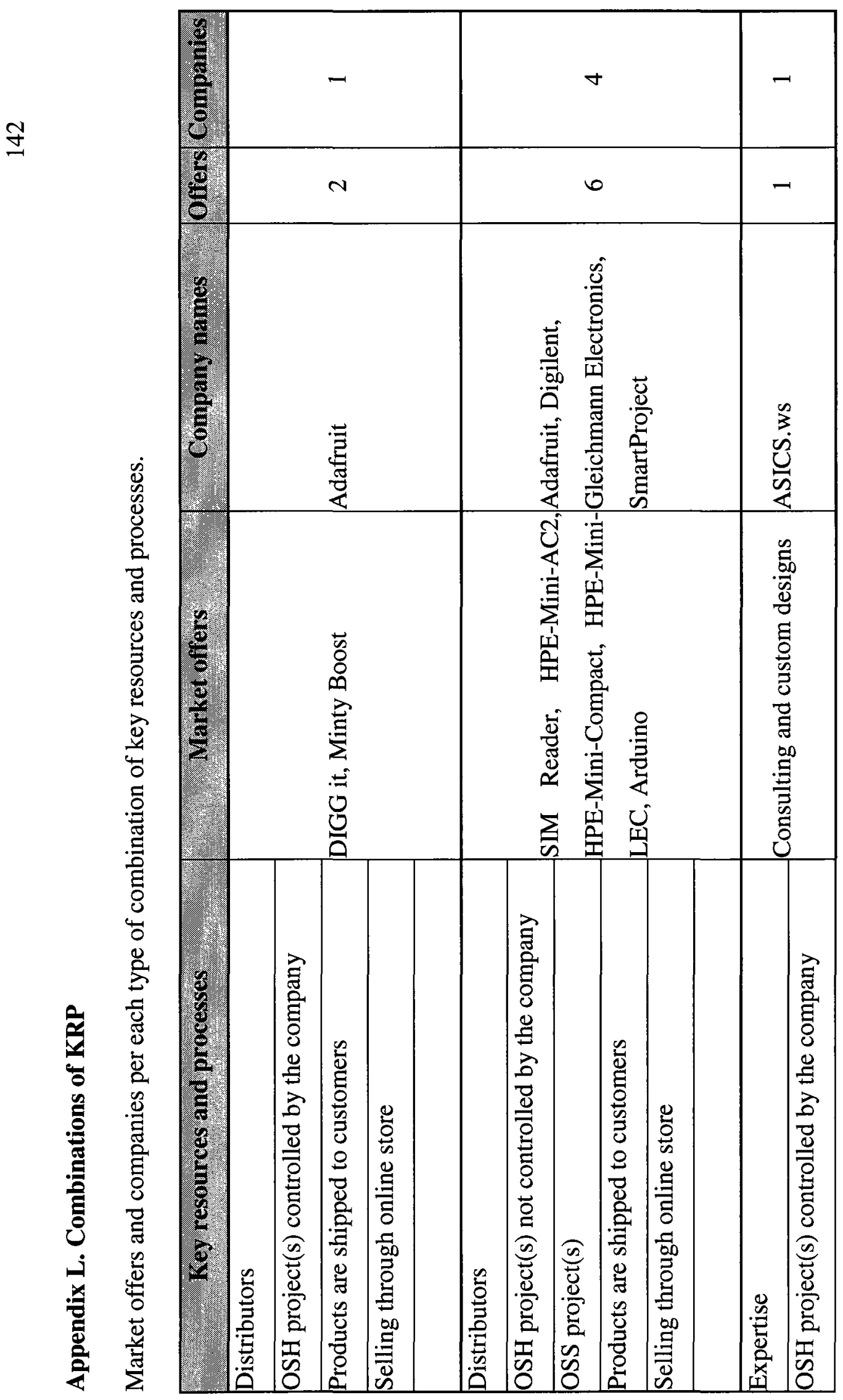




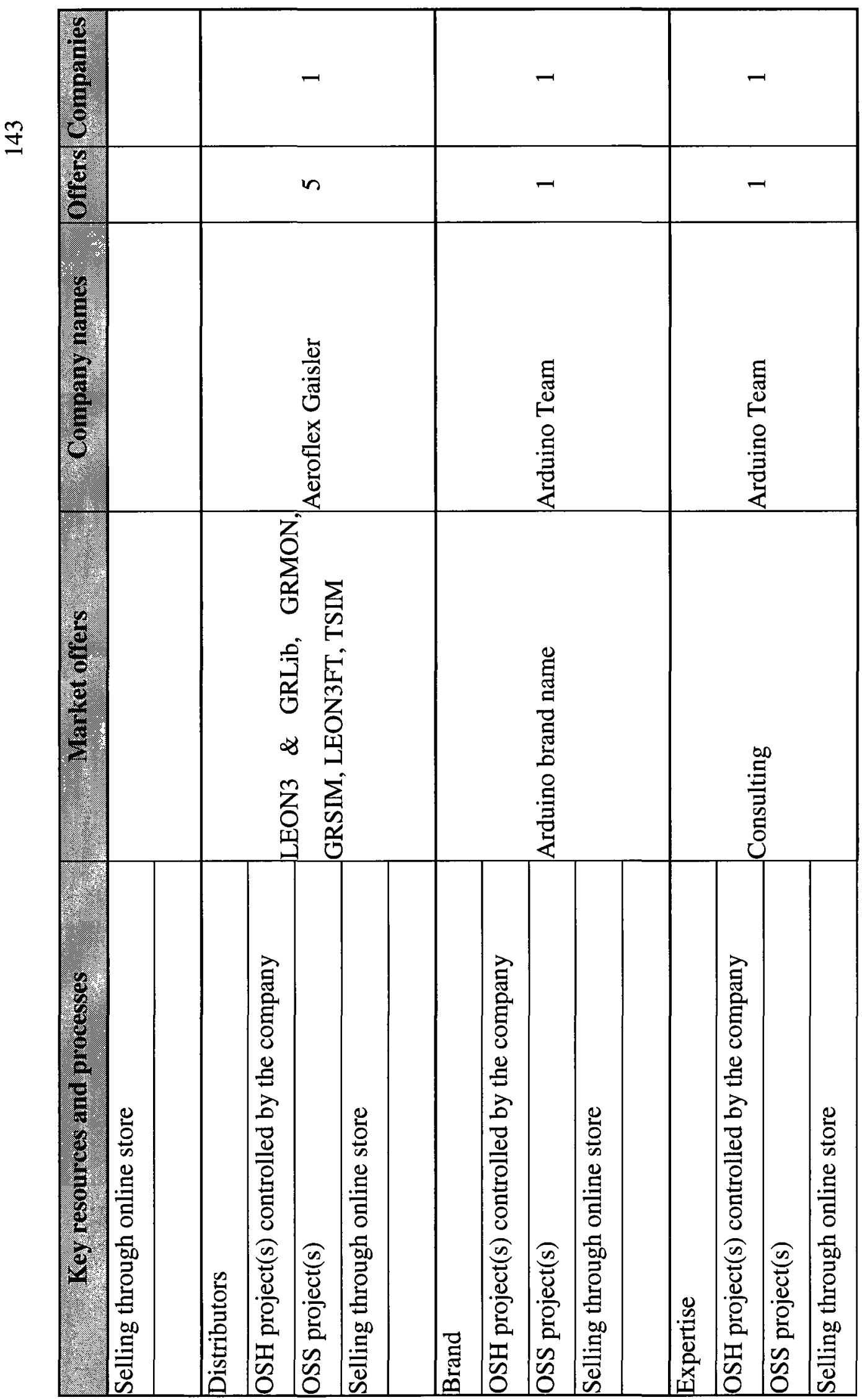




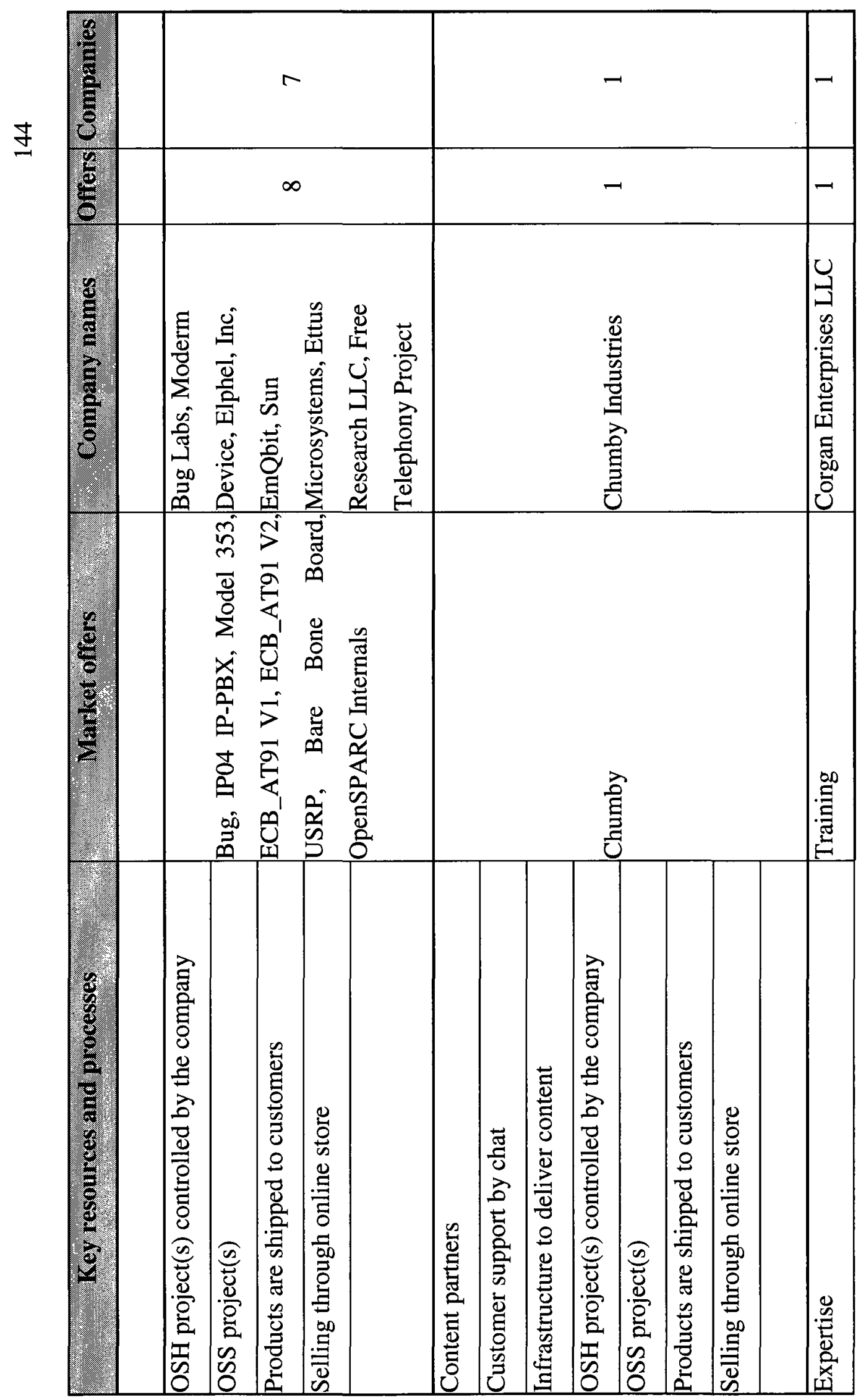




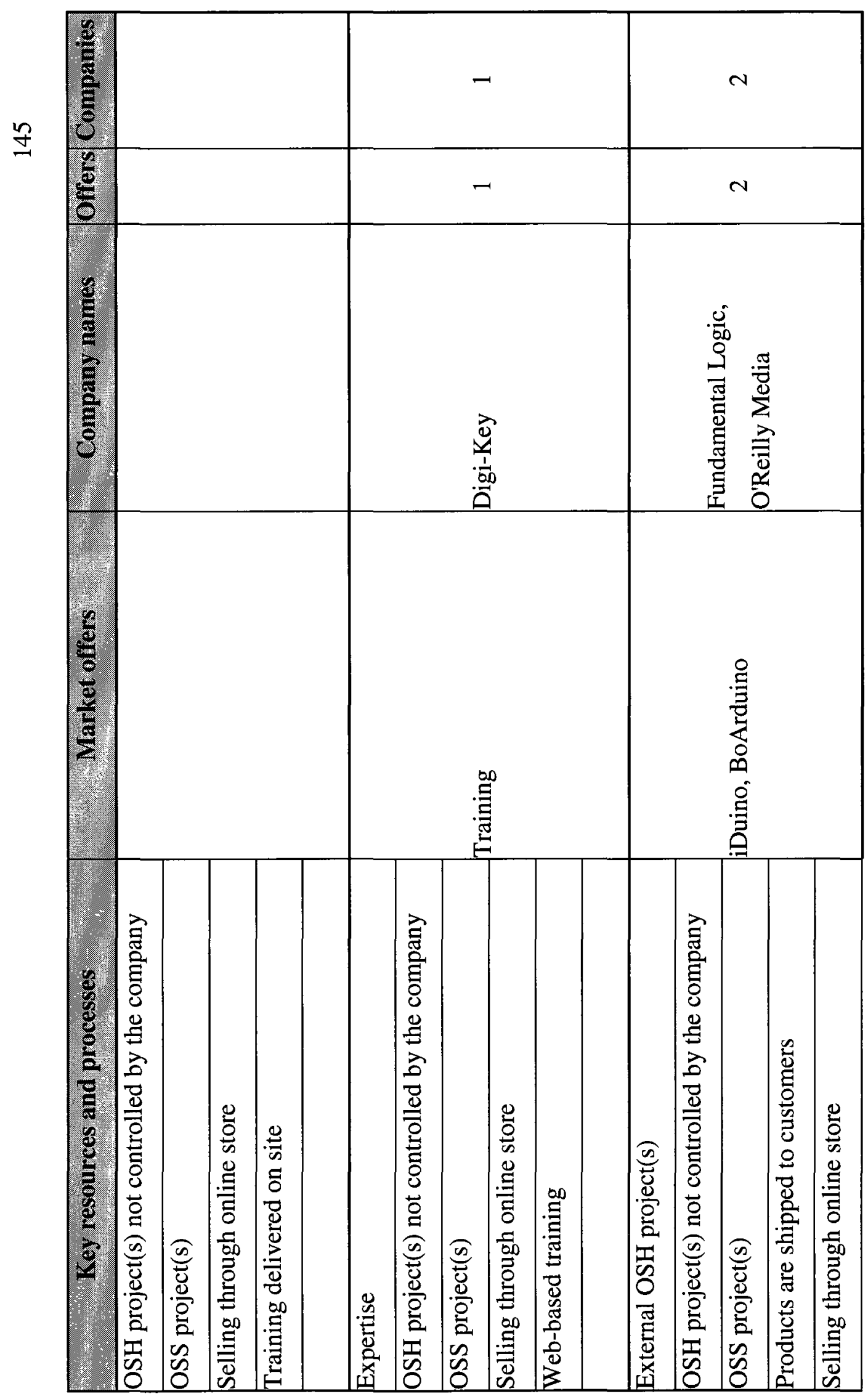




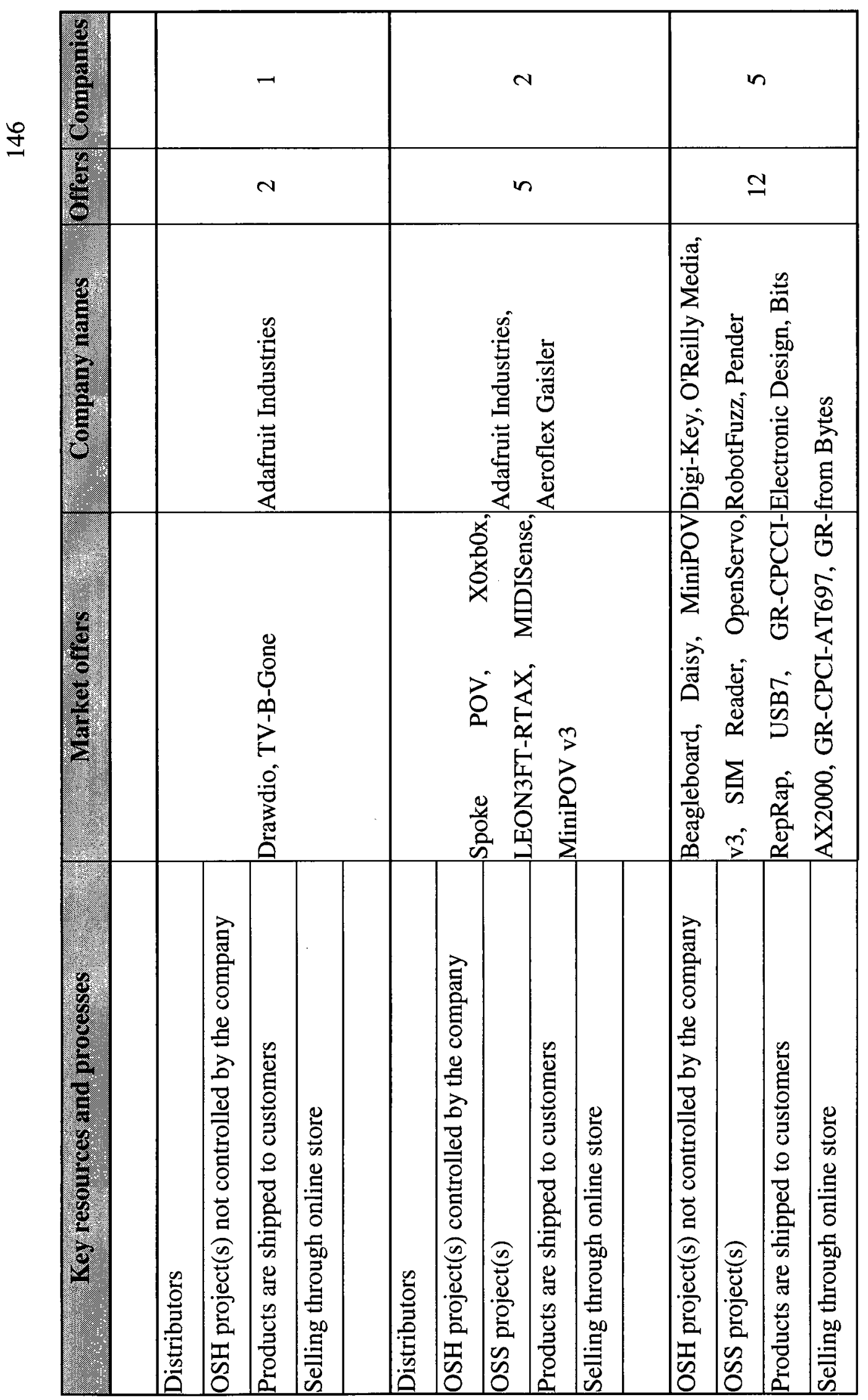




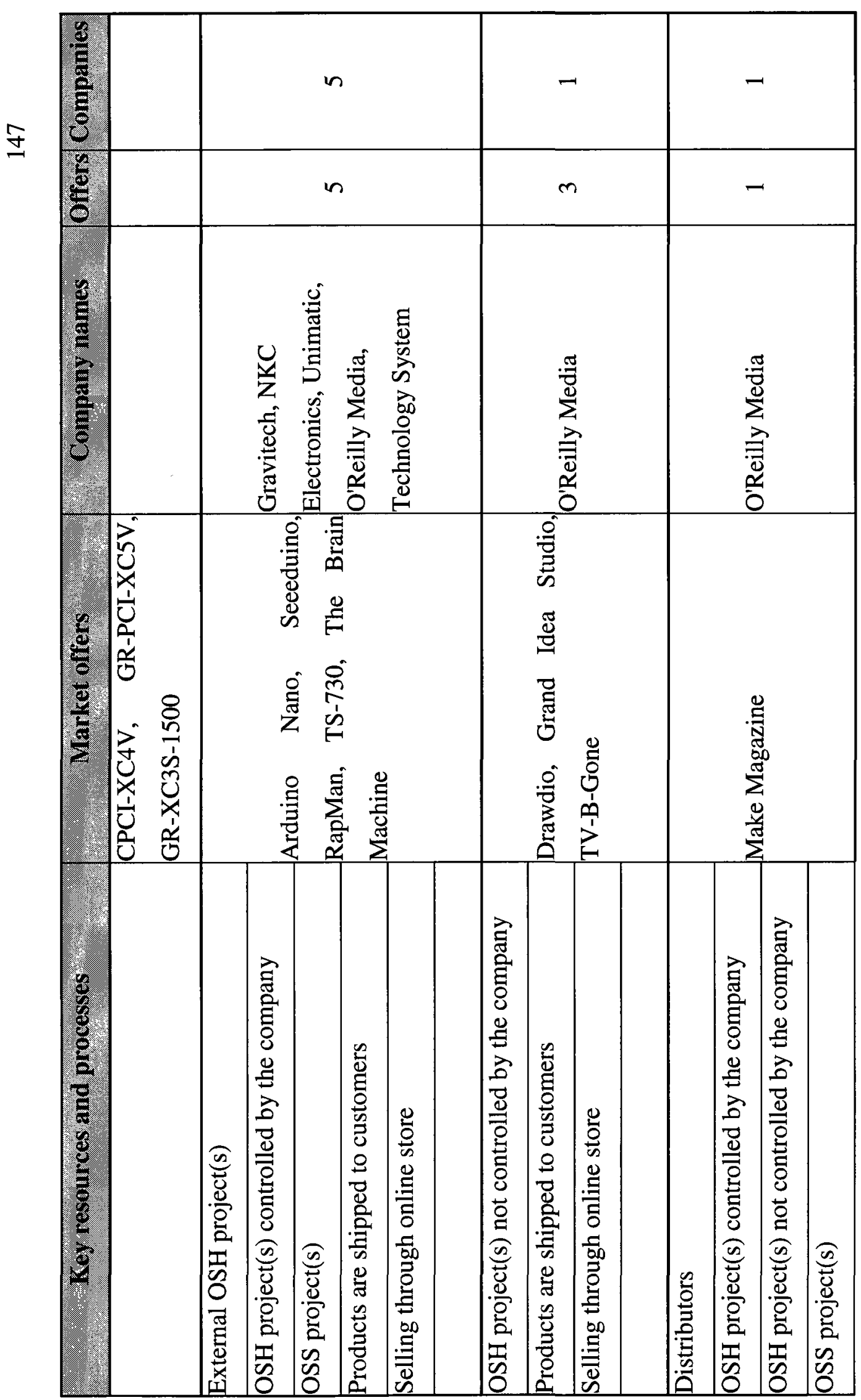




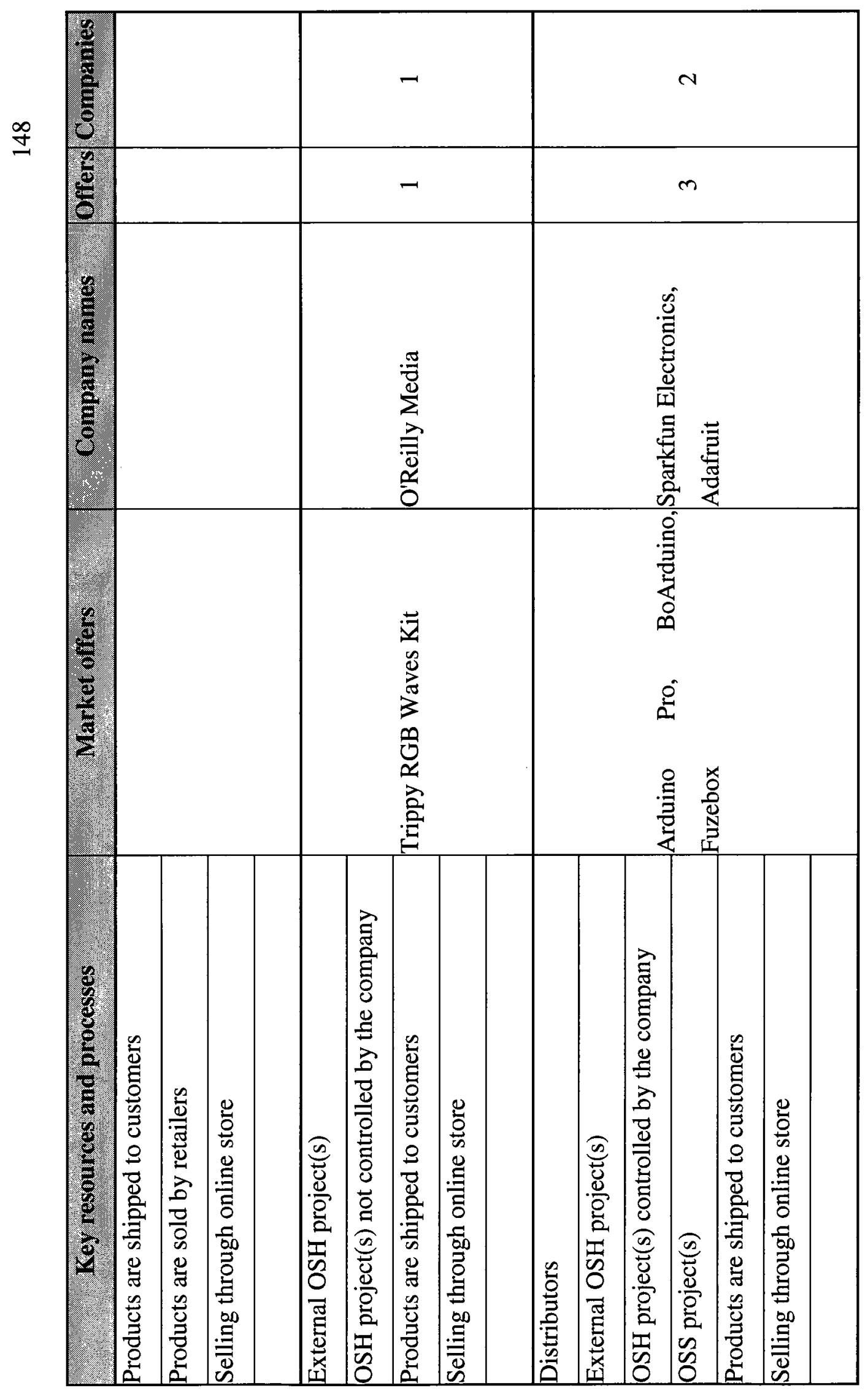




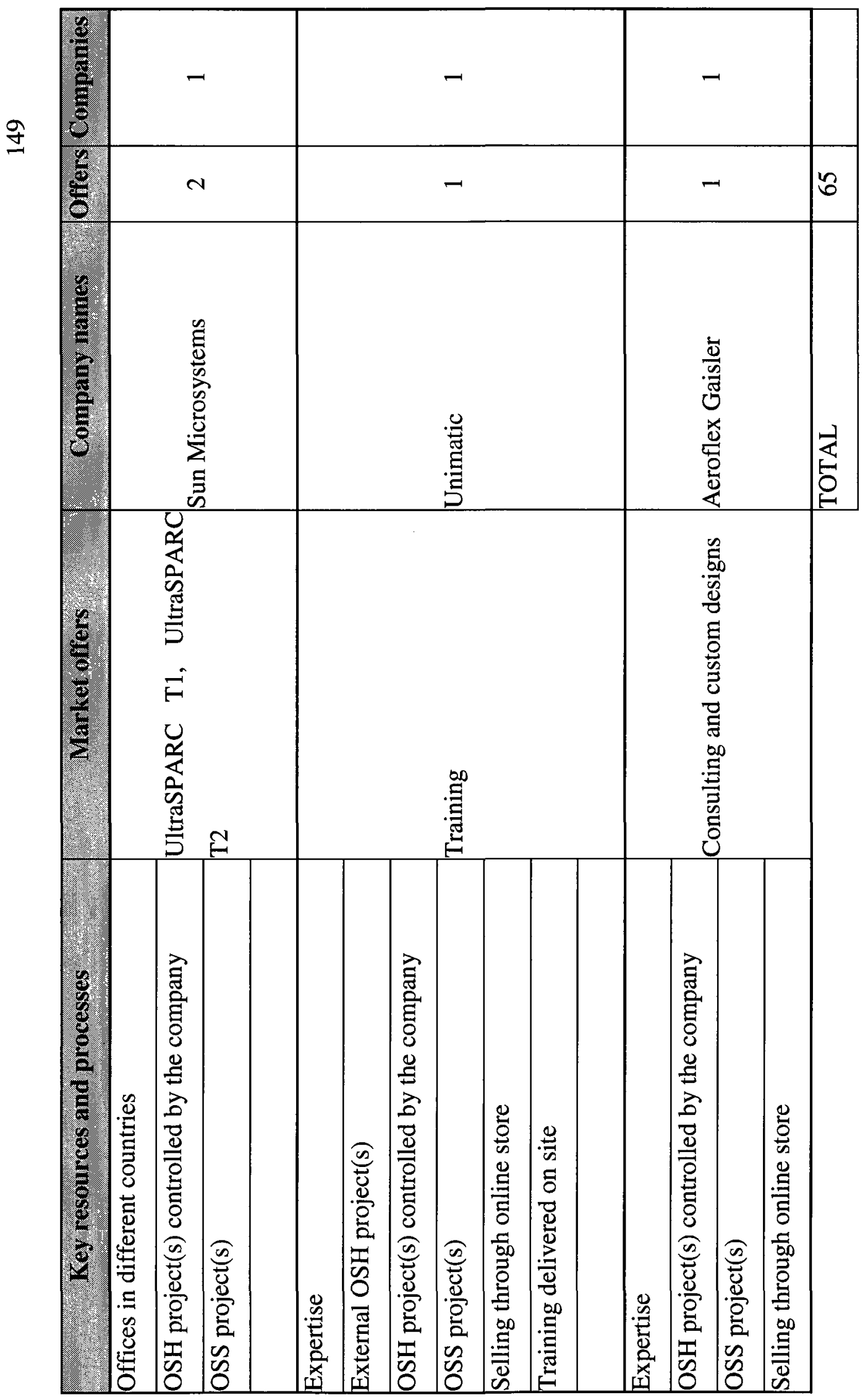

